\title{
Evaluating the impact of oceanic/atmospheric teleconnections on historical wildfires in West Virginia (1939-2006)
}

\author{
Cary Lynch \\ West Virginia University
}

Follow this and additional works at: https://researchrepository.wvu.edu/etd

\section{Recommended Citation}

Lynch, Cary, "Evaluating the impact of oceanic/atmospheric teleconnections on historical wildfires in West Virginia (1939--2006)" (2010). Graduate Theses, Dissertations, and Problem Reports. 876.

https://researchrepository.wvu.edu/etd/876

This Thesis is protected by copyright and/or related rights. It has been brought to you by the The Research Repository @ WVU with permission from the rights-holder(s). You are free to use this Thesis in any way that is permitted by the copyright and related rights legislation that applies to your use. For other uses you must obtain permission from the rights-holder(s) directly, unless additional rights are indicated by a Creative Commons license in the record and/ or on the work itself. This Thesis has been accepted for inclusion in WVU Graduate Theses, Dissertations, and Problem Reports collection by an authorized administrator of The Research Repository @ WVU. For more information, please contact researchrepository@mail.wvu.edu. 


\title{
Evaluating the Impact of Oceanic/Atmospheric Teleconnections on Historical Wildfires in West Virginia (1939-2006)
}

\author{
Cary Lynch \\ Thesis submitted to the \\ Eberly College of Arts and Sciences \\ at \\ West Virginia University \\ For the degree of \\ Master of Arts \\ in \\ Geography \\ Committee: \\ Dr. Amy Hessl, Chair \\ Dr. Robert Hanham \\ Dr. Tim Warner
}

In partial fulfillment of the requirements

Department of Geography

Morgantown, West Virginia

2010

Keywords: Teleconnections; oscillations; wildfire; West Virginia

Copyright 2010 Cary Lynch 


\section{Abstract \\ Evaluating the Impact of Oceanic/Atmospheric Teleconnections on Historical Wildfires in West Virginia (1939-2006)}

\section{Cary Lynch}

Oceanic/atmospheric oscillations affect climate in many ways. This study quantitatively examined climate teleconnection patterns and in turn analyzed the influence of climate on wildfire activity within West Virginia from 1939-2006. Identifying the linkages between oscillations and climate variability has the potential to greatly improve seasonal forecasting capabilities. Despite the complexity inherent in local fire regimes, regional fire activity often oscillates in phase with year-to-year climatic variability. This climate-fire connection raises the possibility that historical factors inherent in the local ecosystem are overridden by regional climatic events and trends. A robust statistical analysis that utilized correlation, regression, principle components, and Superposed Epoch Analysis was conducted to explore these relationships. Results suggest that oscillations in the North Atlantic and the Northern Pacific drive West Virginia's climatic variability. This study also suggests that climate influences West Virginias wildfire activity. 
Title Page $\quad$................................................. i

Abstract $\quad$................................................. ii

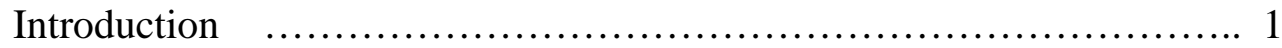

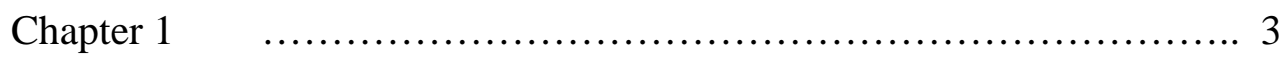

Chapter $2 \quad$................................................... 28

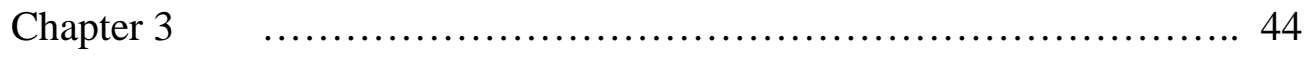

Conclusion $\quad$................................................ 49

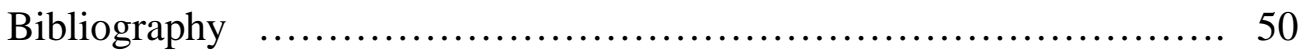

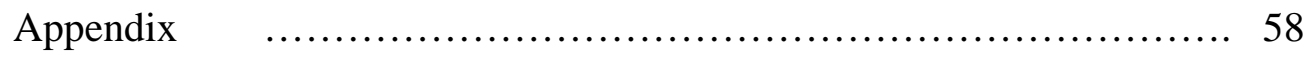




\section{$\underline{\text { Introduction }}$}

Synoptic scale movement of energy in the atmosphere and oceans drives weather and climate patterns across the Earth. The atmosphere and oceans are a coupled system, with highly complex processes and feedback mechanisms (Barry and Chorley, 1998). Changes that occur within this system will be reflected in climatic patterns. Even small changes in atmospheric/oceanic patterns can have a pronounced effect on the Earth's weather and climate (Sutton and Hodson, 2003). These coupled atmospheric/oceanic processes are integral to understanding climatic variability. The influence of these processes on any particular region is not static and is distinct spatially as well as temporally.

Within the large scale atmospheric/oceanic processes smaller events are taking place. These smaller events are often referred to as oscillations and can vary across space and time. Oscillations are somewhat predictable periodic variations between two extremes. In climatological terms they are a reflection of small changes in sea surface pressure or sea surface temperature between two or more centers of action. The effect that oscillations have on other atmospheric/oceanic processes and land surface climates are known as teleconnections (Leathers et al., 1991).

The study of teleconnections is extremely varied and has linked oscillations to everything from biological to socioeconomic processes. Teleconnection patterns have also been shown to shape wildfire activity in both North and South America (Swetnam and Betancourt, 1990; Swetnam, 1993; Grissino-Mayer, 1995; Swetnam and Betancourt, 1998; Swetnam et al., 1999; Veblen et al., 2000; Dale et al., 2001; Kitzberger et al., 2001; McKenzie et al., 2004; RomanCuesta et al., 2003; Westerling et al., 2003; Hessl et al., 2004; Westerling et al., 2006). The idea 
that remote atmospheric/oceanic processes can influence local disturbance patterns is an intriguing subject.

This particular study was done to evaluate how teleconnection patterns influence climate (Chapter 1) and in turn how climate has an effect on wildfire activity (Chapter 2) within the MidAtlantic region. An examination of newer techniques of monitoring fire events is also discussed (Chapter 3). As research techniques and understanding of teleconnections improve, society will benefit from increased awareness of the effect climate has on our daily lives and improved forecasting climate, weather, and associated ecological and socioeconomic processes linked to climate patterns. 


\section{Chapter 1}

\section{$\underline{\text { Introduction }}$}

The fluid-like interaction between the atmosphere and ocean is sustained by the constant meriodional transport of energy from the tropics to the poles (Barry and Chorley, 1998). This interaction creates circulation patterns in the ocean and atmosphere which have strong impacts on weather and climate variability on the Earth's surface. The associations between these global oceanic/atmospheric processes and weather/climate over great distances are known as teleconnections. Teleconnections are used to understand climatological relationships between the synoptic-scale atmospheric circulation patterns and land surface climates, particularly for those relationships that generate low frequency or lagged climatological phenomena (Leathers et al., 1991). These low frequency phenomena allow for climate forecasting months to years in the future and are therefore extremely valuable for a variety of sectors, including recreation, resource management, agriculture, and forestry. However, in North America, the spatial and temporal spectrum of climate variability cannot be captured by a single teleconnection pattern. Local climates are affected by local conditions (vegetation, topography, land use, etc.) and are not always clearly associated with synoptic scale patterns in a uniform manner (Kushnir et al., 2006). In addition, these synoptic scale patterns may affect different regions at different times (monthly, seasonally, annually, etc.) and in different ways (temperature, precipitation, geopotential pressure heights, weather phenomena, etc.).

Oceanic/atmospheric oscillations are generally characterized by their deviation from mean sea surface temperature (SST), sea surface pressure (SSP), or a specific pressure height field at a generalized location. They are cyclic in nature with positive and negative phases that oscillate over times scales from weeks to decades. Even small changes in atmospheric 
circulation and/or sea surface temperatures can have a marked impact on the world's weather and climate (Sutton and Hodson, 2003) as well as ecosystem properties including: fisheries (Mantua et al., 1997), fire (Dale et al., 2001; Kitzberger et al., 2001; McKenzie et al., 2004; Hessl et al., 2004), and biodiversity (Swetnam and Betancourt, 1998; Veblen et al., 2000).

Despite the large volume of research on synoptic scale climate developed in recent decades, little research has addressed the relationship between oceanic/atmospheric oscillations and the climate of the mid-Atlantic region. Relating a single oscillation to the climate of any one region is difficult. The teleconnection pattern(s) in the Mid-Atlantic region is complex due to the difficulty of isolating noise from the climate signal as well as nonlinearity and/or co-linearity of the factors involved. Most research has focused on how or where oscillations occur rather than what they may or may not influence (Barnston and Livezey, 1987; Thompson and Wallace, 1988; Leathers et al., 1991; Vega et al., 1995; Fye et al., 1999; Wallace, 2000; Polyakov and Johnson, 2001; Mantua and Hare, 2002; Wallace and Thompson, 2002; Sheridan, 2003; Dijkstra, 2005; Isaksson et al., 2005; Dijkstra et al., 2006). However, there is a considerable body of work that covers six main oscillations as they relate to North American climate. These oscillations are: the Southern Oscillation (SO), the Pacific Decadal Oscillation (PDO), the Pacific/North American pattern (PNA), the Arctic Oscillation (AO), the North Atlantic Oscillation (NAO), and the Atlantic Multidecadal Oscillation (AMO). Though not an oscillation per se, cyclonic activity in the tropical Atlantic is also thought to influence climate variability for much of the East Coast of the United States. The purpose of this study is to examine the climate of West Virginia and the seasonal teleconnection patterns related to this region from 1948-2006 based on these six oscillations and cyclonic activity. I will do this through the use of quantitative and cartographic methods. I hypothesize that these teleconnection patterns have a significant influence on 
climatic variability in West Virginia which could have a large influence on various economic sectors.

\section{Literature Review:}

\section{The Southern Oscillation}

Under normal conditions, the Walker circulation cell is the dominant atmospheric circulation pattern over the tropical Pacific region. Typically, the trade winds in the southern hemisphere flow westward bringing warm moist air towards the western Pacific. This warm air rises, creating a zone of low pressure in the tropical western Pacific (Ropelewski and Halpert, 1986). The air aloft then travels eastward carried by upper atmospheric winds where it is slowly cooled and then sinks over the tropical eastern Pacific. The influence of the Humboldt Current, which carries cold water northward along the west coast of South America, combined with trade wind-induced upwelling of colder water from below the surface, produces the band of relatively cool ocean waters extending westward from the coast of Peru into the central Pacific. Under these normal conditions, the western Pacific is generally about $3^{\circ} \mathrm{C}$ to $8^{\circ} \mathrm{C}$ warmer than the eastern Pacific.

Approximately every 2-7 years, the waters in the eastern Pacific warm due to warm ocean water damming along the coast of Peru (Hanley et al., 2003). The usual cold ocean water upwelling is then pushed westward and the trade winds reverse, SSP levels are now lower and SSTs are higher in the eastern Pacific and SSP levels are higher with lower SSTs in the western Pacific. As a result, the Walker circulation cell breaks down. This pattern of circulation between the tropical western Pacific and tropical eastern Pacific is known as the Southern Oscillation.

There are two phases of the SO: the negative phase of the SO represents below normal SSP and warmer SSTs in the eastern Pacific and above normal SSP and colder SSTs in the 
western Pacific; the positive phase of SO indicate above normal SSP and colder SSTs in the eastern Pacific and below normal SSP and warmer SSTs in the western Pacific (Hanley et al., 2003). The fluctuation between negative and positive phases show considerable irregularity in amplitude, duration, growth, and size due to chaotic dynamics of the oceanic/atmospheric system or from stochastic weather 'noise' (McPhaden et al., 2006).

Affects of the SO are felt world wide, and often lead to systematic seasonal shifts in regional weather patterns (Ropelewski and Halpert, 1986; Ropelewski and Jones, 1987; Chen and Van Den Dool, 1999; Harrison and Larkin, 1999; McCabe and Dettinger, 1999; McPhaden et al., 2006). The SO has also been shown to affect the frequency, intensity, and duration of tropical storms in the Atlantic (Bove et al., 1998; Elsner, 2007; Donnelly and Woodruff, 2007). Negative or warm phases tend to reduce the number and intensity of tropical storms while, inversely, the positive or cold phases tend to amplify the frequency and intensity of tropical storms (McPhaden et al., 2006). The negative phase has been shown to decrease the number of tropical cyclones that reach a Category 3-5 (Bove et al., 1998). This can be attributed to increased vertical wind shear and cooler North Atlantic basin SST during negative phases. The intensity of North Atlantic cyclonic activity is greater during positive phases of the SO and suppressed during negative phases of the SO (Donnelly and Woodruff, 2007).

The variability in the strength of an SO phase impacts different regions of the United States in different ways (Ropelewski and Halpert, 1986; McCabe and Dettinger, 1999). According to the National Oceanic and Atmospheric Administration, strong negative phases have been associated with below normal precipitation and warmer than average temperatures for the Appalachian region (www.cdc.noaa.gov). Likewise, positive phases usually cause warmer and wetter than average conditions. Strong negative episodes have been linked to below normal 
precipitation ( $70 \%$ to $80 \%$ of normal) over West Virginia during January-March. Similar features were observed during the 1982-83 negative phase of the SO episode. Pre-Winters (November and December) have averaged about $1^{\circ} \mathrm{C}$ above normal over the whole state for these strong negative episodes (www.cdc.noaa.gov).

\section{The Pacific Decadal Oscillation}

In the 1980's and 1990's, the extratropical North Pacific Ocean appeared to be in a continuous negative SO phase despite readings from numerous SO indices in the tropical Pacific that did not show a negative SO event taking place (Mantua et al., 1998; Mantua and Hare, 2002). While observing the oscillatory nature of the relationship of salmon and Pacific climate in the late $20^{\text {th }}$ century, Hare labeled this pattern the PDO.

The PDO is a pattern of Pacific Ocean climate variability that persists for 20 to 30 years. While the causes of the PDO are not known, there are two distinct phases of the PDO. The positive phase occurs when SSTs are cool and SSP are below average in the interior North Pacific with warm SSTs and higher than average SSP along the North American (NA) Pacific coast (Mantua and Hare, 2002). The cold, northward moving Humboldt Current seems to be effectively blocked by high pressure ridging along the NA Pacific coast and pulled toward the lower pressure trough in the interior Pacific. This ridging also tends to keep the jet stream farther north of where it would generally flow. The negative phase occurs when SSTs are warm and SSP is high in the interior Northern Pacific with cool SSTs and SSP is low along the NA Pacific coast. In this phase it appears that the Humboldt Current is blocked by SSP ridging in the interior Northern Pacific and pulled toward the lower pressure trough along the NA Pacific coast.

Analyses and forecasting of precipitation for the United States have focused mainly on the Pacific Ocean oscillations like the aforementioned ENSO and the PDO (McCabe and 
Dettinger, 1999; McCabe et al., 2004). The effects of the PDO are primarily visible in the Northern Pacific and are measured in terms of sea surface temperature anomalies. PDO events largely affect the North Pacific/North American sector, with weaker impacts in the tropics (http://jisao.washington.edu/pdo/). PDO has been shown to modulate winter precipitation, summer drought, and streamflow rates in the Western United States (McCabe et al., 2004). In the Northeastern United States there is a negative correlation of drought and PDO events, but there is a positive correlation of drought and PDO events in the Southeastern United States (Van Den Dool et al., 2006). This is thought to be caused by the northward movement of the jet stream, which is a principle carrier of cyclonic activity across the United States. No research has addressed impacts of the PDO on the Mid-Atlantic region.

Research on the interactions between the PDO and the SO is ongoing. How phases of each oscillation enhance or suppress each other is uncertain (McCabe and Palecki, 2006). Studies have shown that when in a negative SO phase and positive PDO phase, the effect of SO on climate is stronger (LaDochy et al., 2004). Further examination of this relationship is needed and could be beneficial to North American agriculture, power generation, fresh water resources, public health and safety, forestry, fisheries, transportation, tourism, financial markets, and many other areas of climate-sensitive human activities (McPhaden et al., 2006).

\section{The Pacific/North American Pattern}

The PNA is one of the most prominent modes of low-frequency variability in the Northern Hemisphere extratropics and is a major mode of atmospheric variability over North America during Northern Hemisphere winters (Wallace and Gutzler, 1981; Leathers et al., 1991; Vega et al., 1995; Sereze et al., 1998; Sheridan, 2003; LaDochy et al., 2004; Notaro et al., 2006). The PNA is associated with strong fluctuations in the strength and location of the East Asian or 
sub-polar jet stream, which is associated closely with many synoptic-scale phenomena such as cyclogenesis, frontogenesis, monsoon, blocking, and storm track activity for the entire Northern Hemisphere Pacific region and North America. It is also thought to reflect the strength of the Aluetian Low (LaDochy et al., 2004). The PNA has been shown to force seasonal precipitation variability over North America through regulating the amplitude of the sub-polar jet stream (Leathers et al., 1991; Leathers and Palecki, 1992). It is unique in that it can vary over periods ranging from a few days to several years.

The PNA was first recognized in the 1940s as a see-saw pattern of atmospheric pressure between the Aluetian Low and the Plateau High (Southwest United States, Wallace and Gutzler, 1981). Throughout the next several decades the evidence of a relationship of the East Asian Jet and surface climate variability has become much more robust. There are two pronounced phases of the PNA. The negative phase is associated with a high pressure ridging pattern over the high latitudes of the north Pacific, and a strong split-flow configuration of the East Asian jet stream over the central north Pacific. During negative phases the polar front jet is pushed farther north, allowing tropical air masses from the Gulf of Mexico to move northward as well, thereby increasing precipitation for the interior and eastern United States. The positive phase of the PNA features above-average pressure over Hawaii and central Canada, and below-average pressure south of the Aleutian Islands and the southeastern United States. The positive phase is associated with an enhanced East Asian jet stream with an enhanced low pressure trough in the eastern United States which allows for Polar air masses to extend far into the southeastern United States (Leathers et al., 1991). The positive phase of the PNA pattern is associated with above-average temperatures for western Canada and western United States, and below-average temperatures across the south-central and southeastern United States. The associated precipitation anomalies 
include above-average totals in the Gulf of Alaska extending into the Pacific Northwestern United States, and below-average totals over the north-central United States.

Although the PNA is a natural internal mode of climate variability, it is also believed to be influenced by the SO (Leathers and Palecki, 1992). The positive phase of the PNA tends to be associated with a negative SO phase, and the negative phase tends to be associated with a positive SO phase. The PNA is also closely connected to the PDO. When PDO is in a positive phase, it enhances the positive phase of the PNA. However, instrumental PNA data covers only a relatively short time span which makes it difficult to fully understand the natural variability of the phenomenon and its relationship with other modes of climatic events. Again, no research has addressed the impacts of the PNA on the Mid-Atlantic region.

\section{The Arctic Oscillation}

The AO (also known as the Northern Hemisphere annular mode) is the leading mode of high-latitude climate variability in the Northern Hemisphere. This phenomenon was first termed the Arctic Oscillation by Thompson and Wallace (1998) to describe pressure height anomalies over the Arctic. The AO reflects the strength of the polar vortex on decadal to multidecadal timescales (Thompson and Wallace, 1998; Fye et al., 1999; Polyakov and Johnson, 2001; Wu et al., 2006). The AO is a robust pattern that has been shown to influence both intraseasonal and interannual climatic variability throughout the Northern Hemisphere, but can be partially obscured by interdecadal trends.

Most oscillatory phases begin with SST anomalies, which then influence SSP and these pressure anomalies work their way up through the atmosphere. The $\mathrm{AO}$ is unique in that the strengthening or weakening of the circulation in the Arctic region tends to begin in the stratosphere and work its way down through lower levels of the atmosphere (Thompson and 
Wallace, 1998). This is due to the existence of the quasi-stationary Polar High cell. Because Arctic air masses are very dense and very dry, SST and SSP are more stable than tropical or midlatitude air masses, and circulation patterns can extend up through the stratosphere, 10 to 50 kilometers above the Earth's surface.

AO phases are signaled by the $1000 \mathrm{mb}$ pressure height field anomalies over $20-90^{\circ} \mathrm{N}$. There are two phases of the AO (Thompson and Wallace, 1998). The negative phase reflects high pressure over the polar region and low pressure at midlatitudes. This causes polar air masses to extend farther south and bring cooler temperatures to the United States, and depending on the season, generally wetter conditions. In the positive phase, higher pressure at midlatitudes pushes the polar jet farther north and strengthens it, which causes higher than normal temperatures over most of North America. In the positive phase, Arctic air masses are kept from extending into the continental United States, which brings drier conditions to the western United States and wetter conditions to the eastern United States.

Due to global warming and associated sea ice retreat, the AO has been closely monitored in the last few decades (Polyakov and Johnson, 2000; Polyakov et al., 2005). Over most of the past century, the AO has changed from a negative to a positive phase. This has caused lower than average pressure in the polar region, which has brought about higher than average temperatures in much of the United States and Northern Eurasia. Whether this warming trend and the retreat of Arctic ice is an effect of global warming due to anthropogenic causes or is simply the result of a natural oceanic/atmospheric oscillation is an intriguing subject. Decreases in the extent of Arctic ice is within the range of natural variability since the $18^{\text {th }}$ century, but there is evidence to suggest that increases of green house gases and associated warming are decreasing the extent of Arctic ice masses beyond what would be considered natural fluctuation 
(Polyakov and Johnson, 2000). Forcing of the AO due to anthropogenic causes is also possible, and GCMs have shown this to be probable (Fye et al., 1999).

\section{The Northern Atlantic Oscillation:}

The NAO measures the $500 \mathrm{mb}$ pressure height anomalies from $0-90^{\circ} \mathrm{N}$ in the Atlantic Ocean basin, which is influenced by oceanic circulation patterns in the Arctic region. It is a meridional oscillation in atmospheric mass between the Subtropical High (also called the Azores and/or Bermuda High) and the Icelandic Low, which can also affect pressure and ocean current movements between these two pressure regions. The NAO has been shown to strongly influence the strength and direction of storm tracks across the North Atlantic (Marshall et al., 2001). It can exist from time scales of intra-annual to decadal, but is most pronounced during winter months (Durkee et al., 2007).

The connection between Northern Atlantic SSP and land temperatures in North American and Europe was acknowledged by many early climatologists (Wallace and Gutzler, 1981). It was first coined the North Atlantic Oscillation by Walker and Bliss in 1932 (Walker and Bliss, 1932). It has been argued by some that the NAO and the AO are the same oscillatory pattern (Wallace, 2000), and others have argued that the NAO is the Atlantic part of the largerscale AO (Marshall et al., 2001; Wallace and Thompson, 2002).

There are two phases of the NAO. The negative phase indicates a weakening in the Icelandic Low and Arctic air masses are able to move farther south causing a cooling trend over the eastern United States (Hurrell and Van Loon, 1997). The Subtropical High is also weakened allowing for westerly wind tracks and cyclonic activity to be lessened. Cool and dry conditions prevail under a negative phase. When in a positive phase, the Icelandic Low is strong which prevents Arctic air masses from plunging southward. During this phase the Subtropical High is 
also strong creating a ridging pattern that pushes warm moist air masses northward. This generally causes a warming trend over the Eastern United States along with stronger Atlantic storm tracks and higher than average precipitation values.

The NAO also exhibits strong interseasonal and interannual variability, and prolonged periods of either phase are common (Wallace and Thompson, 2002). Although the NAO is in effect throughout the year, it is most pronounced in the winter months. There is a pronounced relationship between snowfall and the NAO (Serreze et al., 1998; Durkee et al., 2007). The NAO has also been shown to influence the movement of the Gulf Stream (Marshall et al., 2001). During positive phases, it can push the Gulf Stream up to $100 \mathrm{~km}$ north. This has many implications for the strength of Atlantic hurricane activity as well as European climate.

Although the NAO is noted as being influential to Northern Hemisphere climate (Marshall et al., 2001), it is not universally accepted, nor is there a strict definition (Van den Dool et al., 2006). It is also hard to predict. Due to its association with the AO, its magnitude and spatial extent, values of the index will be different from differing sources. It is also a relatively stationary event with low frequency variability, making it hard to pinpoint the start and end of a particular phase.

The effect of Pacific oscillations on the NAO are slight and generally show a negative correlation of less than 0.1. However, a study conducted by Hurrell and Van Loon (1997) shows that the NAO and SO combined account for much of the northern hemispheric warming since 1980. Another study (Hurrell, 1996) showed that NAO and SO combined account for $47 \%$ of the temperature variance since 1935. In a later study (Sutton and Hodson, 2003) regression analysis was used to find that the influence of the SO and NAO impact different regions in different ways, and counteract as well as reinforce each other. 


\section{The Atlantic Multidecadal Oscillation:}

A second influential Atlantic oscillation is the AMO. At decadal or longer timescales, the North Atlantic Ocean is associated with the North Atlantic atmosphere via the heat fluctuations of the Atlantic overturning process (Cassou et al., 2007). The Gulf Stream current off the east coast of the United States is part of the Atlantic overturning circulation, which is the cause of the AMO. The AMO is a pattern of multi-decadal SST variability centered on the North Atlantic Ocean from $0-70^{\circ} \mathrm{N}$. It has a range of 50-80 years with a SST range of $0.4^{\circ} \mathrm{C}\left(1^{\circ} \mathrm{F}\right)$. The signal for the AMO is global in scope, but is most intense over the Atlantic Ocean basin.

Studies of paleoclimate proxies, such as tree rings and ice cores, have shown that oscillations similar to the AMO have been occurring naturally for the last millennium (Isaksson et al., 2005). The AMO is then not a product of anthropogenic forcing, and is probably a naturaloccurring oscillation. In the $20^{\text {th }}$ century, the cycles of the AMO have alternately masked and exaggerated the effects of global warming, and made the recognition of global warming more difficult. The AMO has been shown to have a strong influence on summer rainfall over the continental United States (Enfield et al., 2001; McCabe et al., 2004; Curtis, 2007) and may modulate the strength of SO teleconnection patterns.

There are two phases of the AMO. When the overturning circulation weakens, the North Atlantic temperatures become cooler, thereby signaling the cool or negative phase. Because SSTs are influential on SSP, a negative phase will cause SSP variance to decrease or weaken. This weakening causes the pressure trough in the north central United States to deepen and the pressure ridge in the northwestern United States to rise (Enfield et al., 2001). Temperatures for the United States will generally be lower than average with an increase of precipitation amounts. When the overturning circulation of the Atlantic strengthens, North Atlantic SSTs increase, 
signaling the warm or positive phase of the AMO. SSP variance will increase as will cyclonic activity in the Atlantic region. The strengthening in SSP variance causes the trough in the north central United States to weaken, which then causes the ridge in the northwestern United States to weaken as well (Enfield et al., 2001). The strength of the Gulf Stream is also intensified during a positive phase. Temperatures for much of the United States will increase while precipitation amounts decrease. Studies have also shown a positive correlation of AMO events and drought (McCabe et al., 2004).

Many studies have suggested that the influence of low-frequency variations in SSTs on the climate in the north Atlantic region is dominated by the AMO (Enfield et al., 2001; Sutton and Hodson, 2003; Delworth and Mann, 2000; McCabe and Palecki, 2006). The AMO has been shown to be a reliable predictor of drought, and the Dust Bowl Era has shown a strong connection to positive AMO phases (McCabe and Palecki, 2006). Because of the long time scale involved when considering AMO phases, the variability of Atlantic SST may not be attributed correctly. It can instead be explained by the Bjerknes method, which states that heightened wave activity could cause a change in the ocean thermohaline circulation thereby creating a SSP change (Dijkstra et al., 2006). This SST and SSP change then takes many years, if not decades, to work its way through the entire affected ocean basin.

The warm phase of the AMO has been linked to the North Atlantic hurricane season through increased frequency of North Atlantic tropical cyclones (Curtis, 2007). When in a warm phase of the AMO, ocean circulation in the North Atlantic is heightened. Subsequently this phase allows for the Atlantic hurricane season to start earlier and end later, hence more cyclonic activity. The warm phase of the AMO has been shown to affect North Atlantic tropical cyclone intensity through a strengthening of the Atlantic Thermohaline Circulation (Klotzbach, 2006; 
Curtis, 2007; Elsner, 2007). Statistically, North Atlantic SSTs have a strong positive relationship with tropical cyclonic intensity by means of increasing the energy available for tropical cyclone growth.

\section{North Atlantic Tropical Cyclonic Activity}

In addition to (and possibly in combination with) oceanic/atmospheric oscillations, North Atlantic tropical cyclonic activity (TCA) is also thought to influence climatic conditions and patterns for the mid Atlantic states (Curtis, 2007). TCA is associated with strong winds, heavy rain, flooding, storm surges, lightning, embedded tornadoes, hail, and projectile debris. Annually, these storms are estimated to be the cause of 20,000 fatalities, extensive damage to property and ecosystems, and many other secondary effects of large scale natural disturbances (Henderson-Sellers et al., 1998). However, other parts of the world depend on the precipitation from tropical cyclones to replenish their water supply. Even small fluctuations in TCA can have significant impacts on society and ecosystems.

All TCA begins as a lower level atmospheric disturbance. Under certain conditions this disturbance can grow to a tropical depression with wind speeds of up to $17 \mathrm{~ms}^{-1}$. If the tropical depression has enough potential energy to continue to grow, it can become a tropical storm with winds of $17-33 \mathrm{~ms}^{-1}$. If energy is readily available and atmospheric conditions are right, the tropical storm can become a tropical cyclone with a diameter of up to $+650 \mathrm{~km}$ and a height of $15 \mathrm{~km}$. Wind speeds of a tropical cyclone exceed $33 \mathrm{~ms}^{-1}$. While TCA can occur throughout the year, it generally occurs during times of maximum displacement of the Equatorial Trough or late summer and autumn. In addition to the position of the Equatorial Trough, TCA is dependent on a steady supply of heat and moisture, low frictional drag in the lower troposphere, and strong convective activity with positive feedback mechanisms of rising and descending air. As a 
particular storm moves northward it pushes massive amounts of atmospheric moisture northward in a wave formation. These waves are called 'rain bands' and have been shown to affect precipitation patterns throughout the Midwest and east coast of the United States (Curtis, 2007).

An increase in North Atlantic tropical cyclonic frequency during the last few decades has been noted and debated by many (Tsutsui, 2002; Emanuel, 2005; Pielke et al., 2005; Trenberth, 2005; Webster et al., 2005; Klotzbach, 2006; Landsea et al., 2006; Holland and Webster, 2007; Mann et al., 2007). In the last 20 years, the amount of water vapor over global ocean basins has increased by $2.6 \%$ (Trenberth, 2005) which indicates a rapid increase in the hydrologic cycle. Higher SSTs and increases in atmospheric water vapor increase the energy available for atmospheric convection. This increase in potential energy over ocean basins, particularly in the tropics, has been predicted to impact global tropical cyclonic activity in a variety of ways. Recent studies have shown increases in the frequency, intensity, and/or duration of global tropical cyclonic activity in the last 30 years (Trenberth, 2005; Emanuel, 2005; Webster et al., 2005; Pielke et al., 2005; Landsea et al., 2006; Mann et al, 2007). Since the 1940's, TCA has been carefully documented through the use of multiple methods of data collection, most notably routine aircraft reconnaissance (Henderson-Sellers et al., 1998). The North Atlantic was also the first region affected by cyclonic activity that fully utilized satellite imagery for tracking and archiving hurricane information. This region has the longest and most reliable tropical cyclonic data. In recent years there have also been studies that have connected TCA variability to oscillations like the AMO (Klotzbach, 2006; Curtis, 2007) and the SO (Bove et al., 1998; Donnelly and Woodruff, 2007; Elsner, 2007). At this time, the results from such studies are inconclusive and warrant further investigation.

\section{Study Area and Data Sources:}


For this study I examined oscillations within the Pacific, the Arctic, and the Atlantic Oceans that are thought to influence climate in the eastern United States (Table 1).

The SO can be quantified in a variety of ways (Ropelewski and Halpert, 1986; Ropelewski and Jones, 1987; Chen and Van Den Dool, 1999; Harrison and Larkin, 1999; Hanley et al., 2003; McPhaden et al., 2006), each of which has strengths and weaknesses. The most reliable measure of the SO on interannual and annual time scales is the Southern Oscillation Index (SOI, Hanley et al., 2003). The SOI is an index based on the normalized sea level pressure differences between Darwin, $12^{\circ} 25^{\prime} \mathrm{S}, 131^{\circ} 00^{\prime} \mathrm{E}$, and Tahiti, $17^{\circ} 30^{\prime} \mathrm{S}, 149^{\circ} 30^{\prime} \mathrm{W}$. It is a measure of the synoptic scale pressure difference between the eastern and western tropical Pacific. SOI data from the Climate Research Unit (CRU) is calculated based on the method of Ropelewski and Jones (1987), which utilizes a second normalized procedure to give the most unbiased value. Monthly values were summarized into seasonal and annual values.

For this study, PDO fluctuation is captured by the PDO index. The PDO index, as developed by Mantua et al. (1997), is the leading principle component of North Pacific monthly SST variability which calculates North Pacific Basin SST anomalies from $20^{\circ} \mathrm{N}$ to $90^{\circ} \mathrm{N}$. Monthly values are defined as the difference between observed anomalies and the monthly mean global average SST anomaly (Mantua and Hare, 2002). Monthly values were summarized into seasonal and annual values.

The PNA index is constructed from three interconnected fixed points over the North Pacific and North America (Wallace and Gutzler, 1981; Leathers et al., 1991). These points measure the $500 \mathrm{mb}$ height anomalies from $0-90^{\circ} \mathrm{N}$. The PNA is a Northern Hemisphere teleconnection index based on the rotated principal component analysis (RPCA, Barnston and Livezy, 1987) which isolates and enhances the particular monthly mean teleconnection pattern at 
the three points over the course of a year. Monthly values were summarized into seasonal and annual values.

The AO is quantified by using the associated principal component time series to construct the AO index (Thompson and Wallace, 1998). The AO index measures the $1000 \mathrm{mb}$ pressure height field over the entire $50-90^{\circ} \mathrm{N}$ region. Monthly values were summarized into seasonal and annual values.

The NAO index is based on the rotated principal component analysis (RPCA, Barnston and Livezy, 1987) which isolates and enhances the particular monthly mean teleconnection pattern over a series of grid points throughout the North Atlantic Ocean at the three points over the course of a year. These grid points measure the $500 \mathrm{mb}$ pressure height anomalies from $0-90^{\circ}$ $\mathrm{N}$ in the Atlantic Ocean basin. Monthly values were summarized into seasonal and annual values.

The AMO is a low frequency oscillation that persists from 50-80 years with a SST range of $0.4^{\circ} \mathrm{C}$ (Barnston and Livezey, 1987). The AMO index measures the multi-decadal SST variability centered on the North Atlantic Ocean from $0-70^{\circ}$ N. Monthly values were summarized into seasonal and annual values.

The TCA basin covers the area just north of the equator between $0^{\circ} \mathrm{W}$ and the east coast of the Americas. This study utilizes all TCA data which includes the number and month of tropical depressions, storms, and hurricanes as collected by the National Hurricane Center (NHC) located in Miami, Florida. Data was collected through archival documentation, aircraft reconnaissance, and satellite imagery. Monthly values were summarized into seasonal and annual values. 
This study also examined the climatic variability of the state of West Virginia, which has been divided into six climate divisions (Figure 1) as defined by the National Climate Data Center (NCDC). The climate division values obtained from NCDC are based on monthly precipitation and temperature observations and are considered to be climatically homogeneous. The six West Virginia climate division temperature and precipitation values were arranged by month and then grouped into seasonal and annual values. Monthly averages within a climatic division have been calculated by giving equal weight to stations reporting both temperature and precipitation within a division.

Seasonal precipitation and temperature values vary across the state and vary throughout the year (Figures 2-9). There is not a clearly defined wet/dry season, but precipitation values peak in summer and are driest in fall (Figures 4 and 5). Region 4 consistently has the highest precipitation values due to orographic precipitation, while Region 5 generally is the driest as that region is on the leeward side of the Central Appalachian Mountains. Seasonal temperature patterns are also evident (Figures 6-9). Temperatures reach a maximum in summer and are coolest in winter. Region 4 is the coolest region in all seasons and Region 3 is the warmest in all seasons. Topography and land cover are the most likely causes of these temperature distributions.

\section{Data Analysis:}

To explore relationships between oscillations and climate, I created scatterplots and maps to examine the climate of West Virginia and the seasonal teleconnection patterns related to this region based on six oceanic/atmospheric oscillations and cyclonic activity by season and year for the state of West Virginia from 1948-2006. I then conducted bivariate and multivariate correlation analysis based on a 0.01 confidence level for all climate variables to determine the 
strength and significance of seasonal teleconnections patterns. Pearson correlation coefficients were calculated between seasonal oscillation values and seasonal climate values.

A preliminary regression analysis was then used to specify and test the relationship among the response (temperature and precipitation) and explanatory (oscillations) variables. The regression equation was as follows:

$$
\hat{y}=a+b_{1} x_{1}+b_{2} x_{2}+\ldots \ldots b_{p} x_{p}
$$

Where $y$ is the response or dependent variables, $x_{1}$ through $x_{p}$ are the explanatory or independent variables, $a$ is the Y-intercept of the line, and $b_{1}$ through $b_{p}$ are the regression coefficients.

However, the effects of a particular oscillation can vary due to forcing from other oscillations. To determine the most significant explanatory variables. I then used the Autoreg procedure from the SAS software package to account for serial autocorrelation.

The Autoreg procedure estimates and forecasts linear regression models for time series data when the errors are autocorrelated or heteroscedastic. To diagnose autocorrelation, the Autoreg procedure produces generalized Durbin-Watson statistics and their marginal probabilities. A Durbin-Watson statistic has a range of $0-4$ and a value of 2.0 indicates no serial autocorrelation. A value of $<1.5$ or $>2.5$ indicates serial autocorrelation is present within the model. The Autoreg procedure then corrects for serial autocorrelation by augmenting the regression model with an autoregressive model for the random error. The autoregressive error model is as follows:

$$
\begin{aligned}
& Y_{t}=X_{t}^{1} \beta+v_{t} \\
& v_{t}=-\varphi_{1} v_{t-1}-\varphi_{2} v_{t-2}-\ldots \varphi_{m} v_{t-m}+\varepsilon_{t} \\
& \varepsilon_{t} \sim \operatorname{IN}\left(0, \sigma^{2}\right)
\end{aligned}
$$

$Y_{t}$ are the dependent values, $\mathrm{X}_{t}$ is a column vector of regressor variables, $\beta$ is a column vector of structural parameters, $\varepsilon_{\mathrm{t}}$ is normally and independently distributed with a mean of 0 and a 
variance of $\sigma^{2}, \varphi$ represents the vector of autoregressive parameters, and the matrix $v_{t}$ can be computed from the autoregressive parameters.

Principle component analysis (PCA) was also performed to capture the variance in a dataset in terms of its principle components and reduce the dimensionality of the data to summarize the most significant combinations of oscillations while also filtering out noise. PCA is a data reduction method that transforms a set of variables into a new set of variables that are linear combinations of the original set. These new variables attempt to capture the variability of the original dataset and can provide insight on how the oscillations relate to each other. The uncorrelated eigenvalues for each variable were then used in a linear regression analysis to examine the combination of teleconnections affecting each climate region.

\section{$\underline{\text { Results: }}$}

When the $\mathrm{AO}$ and $\mathrm{NAO}$ were in positive phases, winter temperatures in all regions were significantly warmer than the mean winter temperature $(r=0.5527$ to 0.5870 and $r=0.5397$ to 0.5614 , respectively, Table 2). When the PDO and PNA were in positive phases, winter temperatures were significantly cooler $(r=-0.3839$ to -0.4844 and $r=-0.2349$ to -0.3717 , respectively, and winter precipitation decreased $(r=0.0072$ to -0.4192 and $r=-0.0534$ to 0.4501, respectively). Region 6 varied considerably from the other regions in that it had a 'rain shadow effect' and tended to not be influenced by winter oscillation values.

When the $\mathrm{AO}$ was in a positive phase, spring temperatures in all regions tended to be warmer $(r=0.2950$ to 0.3539 , Table 3$)$. When the PNA was in a negative phase spring temperatures were significantly warmer $(r=-0.2971$ to -0.4420$)$. The teleconnection strengths were weaker in spring than in winter for all regions. None of the oscillations appeared to have any significant relationships with spring precipitation patterns. 
When the $\mathrm{AMO}$ was in a positive phase summer temperatures in all regions were significantly warmer $(r=0.3648$ to 0.4725 , Table 4$)$. On the other hand, when the NAO was in a positive phase summer temperatures tended to be cooler $(r=-0.2520$ to -0.3406$)$. None of the oscillations appeared to have any significant relationships with regional precipitation patterns. However, Region 6 precipitation appeared to have a significant negative relationship with the PNA $(r=-0.3276)$, though this relationship may be spurious since other regions had conflicting relationships.

When the $\mathrm{AO}$ was in a positive phase fall temperatures tended to be warmer $(\mathrm{r}=0.2541$ to 0.3206, Table 5). When the PDO and PNA were in negative phases fall temperatures were warmer ( $\mathrm{r}=-0.2799$ to -0.3187 and $\mathrm{r}=-0.2268$ to -0.3531 , respectively). When the PNA was in a negative phase regional precipitation increased $(r=-0.2051$ to -0.4434$)$.

Like the correlation analysis, linear regression analysis demonstrated similar seasonal patterns with the teleconnections (Tables 6-9). During the winter, the strength of the teleconnections on West Virginia temperatures is strong with over $50 \%$ of the variability in winter temperatures accounted for by the oscillations $\left(\mathrm{R}_{\text {adj }}^{2}=0.481\right.$ to 0.541$)$. However, the Durbin-Watson statistic $(d)$ for the winter temperature regression model was below acceptable boundaries ( $d=1.294$ to 1.461$)$, meaning there was significant autocorrelation within the dataset for this season. Spring temperature and precipitation variability was not significantly influenced by spring oscillations $\left(\mathrm{R}_{\text {adj }}^{2}=0.094\right.$ to 0.277$)$. On the other hand, summer temperatures seemed to be significantly influenced by the oscillations $\left(\mathrm{R}^{2}{ }_{\text {adj }}=0.288\right.$ to 0.388$)$. Fall oscillations influenced regional fall temperatures $\left(\mathrm{R}_{\text {adj }}^{2}=0.217\right.$ to 0.286$)$ and fall precipitation in the western regions (regions 1,2 , and $3, \mathrm{R}_{\text {adj }}^{2}=0.301$ to 0.334 ). 
After the preliminary regression analysis was completed, a step-wise regression was performed to identify the most influential oscillations by season. These oscillations were then put into seasonal regression models in the Autoreg procedure (Tables 10-13).

As shown in the preliminary regression analysis, winter temperatures (Table 10) tended to be serially autocorrelated, therefore an autoregressive error model was included. Winter temperatures were heavily influenced by the northern hemisphere oscillations $\left(R_{\text {adj }}^{2}=0.4261\right.$ to 0.4763 ) with the NAO and the PDO being the primary drivers. Winter precipitation was not serially autocorrelated, but the relationship between precipitation and any of the oscillations was not significant $\left(\mathrm{R}_{\text {adj }}^{2}=0.0012\right.$ to 0.2272$)$, with the PNA being the most influential oscillation.

The spring temperature regression models were slightly influenced by the SOI and PNA $\left(\mathrm{R}^{2}{ }_{\text {adj }}=0.143\right.$ to 0.2437$)$, but spring precipitation was not strongly influenced by spring oscillations and the model predicted less than $1 \%$ of regional precipitation variability. Neither spring temperature nor spring precipitation were serially autocorrelated.

The summer temperature regression models (Table 12) were modestly influenced by the Northern Atlantic oscillations $\left(\mathrm{R}_{\text {adj }}^{2}=0.2944\right.$ to 0.3649$)$. Summer precipitation variability cannot be accounted for by any of the oscillations, and the model predicted less than $1 \%$ of regional precipitation variability. Neither summer temperature nor summer precipitation were serially autocorrelated.

For the fall regression models (Table 13), both temperature and precipitation variability were influenced by the oscillations, in particular the PNA. The fall temperature regression models were modestly influenced by the NAO and PNA $\left(R_{\text {adj }}^{2}=0.1397\right.$ to 0.2717$)$. The fall precipitation regression models showed the influence of the Pacific oscillations $\left(\mathrm{R}_{\text {adj }}^{2}=0.0715\right.$ to 0.3054). As evident from the preliminary regression analysis, the western regions $(1,2$, and 3$)$ 
are more influenced by the Pacific oscillations than the eastern regions $(4,5$, and 6$)$. Neither fall temperature nor fall precipitation were serially autocorrelated.

The final analysis performed was a principle component analysis and factor regression analysis. The Pacific oscillations (PNA, PDO, and SOI) tended to be grouped together in most seasons and along with the $\mathrm{AO}$, this combination accounted for most of the seasonal variability (Table 14). Nearly $50 \%$ of temperature variability in winter was accounted for by a combination of the seven climate variables $\left(\mathrm{R}_{\text {adj }}^{2}=0.464\right.$ to 0.524$)$, which supported previous findings that winter temperature is strongly influenced by teleconnection patterns, particularly the PNA and the NAO.

\section{Discussion/Conclusion:}

Identifying the linkages between oscillations and climate variability has the potential to greatly improve seasonal forecasting capabilities. A better understanding of these associations is useful to not only resource managers and agricultural divisions, but it is also beneficial to the public. My results suggest that the North Atlantic oscillations are the primary drivers of West Virginia's temperature variability, while the Northern Pacific oscillations drive West Virginia's precipitation variability. The strongest teleconnection patterns were in winter months. This could be due to the fact that Northern Hemisphere air parcels are denser and geopotential height fields are lower in the winter, thereby allowing for a more efficient transfer of energy across large distances. Winter is also when the strength of the NAO is at its peak, and this influence was evident in the quantitative analysis presented here. It has been recognized that the amplitude of the NAO has increased over time and may in the future play a stronger role in Northern Hemisphere climate patterns (Dickson et al., 2000). There have been many studies that have recognized that both together and independently, the PNA and NAO account for a substantial 
portion of wintertime temperature variability throughout the Eastern half of the United States (Vega et al., 1995; Hurrell and Van Loon, 1997; Serreze et al., 1998; Marshall et al., 2001; Sheridan, 2003; Notaro et al., 2006). My results support these findings on a more local scale. There was very little serial autocorrelation present in the datasets. This may be due to the fact that observations and index values were grouped by season. A monthly analysis may further reduce serial autocorrelation, but the shorter time scale of a monthly analysis would have more noise involved in the results.

TCA and SOI had little to no affect on climate patterns in West Virginia. Teleconnections patterns for the TCA and SOI may be harder to determine. Cyclonic activity may affect weekly or monthly patterns which have been masked by the longer time scale of this study. The SO has been long noted as a driver of climatic variability on a global scale, but the public is much less aware of other such oscillations throughout the five ocean basins. SO effects on other areas of the United States are varied and extreme events may influence West Virginia climate, but this teleconnection pattern is generally not evident in West Virginia. The influence of the Atlantic appears to moderate the impact of the SO in the Northern Hemisphere, particularly in the mid-Atlantic region and the Northeast.

Further complicating the examination of the impacts of teleconnections within the midAtlantic is that the strength of one oscillation phase may modulate the teleconnection strength of another oscillation phase. There may be a particular threshold needed for the effects of the oscillation to be felt in a particular region resulting in non-linear relationships. Isolating a single climate signal from noise at any location is also hard if not impossible, particularly if the teleconnection strength is weak. Finally, all the possible effects of an oscillation on climate in West Virginia cannot be captured with just an analysis of temperature and precipitation patterns. 
The teleconnection patterns throughout the United States vary by intensity, duration, and spatial extent, but the key to understand these teleconnections is in understanding the underlying oceanic/atmospheric oscillations themselves. Studies tend to focus on teleconnections of large regions without thought to the spatial attributes within those regions. The impacts of teleconnections are varied throughout regions of diverse terrain and are not uniformly distributed as evidence here by the different effects on either side of the Appalachian Mountains.

Teleconnection strength will change as global and local temperatures change. The effect of rising SSTs on oscillation strength and duration is not a common subject in existing literature, but clearly changes in SSTs of the Atlantic will have impacts on regional winter temperatures, if the relationships observed here remain robust over time. Warmer SSTs in the Atlantic are also of particular concern to countries in the Northern Hemisphere. An influx of fresh water from melting ice in the Northern Atlantic and Arctic may have severe impacts for global ocean circulation and oceanic/atmospheric interactions (Zhang and Delworth, 2005). Direct anthropogenic causes of global climate variability are important, but they are not the only factor in climate change. Oceanic/atmospheric oscillations are the "wild card" of global warming in that they are not fully understood. Further studies into the role of these oscillations on climate change, particularly on a regional basis, where policy and planning take place, are necessary. 


\section{Chapter 2}

\section{$\underline{\text { Introduction }}$}

It has been hypothesized that climate strongly influences patterns of wildfire even in fire regimes dominated by anthropogenic ignitions or regimes that were altered by fire suppression (Heilman et al., 1998; Swetnam and Betancourt, 1998; Veblen et al., 2000; Shumway et al., 2001; Westerling et al., 2003: Roman-Cuesta et al., 2003; Mckenzie et al., 2004; Lafon et al., 2005; Westerling et al., 2006). In ecological terms, a close linkage between fire and climate could diminish the importance of local processes, such as competition, predation, and random variations in the long-term dynamics of fire prone ecosystems (Swetnam and Betancourt, 1990). A close linkage between fire and climate might also reduce or alter the impacts of human activities such as anthropogenic ignitions, fire suppression and other land uses.

Several studies of fire-climate interactions have suggested that in some systems, teleconnections can strongly affect the synchrony of fire regimes (Swetnam and Betancourt, 1990; Swetnam and Betancourt, 1998; Grissino-Mayer and Swetnam, 2000; Kitzberger et al., 2001; Westerling et al., 2003; Hessl et al., 2004; Heyerdahl et al., 2008). Teleconnections or associations between global oceanic/atmospheric processes and weather/climate over great distances (Barry and Chorley, 1998) can be used to understand climatological relationships between the synoptic-scale atmospheric circulation patterns and land surface climates (Leathers et al., 1991). While the characteristics and impacts of synoptic scale teleconnections have been studied extensively, an examination of the influence of these teleconnections on ecosystem dynamics, such as fire, has been focused primarily on the Western United States (Swetnam and Betancourt, 1990; Swetnam, 1993; Grissino-Mayer, 1995; Swetnam and Betancourt, 1998; Swetnam and Betancourt, 1999; Veblen et al., 2000; Kitzberger et al., 2001; Westerling et al., 
2003; Westerling et al., 2006). Climate conditions, such as humidity, temperature and precipitation during a fire event can directly influence the size, intensity and duration of a fire (Heilman et al., 1998; Kitzberger et al., 2001), so it is likely that teleconnections in other regions of the world generate equally important impacts on fire regimes. The seasonal timing of precipitation and temperature also has strong influences on growth patterns in local vegetation which in turn can control fire characteristics. Teleconnection processes influence many aspects of fire regimes through direct and indirect controls, like precipitation, temperature, and solar radiation on fuel accumulation, fuel moisture, and lightning ignitions (Kitzberger, 2001).

Despite the complexity inherent in local fire regimes, regional fire activity, particularly in arid forest systems, often oscillates in phase with year-to-year climatic variability (Swetnam, 1993). This climate-fire connection raises the possibility that historical factors inherent in the local ecosystem are overridden by regional climatic events and trends. Even with changing vegetation dynamics due to human activities (e.g. fire suppression, logging, grazing, land use change, etc.), the fire-climate linkage could have forecasting value and important implications for fire management (Swetnam and Betancourt, 1990). If climatic oscillations operating on monthly to decadal timescales affect fire occurrence and area burned, then prediction of fire hazard will be broadened (Hessl et al., 2004).

Although many oscillations are thought to affect North American climate, no study has explored which of these affect climate of the Mid-Atlantic States. In addition, though the impact of synoptic scale oscillations on wildfire has been evaluated in the Western United States and elsewhere globally (Swetnam and Betancourt, 1998; Veblen et al., 2000; Westerling et al., 2003: Roman-Cuesta et al., 2003; Hessl et al., 2004; Mckenzie et al., 2004; Westerling et al., 2006), these teleconnections have not been explored in the Mid-Atlantic region. 
Much of the vegetation in the Mid-Atlantic region appears to be fire dependent. Oak and pine are the dominant species in West Virginias forests and may require periodic burning for long term maintenance (Delcourt and Delcourt, 1997; Lafon et al., 2005; Lafon and GrissinoMayer, 2007). Prior to European settlement, indigenous peoples had a long history of using fire in hunting practices, clearing land for habitation, and territorial disputes. European settlers used fire for much the same reasons. During the Industrial Revolution, large iron furnaces were built and steam locomotives traveled throughout West Virginia causing anthropogentically-induced forest fires across the region (Hicks, 1998). In the 1960's, the federal government (USDA Forest Service) became the lead agency of forest fire control by promoting fire suppression (Lafon et al., 2005). All wildfires on federal land were suppressed, unless prescribed, regardless of ignition source. Decades of fire suppression have contributed to declines in certain native species and to increases in stand density and fuel load in some locations. Despite strong human drivers of ecological change, climatic influences on the timing and size of wildfire may still be detectable in the Mid-Atlantic region.

Wildfires in the Mid-Atlantic region occur mainly in the spring and fall during dry periods and are generally limited to ground fires that consume leaf litter and dead vegetation (Hicks, 1998). Humid temperate conditions support high vegetation productivity and rapid fuel accumulation. Seasonal variations in weather conditions contribute to pronounced fire seasonality. Studies predict that fire activity will increase in many regions as a consequence of climate change (Heilman et al., 1998; Grissino-Mayer and Swetnam, 2000; Dale et al., 2001 Roman-Cuesta et al., 2003) although demographic changes may also affect fire regimes.

The purpose of this study is to examine the fire activity and the seasonal climatic drivers of fire activity in West Virginia from 1948-2006. I will do this through the use of quantitative 
and cartographic methods. I propose that these teleconnection patterns have a significant influence on fire activity in West Virginia despite widespread anthropogenic ecosystem changes.

\section{Study Area and Data Sources:}

This study examines the relationship between climate and forest fire events for the state of West Virginia from 1948-2006 using a variety of existing climate data sources, including synoptic scale variables like the Southern Oscillation (SO), Pacific Decadal Oscillation (PDO), Pacific/North American Pattern (PNA), Arctic Oscillation (AO), North Atlantic Oscillation (NAO), and Atlantic Multidecadal Oscillation (AMO, Table 19).

The pattern of anomalous circulation between the tropical western Pacific and tropical eastern Pacific is known as the SO. The SO can be quantified in a variety of ways (Ropelewski and Halpert, 1986; Ropelewski and Jones, 1987; Chen and Van Den Dool, 1999; Harrison and Larkin, 1999; Hanley et al., 2003; McPhaden et al., 2006), each of which has strengths and weaknesses. The most reliable measure of the $\mathrm{SO}$ on interannual and annual time scales is the Southern Oscillation Index, or the SOI (Hanley et al., 2003). The SOI is an index based on the normalized sea level pressure differences between Darwin, $12^{\circ} 25^{\prime} \mathrm{S}, 131^{\circ} 00^{\prime} \mathrm{E}$, and Tahiti, $17^{\circ} 30^{\prime} \mathrm{S}, 149^{\circ} 30^{\prime} \mathrm{W}$. It is a measure of the synoptic scale pressure difference between the eastern and western tropical Pacific. The Climate Research Unit's data calculates the SOI based on the method given by Ropelewski and Jones (1987), which utilizes a second normalized procedure to give the most unbiased value.

The PDO is a pattern of North Pacific Ocean sea surface temperature (SST) variability that persists for 20 to 30 years. For this study, PDO fluctuation is captured by the PDO index. The PDO index, as developed by Mantua et al. (1997), is the leading principle component of North Pacific monthly SST variability which calculates North Pacific Basin SST anomalies from 
$20^{\circ} \mathrm{N}$ to $90^{\circ} \mathrm{N}$. Monthly values are defined as the difference between observed anomalies and the monthly mean global average SST anomaly (Mantua and Hare, 2002).

The PNA is one of the most prominent modes of low-frequency variability in the Northern Hemisphere extratropics and is a major mode of atmospheric variability over North America during Northern Hemisphere winters (Wallace and Gutzler, 1981; Leathers et al., 1991; McNab and Karl, 1991; Vega et al., 1995; Sereze et al., 1998; Sheridan, 2003; Notaro et al., 2006). It is associated with strong fluctuations in the strength and location of the East Asian or sub-polar jet stream. The PNA index is constructed from three interconnected fixed points over the North Pacific and North America (Wallace and Gutzler, 1981; Leathers et al., 1991). These points measure the $500 \mathrm{mb}$ height anomalies from $0-90^{\circ} \mathrm{N}$. The PNA is a Northern Hemisphere teleconnection index that is based on rotated principal component analysis (RPCA, Barnston and Livezy, 1987) which isolates and enhances the particular monthly mean teleconnection pattern at the four points over the course of a year.

Several synoptic scale variables originating in the Atlantic Ocean were also used in this analysis. The $\mathrm{AO}$ is the leading mode of high-latitude climate variability in the Northern Hemisphere. The AO reflects the strength of the polar vortex on decadal to multidecadal timescales (Thompson and Wallace, 1998; Fye et al., 1999; Polyakov and Johnson, 2001; Wu et al., 2006). The $\mathrm{AO}$ is quantified by using the associated principal component time series to construct the AO index (Thompson and Wallace, 1998). The AO index measures the $1000 \mathrm{mb}$ pressure height field over the entire $50-90^{\circ} \mathrm{N}$ region. The $\mathrm{NAO}$ is a meridional oscillation in atmospheric mass between the semi permanent Subtropical High (also called the Azores and/or Bermuda High) and the Icelandic Low. Furthermore, the NAO affects Atlantic SST and current movement between these two pressure centers. The NAO index is based on rotated principal 
component analysis (RPCA, Barnston and Livezy, 1987) which isolates and enhances the particular monthly mean teleconnection pattern over a series of grid points throughout the North Atlantic Ocean. These grid points measure the $500 \mathrm{mb}$ pressure height anomalies from $0-90^{\circ} \mathrm{N}$ in the Atlantic Ocean basin. The AMO is a low frequency oscillation that persists from 50-80 years with a SST range of $0.4^{\circ} \mathrm{C}\left(1^{\circ} \mathrm{F}\right)$ (Barnston and Livezey, 1987). The AMO index measures the multi-decadal SST variability centered on the North Atlantic Ocean from $0-70^{\circ} \mathrm{N}$. For all climate variables, monthly values were compiled into seasonal and annual values.

This study also examines the climatic variability of the state of West Virginia, which has been divided into six climate divisions (Figure 1) as defined by the National Climate Data Center (NCDC). West Virginia is an ecologically, topographically, and demographically diverse state (Table 20). The climate division values obtained from NCDC are based on monthly precipitation and temperature observations and are considered to be climatically homogeneous. The six West Virginia climate division temperature, precipitation, and Palmer Drought Severity Index (PDSI) values were arranged by month and then averaged or totaled to produce seasonal and annual values. Monthly averages within a climatic division have been calculated by giving equal weight to stations reporting both temperature and precipitation within a division.

PDSI is based on precipitation and temperature data, as well as the local water content of the soil (Palmer, 1965). PDSI is a composite monthly index of regional climatic conditions that incorporates both immediate (same month) and cumulative (multi-month) effects of drought. PDSI calculates the water balance of an area based on a two-layer soil model and the hypothetical moisture supply (Keyantash and Dracup, 2002). This index attempts to measure the duration and intensity of the long-term drought-inducing circulation patterns. Long-term drought 
is cumulative, so the intensity of drought during the current month is dependent on the current weather patterns as well as the cumulative impacts of previous months.

Fire data for this study was collected by the West Virginia Division of Forestry (WVDF) and consists of the number of fire events (count) and the area burned (hectares) per season. The WVDF dataset is arranged by season and county. The fire seasons are spring (March-May) and fall (August-November). While some fire events may have occurred in months not included in the aforementioned seasons, such fires are not archived by the WVDF because most fires in this region occur during these two seasons (Hicks, 1998; Lafon et al., 2005). Because fire data were arranged by county, I assigned each county to the appropriate region if they were more than $75 \%$ in that region (Figure 10).

The WVDF fire data from 1939-2001 were collected by individual agents from the WVDF and stored as paper documents (Marion Roger Ozburn, WVDF, Charleston, West Virginia, personal communication). To approximate the area burned, including area burned on private land, topographic maps were utilized to obtain UTM coordinates for a fire's point of origin, then the extent of area burned was estimated. Any fire extend that was large enough to sketch was typically done by hand based upon knowledge of where the fire burned on the ground. Data collection from 2001- present is electronically stored in tabular format. WVDF agents now use portable GPS devices to track area burned.

\section{Methods:}

To explore relationships between climate and fire, I created scatter plots and maps by season and year for the state of West Virginia from 1948-2006. I then conducted bivariate and multivariate correlation analysis based on a 0.01 confidence level for all climate variables and fire data to determine the strength of the fire-climate interaction. Pearson correlation coefficients 
were calculated between seasonal climate values and seasonal fire characteristics. This was done on seasonal and annual timescales. All fire data was Log 10 transformed due to significantly skewed distribution of the seasonal data. Climate data was normally distributed and did not need to be transformed.

A preliminary regression analysis was used to specify and test the relationship among the response (wild fire activity) and explanatory (climate) variables. The regression equation is as follows:

$$
\hat{y}=a+b_{1} x_{1}+b_{2} x_{2}+\ldots . . b_{p} x_{p}
$$

Where $y$ is the response or dependent variables, $x_{l}$ through $x_{p}$ are the explanatory or independent variables, $a$ is the Y-intercept of the line, and $b_{1}$ through $b_{p}$ are the regression coefficients.

For the preliminary regression, the regional models were not sophisticated and all seasonal variables were included in each model. However, the effects of a particular oscillation can vary due to forcing from other oscillations. Some oscillations can limit the spatial extent and the climatic response of other oscillations. To account for this, a step-wise regression analysis was performed to determine the most significant explanatory variables, then by using the Autoreg procedure from the SAS software package, serial autocorrelation was accounted for and corrected.

The Autoreg procedure estimates and forecasts linear regression models for time series data when the errors are autocorrelated or heteroscedastic. The autoregressive error model is used to correct for autocorrelation. To diagnose autocorrelation, the Autoreg procedure produces generalized Durbin-Watson statistics and their marginal probabilities. The Autoreg procedure then corrects for serial autocorrelation by augmenting the regression model with an autoregressive model for the random error. The autoregressive error model is as follows: 


$$
\begin{aligned}
Y_{t} & =X_{t}^{l} \beta+v_{t} \\
v_{t} & =-\varphi_{1} v_{t-l}-\varphi_{2} v_{t-2}-\ldots \varphi_{m} v_{t-m}+\varepsilon_{t} \\
\varepsilon_{t} & \sim I N\left(0, \sigma^{2}\right)
\end{aligned}
$$

$Y_{t}$ are the dependent values, $\mathrm{X}_{t}$ is a column vector of regressor variables, $\beta$ is a column vector of structural parameters, $\varepsilon_{\mathrm{t}}$ is normally and independently distributed with a mean of 0 and a variance of $\sigma^{2}, \varphi$ represents the vector of autoregressive parameters, and the matrix $v_{t}$ can be computed from the autoregressive parameters.

Principle component analysis (PCA) was also performed to capture the variance in seasonal oscillation events in terms of their principle components and reduce the dimensionality of the data to summarize the most significant parts while also filtering out noise. PCA is a data reduction method that transforms a set of variables into a new set of empirical orthogonal factors (EOFs) that are linear combinations of the oscillations. These new variables attempt to capture the variability of the original dataset and can provide insight on how the climate variables relate to each other. The uncorrelated eigenvalues for each principle component were then used in a linear regression analysis to examine the combination of climate variables affecting fire events in each climate region.

Because lag effects of climate on fire have been widely documented and because the relationship between fire and climate may be non-linear (Swetnam and Betancourt, 1990; Swetnam, 1993; Grissino-Mayer, 1995; Swetnam and Betancourt, 1998; Kitzberger et al., 2001; Westerling et al., 2003; Lafon et al., 2005; Westerling et al., 2006), I used Superposed Epoch Analysis (SEA) to evaluate the effect of climate variables on fire events. SEA identifies statistical, non-linear relationships between climate variables and fire years with 95\%,99\%, and 99.9\% bootstrap confidence levels (Grission-Mayer, 1995; Hessl et al., 2004). Seasonal 
oscillation, temperature, and precipitation values were calculated from a nine year window, four years before the event and four years after the event, by quartile for fire events and area burned from 1948-2006. The event years were arranged by size and number for each region into quartiles. Quartiles were divided by the top 25\% (Q1), two mid 25\%'s (Q2 and Q3), and the bottom 25\% (Q4).

\section{$\underline{\text { Results: }}$}

More fires tended to burn in the spring, but the largest fires occurred in the fall (Figures 10-13 and Figures 14-17). The spring season is characterized by numerous small fires, while the fall season has significantly fewer fires, but the total area burned is larger, reflective of larger fires. Region 3 had the most area burned and the largest number of fires of all the regions throughout the study period; however, Region 3 is the largest area and has the most forest cover of all the regions. Standardizing each region by forested area and fire characteristics (i.e. size and season) reveals that West Virginia has relatively few fire events and area burned per hectare, however, region 3 still surpasses the other regions in both area burned and number of fires per season (Table 21).

Area burned and the number of fires occurring during the spring season were strongly influenced by spring precipitation and drought (Tables $22 \& 23$ ). When PDSI values were negative and drought conditions predominated, spring area burned increased $(r=-0.3686$ to 0.5924). When the winter and spring AMO were in negative phases there were more spring fires ( $r=-0.0661$ to -0.4808 and $r=-0.1263$ to -0.4178 , respectively), particularly in the northern regions. Significant relationships were also evident with spring PDO and spring number of fires $(r=-0.1296$ to -0.4872$)$ and spring SOI and spring number of fires $(r=0.1916$ to 0.4029$)$ although these relationships were not as strong and were less consistent across regions. These 
associations suggest that cool, dry conditions in winter and in the spring, likely driven by the AMO, seem to increase the number of fires and the area burned in the spring.

Warmer temperatures in the summer increased area burned in the fall $(r=0.1897$ to 0.3516, Tables $24 \& 25)$. Similarly, low summer precipitation and a negative summer PDSI increased area burned in the fall $(r=-0.2027$ to -0.3452 and $r=-0.2586$ to -0.3546 , respectively). The strongest relationships were with fall precipitation and fall number of fires $(r$ $=-0.2621$ to -0.5845$)$, fall PDSI and fall number of fires $(r=-0.3866$ to -0.5978$)$, fall precipitation and fall area burned $(r=-0.3574$ to -0.5784$)$, and fall PDSI and fall area burned $(r$ $=-0.2423$ to -0.5684$)$. When AMO was in a positive phase, area burned increased $(r=0.282$ to 0.4107). These associations indicate that warm and dry conditions during the summer and fall, possibly associated with the positive phase of the AMO, are strong influences on increased fire activity across the entire state.

The preliminary linear regression analysis was conducted by region and by season (Tables 26-29). All independent variables for a particular region and season were put into the models regardless of consideration of multicolinearity and autocorrelation. Fire events in Region 4 , the driest and least populated region, appeared to be heavily influenced by winter $\left(R^{2}{ }_{a d j}=\right.$ 0.367 and 0.388$)$ and spring $\left(R_{a d j}^{2}=0.396\right.$ and 0.503$)$ climate variables. However, this region did not show a similar trend in the summer and fall models. The strength of summer independent variables on fall fire occurrence was weak (Table 28), and little variance in fall fire activity could be explained by summer climate variables. Same season climate and fire activity had the strongest relationships (Tables $27 \& 29$ ).

After the preliminary regression analysis was done, a step-wise regression was performed to identify the most influential climate variables by season. These variables were then put into 
seasonal regression models in the Autoreg procedure. The spring number of fires and area burned regression models (Table 30) did not have as much serial autocorrelation present, in fact, only one model had to be rerun through the Autoreg procedure. The combined effect of the influential winter and spring climate variables, in particular the AMO, accounted for up to $50 \%$ of the variability in spring number of fires $\left(R_{a d j}^{2}=0.222\right.$ to 0.519$)$. Results from the spring area burned were more modest $\left(R_{a d j}^{2}=0.149\right.$ to 0.488$)$.

The fall number of fires and area burned regression models (Table 31) also did not have a great deal of serial autocorrelation present. The combined effect of the summer and fall climate variables accounted for almost $60 \%$ of the variability in fall number of fires $\left(R_{a d j}^{2}=0.339\right.$ to 0.596). Results from the spring area burned regression models were more modest and inconsistent $\left(R^{2}{ }_{a d j}=0.083\right.$ to 0.474$)$.

In the PCA, the groupings of climate variables in winter and spring were almost identical, while summer and fall groupings were highly dissimilar (Table 32). EOFs revealed interesting relationships for the winter and spring between the Atlantic and Pacific oscillations, in particular the NAO and the SOI. The regression analysis using the loadings from the PCA was similar to the results from the preliminary regression analysis and the Autoreg procedure, but with less robust results (Table 33). In the spring, the loadings explained a substantial portion of fire event variability, particularly in Region 4 \& 5. In the Fall, the coefficients were more uniform $\left(R_{a d j}^{2}=\right.$ 0.26 to 0.36$)$, with Region 1 being the exception $\left(R_{a d j}^{2}=0.12\right)$.

The SEA was performed by region and by season, however most variables had a similar effect throughout the study area and an examination at the state level by season was therefore deemed sufficient. Spring was significantly warmer and drier than average during the fire year for years with large areas burned (upper quartile "Q1") and significantly cooler and wetter during 
the fire year for years with small areas burned (lower quartile "Q4", Figures 18 \& 19). Similar relationships were observed for spring number of fires and spring climate (Figures 20-22). Fall fire events were also significantly warmer and drier than average during the fire year for years with large areas burned (upper quartile "Q1") and significantly cooler and wetter during the fire year for years with smaller areas burned (lower quartile "Q4", Figures 23-25). Similar relationships were observed for fall number of fires and fall climate (Figures $26 \& 27$ ). The most significant results were from same season climate variables and lag effects of climate on fire activity were rare and possibly spurious.

\section{Discussion/Conclusion:}

The frequency, size, and seasonality of wildfire depend on weather and climate as well as forest structure and composition (Dale et al., 2001). Typically areas with a long history of human land use are thought to have fire regimes dominated by human drivers, particularly anthropogenic ignitions. This study suggests that even in largely human dominated landscapes, where anthropogenic rather than lightning ignitions are common, climate may still influence the area burned and number of wildfires. Results presented here indicate that precipitation, temperature, and PDSI are strongly linked to both area burned and number of fires during the spring and fall fire seasons. According to the National Oceanic and Atmospheric Association (NOAA), West Virginia receives an average of $112.83 \mathrm{~cm}$ of precipitation per year, with an increasing trend of $0.64 \mathrm{~cm}$ per decade from 1895 to the present. Given this humid environment, it is surprising that PDSI and other drought indices remain good predictors of high fire years. The results from the SEA analysis and statistical correlations show that PDSI does not show a lagged effect, yielding little long term predictive power for fire management. In a prior study in the Northwest United States by Heyerdahl and others (2008), climate in years prior to a fire 
event was not a significant influence on fire variability. However, this research suggests that management focused on curtailing anthropogenic ignitions rather than observing climate conditions may be unproductive.

Paleoclimate data can provide useful insight on the influence of climate on wildfire variability during periods that pre-date suppression policies, logging, and land cover change (Heyerdahl et al., 2008). Proxy fire history data for the last 150-400 years suggest that fires in this region burned at intervals of 5-15 years and were of low intensity (Shumway et al., 2001). Intense fire events in the past also appear to be associated with drought, broadly consistent with the results presented here.

Several low frequency Pacific and Atlantic oscillations are known to affect the regional climate of the Mid-Atlantic (see chapter 1) suggesting that longer range predictions of fire activity might be possible. In this study, only AMO demonstrated a consistent relationship with area burned and number of fires (particularly for the number of spring fires). Because AMO varies over 30-60 years, this index may be used to help make predictions about the upcoming fire season or several seasons, rather than depending on daily or weekly forecasts derived from weather. AMO has shown a strong association with drought throughout the United States (McCabe and Palecki, 2006). However, it should be noted that based on all the statistical methods, climate variables have a stronger association with the number of fires than area burned. Why some fire starts develop into large fires while others do not, remains unexplained by the climate data analyzed here. An increase in lightning events associated with particular climate conditions is a possible explanation, however, lightning accounts for a very minor percentage $(<$ $0.5 \%$ ) of fire events in West Virginia. It is more likely that other climatic variables, not included here (e.g. wind) may explain this variability. 
Some of the results presented here contradict previous studies in adjacent areas. Contrary to the findings of Lafon et al. (2005), I found that there were more fires recorded in the spring than in the fall. There also did not appear to be a strong increase in area burned during the last three decades, as opposed to the results of the aforementioned study. Their study area encompassed region four and five as well as parts of Virginia and was entirely within the Ridge and Valley Province, while this study included portions of the Appalachian Plateau and Ohio River Valley. Forest composition, human population density, and climate all vary across these regions, so there is little reason to expect that relationships to remain stable over space. In addition, Lafon et al. (2005) examined different fire variables (collected by federal agencies rather than WVDF) which allowed them to study intensity as well as size and number of fire events. In addition, that study utilized lightning data from the Lightning Detection Network (LDN), which, due to the limits of this study, I did not analyze. As most fires tend to be anthropogenical ignitions, the LDN information would not significantly improve my dataset. In fact, in an analysis of WVDF data from 2001-2006, lightning accounted for less than $0.5 \%$ of annual fire events (West Virginia Division of Forestry). The leading causes of fire activity in West Virginia were from debris burning and arson. Together, these factors accounted for over $65 \%$ of annual fire events.

In recent decades, climatic changes have modified the geography and dynamics of fire, so that fire regimes have been altered practically everywhere. Global warming or shifts in weather patterns due to global atmospheric-oceanic oscillations can cause subtle or even extreme changes to local environments. A greater understanding of climatic patterns and their changes will be highly beneficial for forest fire and resource management. Fire effects on forests are multifaceted. They induce an acceleration of nutrient cycling, changes in soil composition, tree 
mortality, seed germination, loss of seed bank, increased landscape heterogeneity, and allow for invasive species invasions (Dale et al., 2001). How these effects will change with changing synoptic scale weather patterns is uncertain. In addition, regardless of ignition source, wildfires have pronounced climate forcing effects (Packham and Tapper, 1996; Leenhouts, 1998). In essence, while climate has an affect on wildfire variability, wildfire variability will have an affect on climate.

The effect that climate change will have on fire occurrence within the central Appalachians is unknown. Climate change scenarios predict that while some areas will have a decrease in fire events and area burned, other regions will have increases (Dale et al., 2001). With increasing temperatures and increasing precipitation predicted for this region, fire activity is likely to increase. More natural fire events may occur due to increased lightning, while anthropogenic ignitions may remain the same. 


\section{Chapter 3}

\section{$\underline{\text { Introduction }}$}

As wildland urban interfaces increase due to the growth of human populations, lives and property become increasingly threatened by forest fire events. There is a very real need for better management, mitigation, and monitoring of fire events. The archival effects of fire on the natural and human environment are limited to empirical and proxy information. Until the last few decades only rough approximations are available of fire event characteristics. In the past, West Virginia fire events were monitored and archived through the use of firsthand accounts, rough approximations, and aerial photography. Satellite technology offers a new means of monitoring forest fires in real time.

The first instrument onboard a low-orbitting satellite that could detect fire activity was the Advanced Very High Resolution Radiometer (AVHRR). The AVHRR was initially launched in 1978 onboard the US civilian meteorological satellite TIROS-N. Until 2000, the AVHRR was the only instrument that could provide observations of the large scale spatial distribution of fire with high temporal frequency (Morisette et al., 2005). Despite the relatively high saturation threshold of the AVHRR, heating of the earth by the sun, cloud and aerosol obscuration, and fire event properties, pixels become saturated thereby causing errors of commission (Robinson, 1991; Sousa et al., 2003). Also, the AVHRR is not successful in recognizing real time events. Because of AVHRR's large spatial resolution, errors of omission are very high and contextual information on individual fire events are lacking.

In the late 1990's, NASA developed the Moderate Resolution Imaging Spectroradiometer (MODIS). MODIS was launched onboard the TERRA platform in December of 1999 and the AQUA platform in May of 2002 as part of NASA's Earth Observing System 
(EOS) and was designed to provide improved monitoring of the land, ocean, and atmosphere. MODIS provides data in 36 spectral bands at 3 different resolutions and offers global, near-daily imaging capability, complementing many of the other sensors onboard the TERRA and AQUA platforms (Justice et al, 1998). The MODIS suite of fire products contain information on the location, size, and intensity of fire events as well as area burned. This information is used to monitor the spatial and temporal distribution of fires in many different ecosystems, to detect changes in fire distribution, and to identify changes in the frequency and strength of fire events. MODIS produces an algorithm that uses thermal signatures (the 4 and $11 \mu \mathrm{m}$ channels) to separate the fire signal from background noise to create the global daily fire product at a $1 \mathrm{~km}$ resolution (Giglio, 2005). The daily fire product is then used to create an 8-day composite. The 8-day composite is utilized, along with higher frequency bands, to generate an area burned product at a $1 \mathrm{~km}$ resolution (Justice, et al, 1998).

The increased saturation temperatures and the higher resolution of MODIS sensors made it more ideal in monitoring fire events than AVHRR (Morisette et al., 2005). The sensitivity of the MODIS instruments allow for improved fire detection and characterization over other methods of remotely sensing forest fire events (Justice et al., 1998; Justice et al., 2002). The geolocation accuracy of MODIS is a fraction of a pixel, and MODIS information is highly compatible with products derived from GOES and AVHRR which when combined increases the amount of information available per fire events.

However, the MODIS Fire Products are missing ecologically significant information like ignition sources, ignition potential, and provides only a short-term record of fires (extending back to 2000). In the MODIS fire products, cloud cover, heavy smoke, or tree canopy may completely obscure a fire. In order to understand the climatic variables involved in driving fire 
events, MODIS could be combined with other data sources to get a longer-term and more detailed description of past fire events. Climatic drivers of fire, such as drought have been described in arid systems throughout the world, but little attention has been paid to these controls on wildfire in moist climates like that of West Virginia. By examining MODIS Fire Products with archival forest fire datasets and climatic conditions of forest fire events, errors in commission/omission within the MODIS dataset could be identified. It was my hypothesis that through a simple empirical analysis, I could compare the MODIS dataset to the WV Division of Forestry dataset, and potentially evaluate the accuracy and the similarity of the datasets, and determine the strengths and weaknesses of each. The purpose was to aide resource managers throughout the state and region, potentially saving millions of dollars in fire suppression expenditures by providing seasonal to multi-annual forecasts of fire conditions. However, this analysis could not be completed due to unforeseen complications.

\section{Data Sources:}

The MODIS Fire Products consist of point data by day, week, and year on a continental or regional scale from 2000-2007. This data is available in shape file formats as well as text file format. Both products list coordinates and duration of fire events, but do not have area burned calculations. There are 3 levels of data collection: Level 2, Level 2G, and Level 3. For the purposes of this study, only Level 2 and Level 3 were examined from 2000-2007 for the state of West Virginia. Level $2 \mathrm{G}$ is a temporary diurnal product that is used mainly for immediate purposes and is not archived. The Level 2 product covers an area of approximately 2340 by $2030 \mathrm{~km}$ with a 1-km pixel resolution (Giglio, 2005, pp.17). Level 3 fire products are tile-based, with each product file spanning one of the 460 MODIS tiles, of which 326 contain land pixels. The product is a 1-km gridded composite of daily fire pixels (Giglio, 2005, pp.22) 
The West Virginia Division of Forestry fire history dataset lists fire events by season, spring and fall, by county. Spring months are March-June, and fall months are AugustNovember. For the state of West Virginia there are 55 counties. This data set also lists the probable cause of the fire event as well as duration, area burned, and coordinates of fire events within the affected county. These records are available from the fall of 1948 to the fall of 2006.

\section{Problems:}

There were several problems with this particular study. The first problem that needed to be addressed was that there were large gaps in the temporal coverage of Level 3 data (area burned). Due to versioning procedures, there is no coverage of the two tiles that cover West Virginia from 2003 to 2006, and data is limited in 2001 and 2002.

The second problem was that the Level 2 data (8 day composite) was available in varying formats, but none could be used in this particular study. Due to versioning procedures, there were large temporal gaps in the two tiles that cover West Virginia from 2001-2006 during the spring and fall seasons. Consistency was a problem that could not be overcome in the time span of this study.

\section{Discussion/Conclusion:}

Due to recent events in the United States as well as throughout the world, awareness of the consequences of forest fires has grown substantially in the last decade. There is a very real need for research and monitoring of both the ecological and the socio-economic consequences of fire. As temperatures increase in the mid and lower latitudes the growing season is extended and fuels are able to accumulate, thereby increasing the risk of many areas to fire events. These events also have pronounced climate forcing effects. The extent of the wildland urban interface is also increasing putting more people at risk every day. 
The scope of this study was perhaps too far reaching given the state of available data. I had not considered that the availability of the MODIS fire data in a consistent format would be a problem. However, once the MODIS fire team finishes updating the fire products, consistency and availability will not be a problem. A simple examination of errors in commission/omission can be easily achieved in the near future. 


\section{Conclusion}

Oceanic/atmospheric oscillations play a role in global climate variability, and it has been shown that oscillations in the Pacific and Atlantic Ocean affect the regional climate of the MidAtlantic. Climatic variability influences wildfire activity even in regions dominated by anthropogenic ignitions, like West Virginia. Therefore a relationship between oceanic/atmospheric oscillations and wildfire can be deduced. This relationship suggests that longer range predictions of fire activity might be possible due to the semi-periodicity of oceanic/atmospheric oscillations.

Nevertheless, these oscillations are not entirely static and will be influenced by anthropogenically-induced climate forcing. How climate change will impact these oscillations in the future is uncertain. In addition, changing synoptic scale patterns in the oceans and atmosphere will also affect society. A greater understanding of climatic patterns and their changes will be highly beneficial for all sectors of society.

New technologies and methods of data acquisition will also improve our awareness of the multifaceted effect of climate on fire events. Understanding of the consequences of forest fires has grown substantially in the last few decades. However, there is a very real need for research and monitoring of both the ecological and the socio-economic consequences of fire. As temperatures increase in the mid and lower latitudes the growing season is extended and fuels are able to accumulate, thereby increasing the risk of many areas to fire events. These events also have pronounced climate forcing effects. The extent of the wildland urban interface is also increasing putting more people at risk every day. 


\section{Bibliography:}

1. Aguado, E., and Burt, J. Understanding Weather and Climate: Fourth Edition. New Jersey: Pearson Education, Inc., 2007.

2. Alley, W. 1984. "The Palmer Drought Severity Index: Limitations and Assumptions." Journal of Applied Meteorology 23:1100-1109.

3. Barnston, A., and Livezey, R. 1987. "Classification, Seasonality, and Persistence of Low Frequency Atmospheric Circulation Patterns.” Monthly Weather Review 115: 1083-1126.

4. Barry, R., and Chorley, R. Atmosphere, Weather, and Climate. New York, NY: Routledge, 1998.

5. Bell, G., and Janowiak, J. 1995. "Atmospheric Circulation Associated with the Midwest Floods of 1993." Bulletin of the American Meteorological Society 76:681-695

6. Bove, M.C., J.B. Elsner, C.W. Landsea, X. Niu, and J.J. O’Brien, 1998. "Effect of El Nino on US Landfalling Hurricanes, Revisited." Bulletin of the American Meteorological Society 79(11): 2477-2482

7. Cassou, C., Deser, C., and Alexander, M. 2007. "Investigating the Impact of Reemerging Sea Surface Temperature Anomalies on the Winter Atmospheric Circulation Over the North Atlantic." Journal of Climate 20(14):3510-3526.

8. Chen, W., and Van Den Dool, H. 1999. "Significant Change of Extratropical Natural Variability and Potential Predictability Associated with the El Nino/Southern Oscillation." Tellus 51(A): 790-802.

9. Climate Diagnostics Center, Earth System Research Laboratory, National Oceanic and Atmospheric Administration, United States Department of Commerce: http://www.esrl.noaa.gov/psd

10. Climatic Research Unit, School of Environmental Sciences, University of East Anglia, Norwich NR4 7TJ, UK: http://www.cru.uea.ac.uk

11. Curtis, S., 2007. "More Than Just Hurricanes: The Atlantic Multidecadal Oscillation and Extreme Daily Precipitation over the US and Mexico from August to October." EOS Transactions 88(52): 1-9.

12. Dale, V., Joyce, L., McNulty, S., Neilson, R., Ayres, M., Flannigan, M., Hanson, P., Irland, L., Lugo, A., Peterson, C., Simberloff, D., Swanson, F., Stocks, B., and Wotton, M., 2001. "Climate Change and Forest Disturbances." Bioscience 59(9): 723-734.

13. Deedler, W. 2003. “Strong E1 Niño’s Bring Mild and Relatively Dry Winters to Southeast Lower Michigan, But What of the Weak to Moderate El Niño's?" NOAA's National 
Weather Service Weather Forecast Office May 2003 Report.

http://www.crh.noaa.gov/dtx/winter_2002-03_outlook_review.php

14. Delcourt, H, and Delcourt, P. 1997. "Pre-Columbian Native American Use of Fire on Southern Appalachian Landscapes." Conservation Biology 11: 1010-1014.

15. Delworth, T., and Mann, M. 2000. "Observed and Simulated Multidecadal Variability in the Northern Hemisphere.” Climate Dynamics 6: 661-676.

16. Dijkstra, H. 2005. "Interaction of SST Modes in the North Atlantic Ocean." Journal of Physical Oceanography 36: 286-300.

17. Dickson, R., Osborn, T., Hurrell, J., Meincke, J., Blindheim, J., Adlandsvik, B., Vinje, T., Alekseev, G., and Maslowski, W. 2000. "The Arctic Response to the North Atlantic Oscillaiton." Journal of Climate 13(15):2671-2696.

18. Dijkstra, H., te Raa, L., Schmeits, M., and Gerrits, J., 2006. "On the Physics of the Atlantic Multidecadal Oscillation." Ocean Dynamics 56: 36-50.

19. Donnelly, J.P., and J.D. Woodruff, 2007. "Intense hurricane activity over the past 5,000 years controlled by El Nino and the West African monsoon." Nature 447: 465-468.

20. Durkee, J., Frye, J., Fuhrmann, C., Lacke, M., Jeong, H., and Mote T., 2007. "Effects of the North Atlantic Oscillation on Precipitation-type frequency and distribution in the Eastern US." Theoretical and Applied Climatology 2007: 1-15.

21. Elsner, J.B., 2007. “Granger Causality and Atlantic Hurricanes.” Tellus 59 (A): 476-485.

22. Emanuel, K., 2005. "Increasing Destructiveness of Tropical Cyclones over the Past 30 Years." Nature 436: 686-688.

23. Enfield, D. B., Mestas-Nunez, A. M., and Trimble, P.J., 2001. "The Atlantic Multidecadal Oscillation and its Relation to Rainfall and River Flows in the Continental U.S." Geophysical Research Letters 28: 2077-2080.

24. Fyfe, J., Boer, G., and Flato, G. 1999. "The Arctic and Antarctic Oscillations and their Projected Changes Under Global Warming." Geophysical Research Letters 26:1601-1604.

25. Giglio, L. 2005. "MODIS Collection 4 Active Fire Product User's Guide Version 2.1, June 2005."

26. Grissino-Mayer, H. 1995. "Tree-ring Reconstructions of Climate and Fire History at El Malpais National Monument, NM." PhD Dissertation, University of Arizona, Tucson, AZ: 407 pgs. 
27. Grissino-Mayer, H., and Swetnam, T. 2000. "Century-scale Climate Forcing of Fire Regimes in the American Southwest." The Holocene 10: 213-220.

28. Hanley, D., Bourassa, M., O’Brien, J., Smith, S., and Spade, E. 2003. “A Quantitative Evaluation of ENSO Indices." Journal of Climate 16: 1249-1258.

29. Harrison, D. and Larkin, N. 1999. "Seasonal US Temperature and Precipitation Anomalies Associated with El Nino Historical Results and Comparison with 1997-98." Geophysical Research Letters

30. Heilman, W., Potter, B., and Zerbe, J. "Chapter 37. Regional Climate Change in the Southern United States: The Implications for Wildfire Occurrence." The Productivity and Sustainability of Southern Forest Ecosystems in a Changing Environment. New York: Springer-Verlag Inc. 1998. 683-699.

31. Henderson-Sellers, A., Zhang, H., Berz, G., Emanuel, K., Gray, W., Landsea, C., Holland, G., Lighthill, J., Sheih, S., Webster, P., and McGuffie, K. 1998. "Tropical Cyclones and Global Climate Change: A Post-IPCC Assessment." Bulletin of the American Meteorological Society 79(1):19-38.

32. Hessl, A., McKenzie, D., and Schellhaas, R. 2004. "Drought and Pacific Decadal Oscillation Linked to Fire Occurrence in the Inland Pacific Northwest." Ecological Applications 14: 425-442.

33. Heyerdahl, E., McKenzie, D., Daniels, L., Hessl, A., Littell, J., and Mantua, N. 2008. "Climate Drivers of Regionally Synchronous Fires in the Inland Northwest." International Journal of Wildland Fire 17: 40-49.

34. Hicks, Ray. Ecology and Management of the Central Hardwood Forests. New York: John Wiley \& Sons, Inc. 1998.

35. Holland, G., and Webster, P., 2007. "North Atlantic Tropical Cyclone Changes." Philosophical Transactions of the Royal Society 365: 2695-2716.

36. Hurrell, J. 1996. "Influence of Variation in Extratropical Wintertime Teleconnections on Northern Hemisphere Temperature." Geophysical Research Letters 23:665-668.

37. Hurrell, J., Van Loon, H. 1997. "Decadal Variations in Climate Associated with the North Atlantic Oscillation." Climate Change 36: 301-326.

38. Isaksson, E., Divine, D., Kohler, J., Martma, T., Pohjola, V., Motoyama, H., and Watanabe, O. 2005. "Climate Oscillations as Recorded in Svalbard Ice Core Records Between 1200 and 1997.” Geografiska Annaler 87: 205-213.

39. Joint Institute for the Study of the Atmosphere and Ocean, Cooperative Institute between the National Oceanic and Atmospheric Administration and the University of Washington: http://jisao.washington.edu/pdo 
40. Justice, C., Vermote, E., Townshend, J., Defries, R., Roy, D., Hall, D., Salomonson, V., Privette, J., Riggs, G., Strahler, A., Lucht, W., Myneni, R., Knyazikhin, Y., Running, S., Nemani, R., Wan, Z., Huete, A., Leeuwen, W., Wolfe, R., Giglio, L., Muller, J., Lewis, P., and Barnsley, M. 1998. "The Moderate Resolution Imaging Spectroradiometer (MODIS): Land Remote Sensing for Global Change Research." IEEE Transactions of Geoscience and Remote Sensing 36(4): 1228-1249.

41. Justice, C., Giglio, L., Korontizi, S., Owens, J., Morisette, J., Roy, D., Descloitres, J., Alleaume, S., Petitcolin, F., and Kaufman, Y. 2002. "The MODIS Fire Products." Remote Sensing of Environment 83: 244-262.

42. Keyantash, J. and Dracup, J., 2002. "The Quantification of Drought: An Evaluation of Drought Indices." Bulletin of the American Meteorological Society August: 1167-1180.

43. Kitzberger, T., Swetnam, T., and Veblen, T. 2001. "Inter-hemispheric Synchrony of Forest Fires and the El Nino-Southern Oscillation." Global Ecology and Biography 10:315-326.

44. Klotzbach, P., 2006. "Trends in global tropical cyclone activity over the past twenty years (1986-2005).” Geophysical Research Letters 33: 1-4.

45. Kushnir, Y., Robinson, W., Chang, P., and Robertson, A. 2006. "The Physical Basis for Predicting Atlantic Sector Seasonal-to-Interannual Climate Variability." Journal of ClimateSpecial Section 19: 5949-5970.

46. LaDochy, S., Brown, J., Selke, M., and Patzert, W. 2004. "Can US West Coast Climate Be Forecast?" American Meteorological Symposium on Forecasting Weather and Climate of the Atmosphere and Ocean

47. Lafon, C., Hoss, J., and Grissino-Mayer, H. 2005. "The Contemporary Fire Regime of the Central Appalachian Mountains and Its Relation to Climate." Physical Geography 26: 126146.

48. Lafon, C. and Grissino-Mayer, H. 2007. "Spatial Patterns of Fire Occurrence in the Central Appalachian Mountains and Implications for wildland Fire Management" Physical Geography 28: 1-20

49. Landsea, C., Pielke, R., Mestas-Nunez, A., and Knaff, J., 1998. "Atlantic Basin Hurricanes: Indices of Climate Changes.” Climate Change 42: 89-129.

50. Landsea, C., Harper, B., Hoarau, K., Knaff, J. 2006. "Can We Detect Trends in Extreme Tropical Cyclones?" Science 313: 452-454.

51. Leathers, D., Yarnal, B., and Palecki, M. 1991. "The Pacific/North American Teleconnection Pattern and United States Climate. Part I: Regional Temperature and Precipitation Associations." Journal of Climate 4: 517-528. 
52. Leathers, D., and Palecki, M. 1992. "The Pacific/North American Teleconnection Pattern and the United States Climate. Part II: Temporal Characteristics and Index Specification." Journal of Climate 5: 707-716.

53. Leenhouts, B. 1998. "Assessment of Biomass Burning in the Conterminous United States." Conservation Ecology [online] 2(1).

54. Mann, M., Emanuel, K., Holland, G., and Webster, P., 2007. "Atlantic Tropical Cyclones Revisited.” EOS Transactions 88(36):349-350.

55. Mantua, N., and Hare, S. 2002. “The Pacific Decadal Oscillation.” Journal of Oceanography 58: 35-44

56. Mantua, N., Hare, S., Zhang, Y., Wallace, J., Francis, R. 1997. "A Pacific Interdecadal Climate Oscillation with Impacts on Salmon Production." Bulletin of the American Meteorological Society 78: 1069-1079.

57. Marshall, J., Kushnir, Y., Battisti, D., Chang, P., Czaja, A., Dickson, R., Hurrell, J., McCartney, M., Saravanan, R., and Visbeck, M. 2001. "North Atlantic Climate Variability: Phenomena, Impacts, and Mechanisms.” International Journal of Climatology 21: 18631898.

58. McCabe, G., and Dettinger, M., 1999. "Decadal Variations in the Strength of ENSO Teleconnections with Precipitation in the Western US." International Journal of Climatology 19: 1399-1410.

59. McCabe, G., Palecki, M., and Betancourt, J. 2004. "Pacific and Atlantic Ocean Influences on Multidecadal Drought Frequency in the United States." PNAS 101: 4136-4141.

60. McCabe, G., and Palecki, M. 2006. "Multidecadal Climate Variability of Global Lands and Oceans." International Journal of Climate 26: 849-865.

61. McKenzie, D., Gedalof, Z., Peterson, D.L., and Mote, P. 2004. "Climatic Change, Wildfire, and Conservation." Conservation Biology 18: 890-902.

62. McPhaden, M., Zebiak, S., and Glantz, M. 2006. "ENSO as an Integrating Concept in Earth Science." Science 314:1740-1744.

63. Morisette, J., Giglio, L., Csiszar, I., and Justice, C. 2005. "Validation of the MODIS Active Fire Product Over Southern Africa with Aster Data." International Journal of Remote Sensing 26(19): 4239-4264.

64. Myatt, K. 2006. "Oscillations Have Their Ups and Downs." Roanoke Times. Saturday, January 28, 2006.

65. National Climate Data Center (NCDC): http://www1.ncdc.noaa.gov/pub/data/cirs 
66. Notaro, M., Wang, W., and Gong, W. 2006. "Model and Observational Analysis of the Northeast US Regional Climate and Its Relationship to the PNA and NAO Patterns during Early Winter." Monthly Weather Review 134: 3479-3505.

67. Packham, D., and Tapper, N. 1996. "Climate Change and Biomass Burning." $13^{\text {th }}$ Fire and Forest Meteorology Conference, Lorne, Australia.

68. Palmer, W. 1965. "Meteorological Drought" Weather Bureau Research Paper 45, U.S. Department of Commerce, Washington, DC: 1-65.

69. Pielke, R., Landsea, C., Mayfield, M., Laver, J., and Pasch, R. 2005. "Hurricanes and Global Warming.” BAMS 86: 1571-1575.

70. Polyakov, I., and Johnson, M. 2000. “Arctic Decadal and Interdecadal Variability." Geophysical Research Letters 27: 4097-4100.

71. Polyakov, I., Bhatt, U., Simmons, H., Walsh, D., Walsh, J., and Zhang, X. 2005. "Multidecadal Variability of North Atlantic Temperature and Salinity during the Twentieth Century." Journal of Climate 18: 4562-4581

72. Roman-Cuesta, R., Gracia, M., and Retana, J. 2003. "Environmental and Human Factors Influencing Fire Trends in ENSO and Non-ENSO Years in Tropical Mexico." Ecological Applications 13: 1177-1192.

73. Ropelewski, C. and Halpert, M. 1986. "North American Precipitation and Temperature Patterns Associated with the El Nino Southern Oscillation (ENSO)." Monthly Weather Review 114: 2353-2362.

74. Ropelewski, C., and Jones, P. 1987. "An Extension of the Tahiti-Darwin Southern Oscillation Index." Monthly Weather Review 115: 2161-2165

75. Schueler, T, and Mclain, W. 2003. "Fire History of a Ridge and Valley Oak Forest." USDA Forest Service Research Paper NE-724.

76. Sereze, M., Clark, M., McGinnis, D., and Robinson, D. 1998. "Characteristics of Snowfall Over the Eastern Half of the U.S. and Relationships with Principal Modes of Low-Frequency Atmospheric Variability." Journal of Climate 11: 234-250.

77. Sheridan, S., 2003. "North American Weather-Type Frequency and Teleconnection Indices." International Journal of Climatology 23: 27-45.

78. Shumway, D., Abrams, M., and Ruffner, C. 2001. "A 400-Year History of Fire and Oak Recruitment In An Old-Growth Oak Forest in Western Maryland, USA." Canadian Journal of Forest Research 31: 1437-1443. 
79. Swetnam, T., and Betancourt, J. 1990. "Fire-Southern Oscillation Relations in the Southwestern United States." Science 249: 1017-1020.

80. Swetnam, T., and Betancourt, J., 1998. "Mesoscale Disturbance and Ecological Response to Decadal Climate Variability in the American Southwest." Journal of Climate 11: 3128-3147

81. Swetnam, T, Allen, C., and Betancourt, J., 1999. "Applied Historical Ecology: Using the Past to Manage For the Future." Ecological Applications 9: 1189-1206.

82. Swetnam, T. 1993. "Fire History and Climate Change in Giant Sequoia Groves." Science 262: $885-889$.

83. Sutton, R., and Hodson, D., 2003. "Influence of the Ocean on North Atlantic Climate Variability 1871-1999." Journal of Climate 16: 3296-3313.

84. Thompson, D., and Wallace, J. 1998. "The Arctic Oscillation Signature in the Wintertime Geopotential Height and Temperature Fields." Geophysical Research Letters 25: 1297-1300.

85. Trenberth, K., 2005. "Uncertainty in Hurricanes and Global Warming.” Science 308: 17531754.

86. Trenberth, K., Moore, B., Karl, T., and Nobre, C. 2006. "Monitoring and Prediction of the Earth's Climate: A Future Perspective." Journal of Climate - Special Section 19: 50015008.

87. Tsutsui, J., 2002. "Implications of Anthropogenic Climate Change for Tropical Cyclonic Activity: A Case Study with the NCAR CCM2." Journal of the Meteorological Society of Japan 80(1): 45-65.

88. Van Den Dool, H., Peng, P., Johansson, A., Chelliah, M., Shabbar, A., and Saha, S. 2006. "Seasonal-to-Decadal Predictability and Prediction of North American Climate-The Atlantic Influence." Journal of Climate-Special Section 19: 6005-6024.

89. Veblen, T, Kitzberger, T., Donnegan, J. 2000. "Climatic and Human Influences on Fire Regimes in Ponderosa Pine Forests in the Colorado Front Range." Ecological Applications 10: $1178-1195$.

90. Vega, A., Henderson, K., and Rohli, R. 1995. "Comparison of Monthly and Intramonthly Indices for the Pacific/North American Teleconnection Pattern." Journal of Climate 8: 20972103.

91. Walker, G., Bliss, E., 1932. "World Weather V. Mem. Report.” Meteorological Society Publication 1932.

92. Wallace, J. 2000. "North Atlantic Oscillation/annular Mode: Two Paradigms-One Phenomenon." Quarterly Journal of the Royal Meteorological Society 126: 791-805. 
93. Wallace, J., and Gutzler, D. 1981. "Teleconnections in the Geopotential Height Field in Northern Hemisphere Winter." Monthly Weather Review 109: 784-812.

94. Wallace, J., and Thompson, D. 2002. "The Pacific Center of Action of the Northern Hemisphere Annular Mode: Real or Artifact?” Journal of Climate 15: 1987-1991.

95. Webster, P., Holland, G., Curry, J., and Chang, H., 2005. "Changes in Tropical Cyclone Number, Duration, and Intensity in a Warming Environment." Science 309: 1844-1846.

96. Westerling, A., Gershunov, A., Brown, T, Cayan, D, and Dettinger, M. 2003. "Climate and Wildfire in the Western United States." Bulletin of the American Meteorological Society 84: 595-604.

97. Westerling, A., Hidalgo, H., Cayan, D, and Swetnam, T., 2006. "Warming and Earlier Spring Increases Western U.S. Forest Wildfire Activity.” Sciencexpress 10 (1126): 1-9

98. West Virginia Division of Forestry (WVDF): http://www.wvforestry.com

99. Whiteman, C.D. Mountain Meteorology: Fundamentals and Applications. New York: Oxford University Press. 2000.

100. Wu, A., Hsieh, W., Shabbar, A., Boer, G., and Zwiers, F., 2006. "The Nonlinear Association Between the Arctic Oscilliation and North American Winter Climate." Climate Dynamics 26: 865-879.

101. Zhang, R., and Delworth, T. 2005. "Simulated Tropical Response to a Substantial Weakening of the Atlantic Thermohaline Circulation." Journal of Climate 18(12): 18531860. 


\section{Appendix:}

\begin{tabular}{|l|cccc|}
\hline Variables: & $\begin{array}{c}\text { Begin } \\
\text { Year }\end{array}$ & $\begin{array}{c}\text { End } \\
\text { Year }\end{array}$ & Source & URL \\
\hline Southern Oscillation (SO) & 1948 & 2006 & CRU & http://www.cru.uea.ac.uk \\
Pacific Decadal Oscillation (PDO) & 1948 & 2006 & JISAO & http://jisao.washington.edu \\
Pacific/North American Pattern (PNA) & 1948 & 2006 & CDC & http://www.cdc.noaa.gov \\
Arctic Oscillation (AO) & 1948 & 2006 & JISAO & http://jisao.washington.edu \\
North Atlantic Oscillation (NAO) & 1948 & 2006 & CRU & http://www.cru.uea.ac.uk \\
Atlantic Multidecadal Oscillation (AMO) & 1948 & 2006 & CDC & http://www.cdc.noaa.gov \\
North Atlantic Tropical Cyclonic Activity (TCA) & 1948 & 2006 & NHC & http://www.nhc.noaa.gov \\
NCDC Climate Division Precipitation & 1948 & 2006 & NCDC & http://www1.ncdc.noaa.gov/pub/data/cirs \\
NCDC Climate Division Temperature & 1948 & 2006 & NCDC & http://www1.ncdc.noaa.gov/pub/data/cirs \\
\hline
\end{tabular}

Table 1. Study variables with begin year, end year, source, and site.

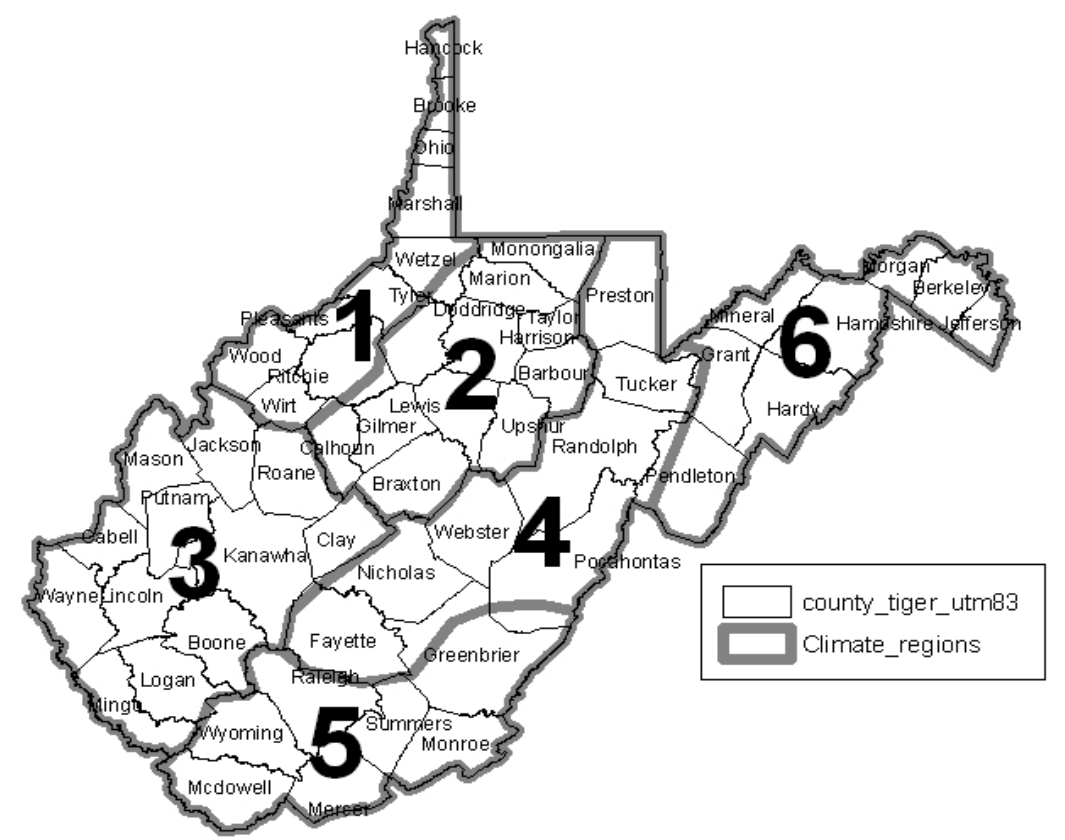

Figure 1. NCDC climate regions for the state of West Virginia

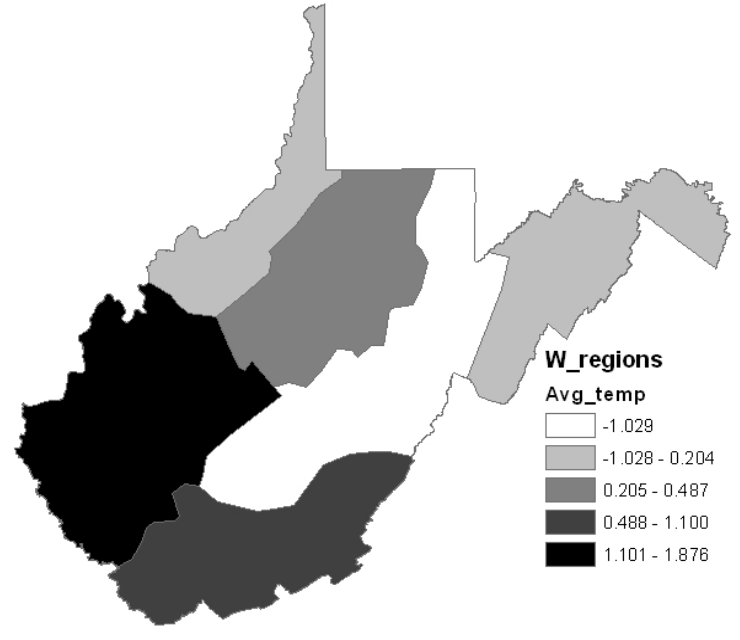

Figure 2. Winter average temperature 1948-2006.

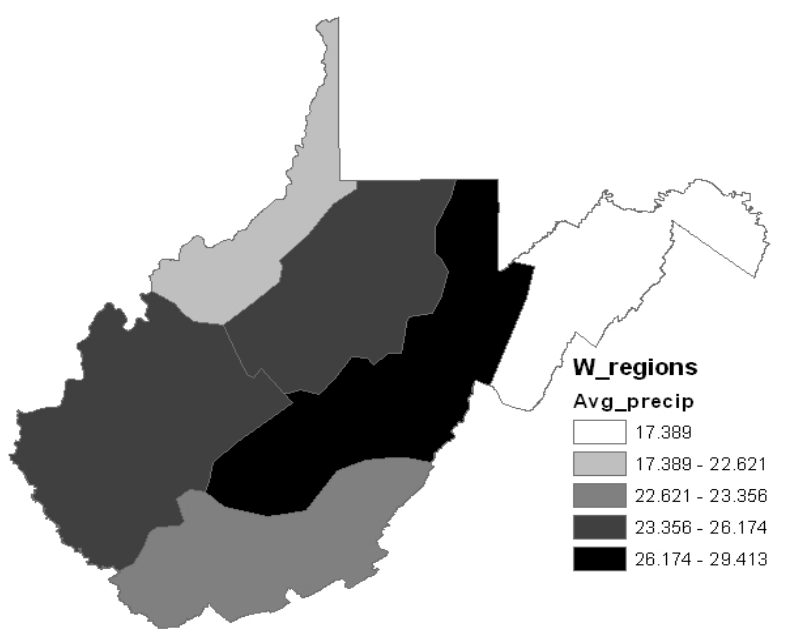

Figure 3. Winter average precipitation 1948-2006. 


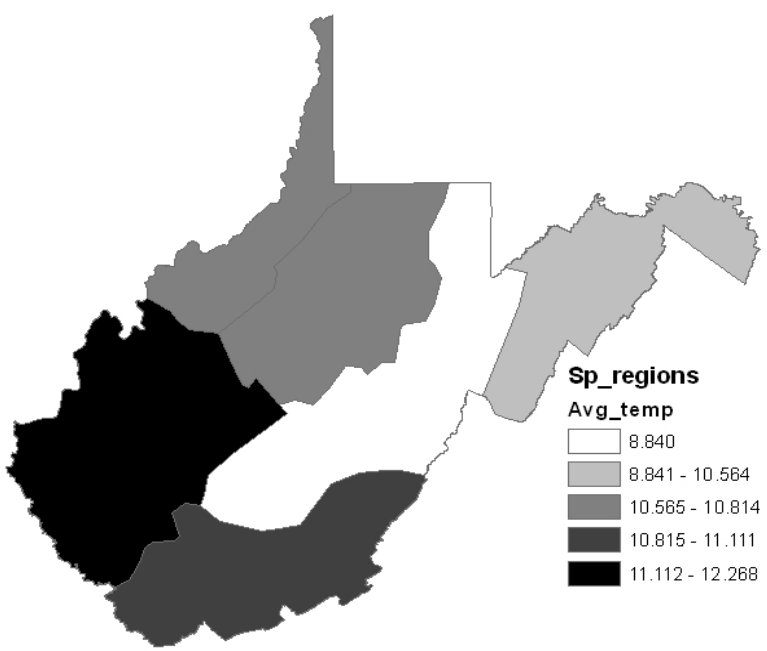

Figure 4. Spring average temperature 1948-2006.

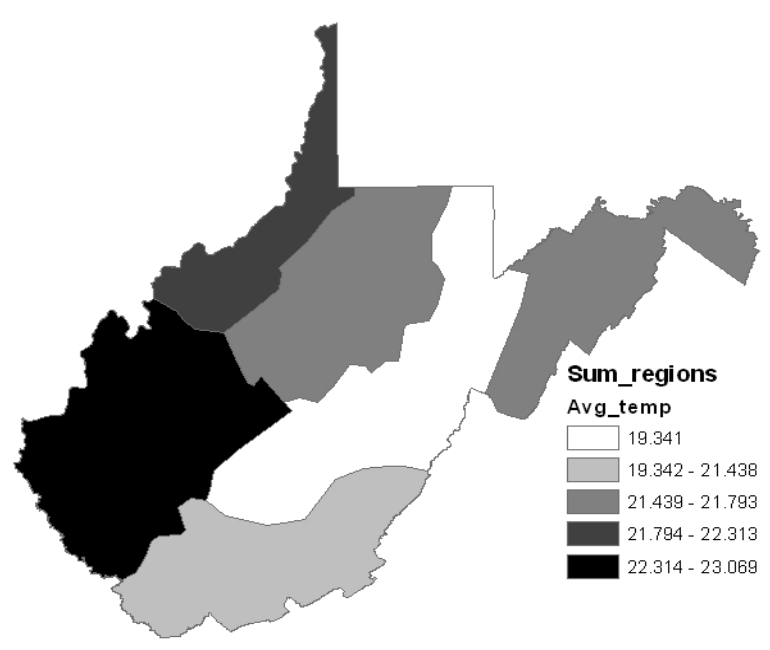

Figure 6. Summer average temperature 1948-2006.

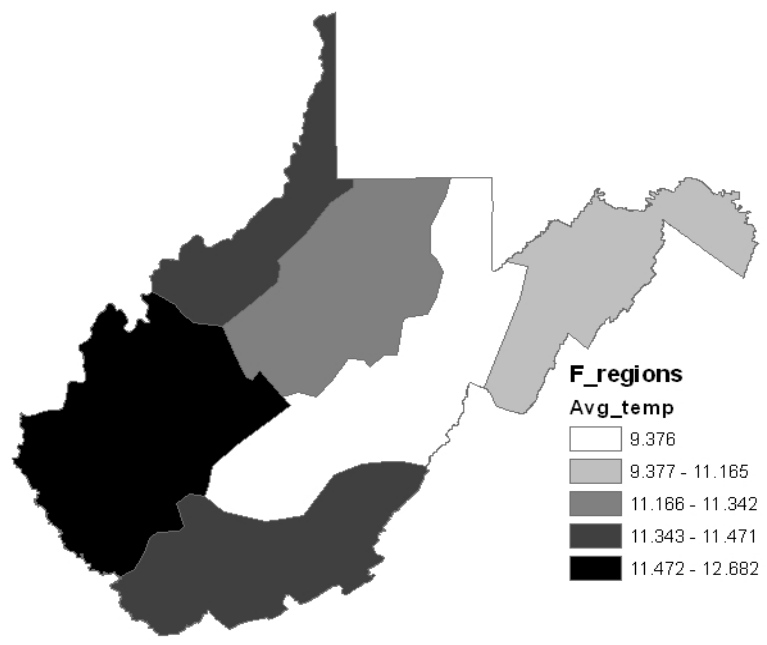

Figure 8. Fall average temperature 1948-2006.

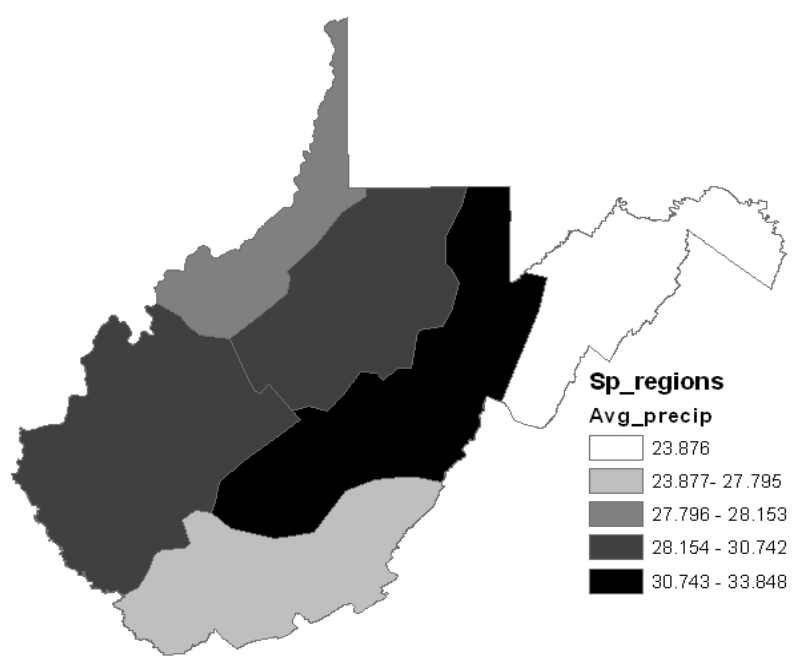

Figure 5. Spring average precipitation 1948-2006.

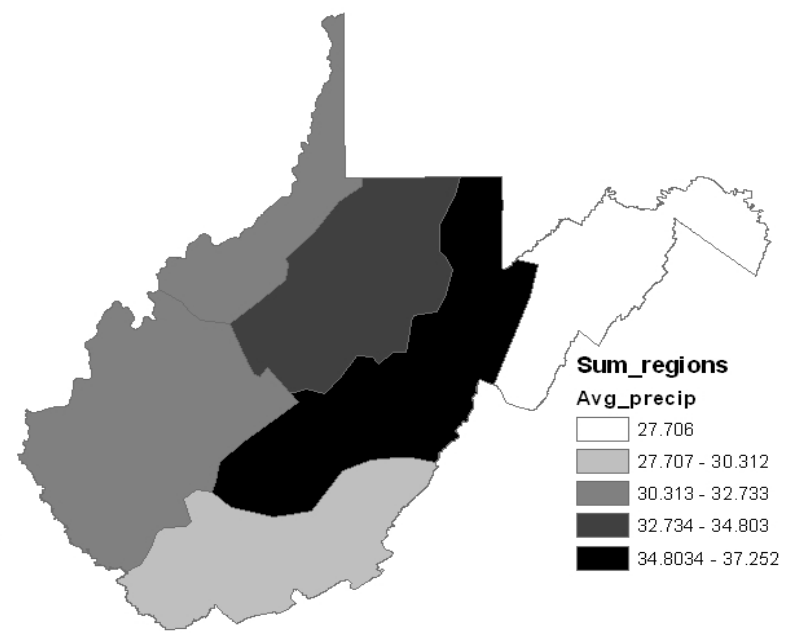

Figure 7. Summer average precipitation 1948-2006.

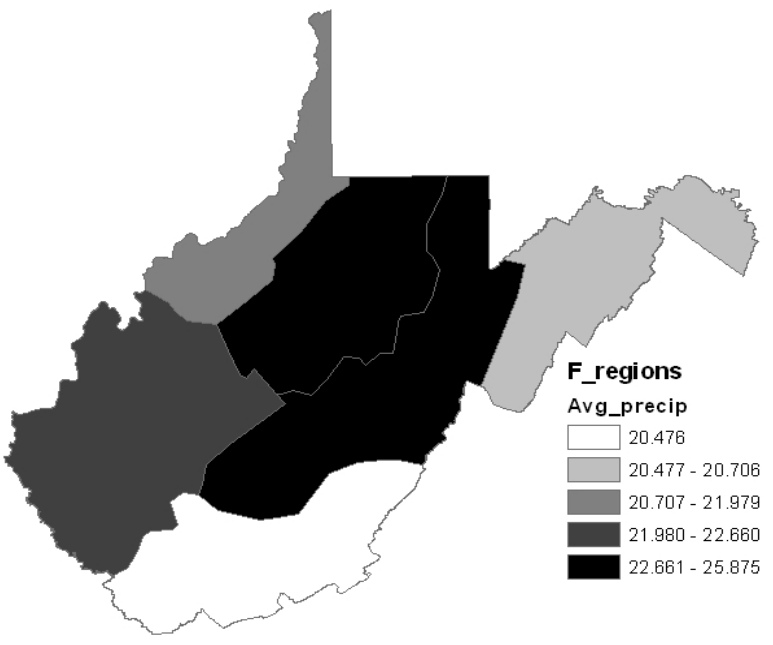

Figure 9. Fall average precipitation 1948-2006. 


\begin{tabular}{|l|ccccccc|}
\hline & AMO_W & AO_W & NAO_W & PDO_W & PNA_W & SOI_W & TCA_W \\
\hline r1t_w & 0.18 & $\mathbf{0 . 5 7}$ & $\mathbf{0 . 5 5}$ & $\mathbf{- 0 . 3 8}$ & -0.23 & 0.01 & 0.03 \\
r2t_w & 0.21 & $\mathbf{0 . 5 5}$ & $\mathbf{0 . 5 4}$ & $\mathbf{- 0 . 4 4}$ & $\mathbf{- 0 . 3 2}$ & 0.05 & 0.03 \\
r3t_w & 0.15 & $\mathbf{0 . 5 7}$ & $\mathbf{0 . 5 5}$ & $\mathbf{- 0 . 4 6}$ & $\mathbf{- 0 . 3 3}$ & 0.06 & 0.01 \\
r4t_w & 0.15 & $\mathbf{0 . 5 8}$ & $\mathbf{0 . 5 6}$ & $\mathbf{- 0 . 4 8}$ & $\mathbf{- 0 . 3 4}$ & 0.09 & 0.00 \\
r5t_w & 0.13 & $\mathbf{0 . 5 8}$ & $\mathbf{0 . 5 6}$ & $\mathbf{- 0 . 4 7}$ & $\mathbf{- 0 . 3 7}$ & 0.10 & 0.00 \\
r6t_w & 0.13 & $\mathbf{0 . 5 9}$ & $\mathbf{0 . 5 5}$ & $\mathbf{- 0 . 4 1}$ & -0.26 & 0.06 & 0.01 \\
\hline r1p_w & 0.07 & 0.22 & 0.20 & $\mathbf{- 0 . 4 2}$ & $\mathbf{- 0 . 4 5}$ & 0.12 & -0.04 \\
r2p_w & -0.01 & 0.17 & 0.15 & $\mathbf{- 0 . 3 9}$ & $\mathbf{- 0 . 4 2}$ & 0.15 & -0.06 \\
r3p_w & -0.02 & 0.21 & 0.18 & $\mathbf{- 0 . 3 8}$ & $\mathbf{- 0 . 4 2}$ & 0.14 & -0.07 \\
r4p_w & 0.04 & 0.18 & 0.14 & $\mathbf{- 0 . 3 0}$ & $\mathbf{- 0 . 3 5}$ & 0.09 & -0.08 \\
r5p_w & 0.02 & 0.13 & 0.11 & -0.18 & -0.27 & 0.07 & -0.10 \\
r6p_w & 0.01 & 0.02 & 0.05 & 0.01 & -0.05 & -0.11 & -0.02 \\
\hline
\end{tabular}

Table 2. Winter bivariate correlation analysis. Significant values at the 0.01level are highlighted.

\begin{tabular}{|l|ccccccc|}
\hline & AMO_SP & AO_SP & NAO_SP & PDO_SP & PNA_SP & SOI_SP & TCA_SP \\
\hline r1t_sp & -0.02 & 0.30 & 0.17 & -0.05 & -0.30 & -0.18 & 0.08 \\
r2t_sp & 0.02 & 0.30 & 0.19 & -0.12 & $\mathbf{- 0 . 3 8}$ & -0.14 & 0.09 \\
r3t_sp & -0.09 & $\mathbf{0 . 3 5}$ & 0.24 & -0.14 & $\mathbf{- 0 . 4 3}$ & -0.10 & 0.07 \\
r4t_sp & -0.10 & $\mathbf{0 . 3 3}$ & 0.17 & -0.15 & $\mathbf{- 0 . 4 4}$ & -0.06 & 0.06 \\
r5t_sp & -0.08 & $\mathbf{0 . 3 3}$ & 0.18 & -0.14 & $-\mathbf{0 . 4 3}$ & -0.04 & 0.07 \\
r6t_sp & -0.09 & $\mathbf{0 . 3 0}$ & 0.14 & -0.09 & -0.30 & -0.14 & 0.06 \\
\hline r1p_sp & 0.05 & 0.20 & -0.02 & -0.05 & -0.28 & 0.01 & -0.02 \\
r2p_sp & 0.02 & 0.16 & -0.05 & 0.06 & -0.18 & -0.06 & -0.04 \\
r3p_sp & 0.03 & 0.14 & -0.06 & -0.02 & -0.24 & -0.10 & -0.06 \\
r4p_sp & 0.13 & 0.11 & -0.05 & 0.08 & -0.14 & -0.10 & -0.04 \\
r5p_sp & -0.00 & 0.07 & -0.16 & 0.06 & -0.11 & -0.10 & -0.06 \\
r6p_sp & 0.11 & -0.03 & -0.08 & 0.25 & 0.07 & -0.21 & -0.01 \\
\hline
\end{tabular}

Table 3. Spring bivariate correlation analysis. Significant values at the 0.01level are highlighted.

\begin{tabular}{|l|ccccccc|}
\hline & AMO_SUM & AO_SUM & NAO_SUM & PDO_SUM & PNA_SUM & SOI_SUM & TCA_SUM \\
\hline r1t_sum & $\mathbf{0 . 4 5}$ & 0.24 & -0.29 & 0.09 & 0.11 & 0.05 & 0.24 \\
r2t_sum & $\mathbf{0 . 4 7}$ & 0.17 & -0.29 & -0.01 & 0.07 & 0.10 & 0.17 \\
r3t_sum & $\mathbf{0 . 4 3}$ & 0.17 & $\mathbf{- 0 . 3 2}$ & 0.14 & 0.09 & 0.04 & 0.21 \\
r4t_sum & $\mathbf{0 . 4 1}$ & 0.20 & -0.25 & 0.06 & 0.06 & -0.00 & 0.20 \\
r5t_sum & $\mathbf{0 . 4 7}$ & 0.08 & $\mathbf{- 0 . 3 4}$ & 0.09 & 0.07 & 0.03 & 0.19 \\
r6t_sum & $\mathbf{0 . 3 6}$ & 0.18 & $\mathbf{- 0 . 3 3}$ & 0.11 & 0.12 & -0.03 & 0.18 \\
\hline r1p_sum & 0.01 & -0.02 & 0.20 & 0.00 & -0.10 & 0.18 & 0.05 \\
r2p_sum & 0.03 & 0.02 & 0.14 & -0.06 & -0.19 & 0.13 & 0.06 \\
r3p_sum & 0.10 & -0.05 & 0.16 & 0.08 & -0.03 & 0.00 & 0.11 \\
r4p_sum & -0.00 & 0.06 & 0.22 & -0.11 & -0.23 & 0.09 & 0.04 \\
r5p_sum & 0.14 & -0.01 & 0.15 & -0.05 & -0.18 & -0.10 & 0.07 \\
r6p_sum & -0.04 & 0.26 & 0.19 & -0.25 & -0.33 & 0.16 & 0.16 \\
\hline
\end{tabular}

Table 4. Summer bivariate correlation analysis. Significant values at the 0.01level are highlighted. 


\begin{tabular}{|l|ccccccc|}
\hline & AMO_F & AO_F & NAO_F & PDO_F & PNA_F & SOI_F & TCA_F \\
\hline r1t_f & 0.09 & $\mathbf{0 . 3 2}$ & 0.25 & -0.28 & -0.28 & 0.11 & 0.16 \\
r2t_f & 0.13 & 0.29 & 0.26 & $-\mathbf{0 . 3 2}$ & -0.30 & 0.09 & 0.14 \\
r3t_f & 0.07 & 0.28 & 0.22 & -0.29 & $\mathbf{- 0 . 3 5}$ & 0.14 & 0.10 \\
r4t_f & 0.04 & $\mathbf{0 . 3 2}$ & 0.22 & $-\mathbf{0 . 3 1}$ & $-\mathbf{0 . 3 5}$ & 0.12 & 0.14 \\
r5t_f & 0.06 & $\mathbf{0 . 3 1}$ & 0.25 & -0.29 & -0.30 & 0.13 & 0.12 \\
r6t_f & 0.11 & 0.25 & 0.25 & $\mathbf{- 0 . 3 1}$ & -0.23 & 0.11 & 0.17 \\
\hline r1p_f & -0.09 & 0.14 & -0.18 & 0.14 & $-\mathbf{0 . 4 4}$ & 0.10 & -0.18 \\
r2p_f & -0.12 & 0.11 & -0.18 & 0.23 & $-\mathbf{0 . 3 5}$ & 0.11 & -0.14 \\
r3p_f & -0.12 & 0.10 & -0.20 & 0.16 & $-\mathbf{0 . 3 9}$ & 0.10 & -0.22 \\
r4p_f & -0.08 & -0.03 & -0.19 & 0.26 & -0.25 & 0.09 & -0.18 \\
r5p_f & -0.14 & 0.06 & -0.20 & 0.21 & -0.21 & 0.02 & -0.27 \\
r6p_f & -0.05 & -0.05 & -0.22 & 0.25 & -0.25 & 0.03 & -0.27 \\
\hline
\end{tabular}

Table 5. Fall bivariate correlation analysis. Significant values at the 0.01level are highlighted.

\begin{tabular}{|l|ccc|}
\hline & AdjR2 & D-W stat & Variables \\
\hline r1t_w & 0.48 & 1.29 & all W. Oscs \\
r2t_w & 0.52 & 1.39 & all W. Oscs \\
r3t_w & 0.52 & 1.33 & all W. Oscs \\
r4t_w & 0.54 & 1.42 & all W. Oscs \\
r5t_w & 0.54 & 1.39 & all W. Oscs \\
r6t_w & 0.49 & 1.46 & all W. Oscs \\
\hline r1p_w & 0.26 & 2.04 & all W. Oscs \\
r2p_w & 0.21 & 2.06 & all W. Oscs \\
r3p_w & 0.22 & 2.09 & all W. Oscs \\
r4p_w & 0.15 & 2.13 & all W. Oscs \\
r5p_w & 0.09 & 2.10 & all W. Oscs \\
r6p_w & 0.03 & 2.09 & all W. Oscs \\
\hline
\end{tabular}

\begin{tabular}{|l|ccc|}
\hline & AdjR2 & D-W stat & Variables \\
\hline r1t_sp & 0.20 & 2.05 & all Sp. Oscs \\
r2t_sp & 0.24 & 2.16 & all Sp. Oscs \\
r3t_sp & 0.28 & 2.16 & all Sp. Oscs \\
r4t_sp & 0.27 & 2.14 & all Sp. Oscs \\
r5t_sp & 0.24 & 2.00 & all Sp. Oscs \\
r6t_sp & 0.19 & 2.33 & all Sp. Oscs \\
\hline r1p_sp & 0.15 & 2.06 & all Sp. Oscs \\
r2p_sp & 0.12 & 2.01 & all Sp. Oscs \\
r3p_sp & 0.14 & 1.99 & all Sp. Oscs \\
r4p_sp & 0.11 & 2.13 & all Sp. Oscs \\
r5p_sp & 0.12 & 2.16 & all Sp. Oscs \\
r6p_sp & 0.09 & 1.94 & all Sp. Oscs \\
\hline
\end{tabular}

Table 6. Winter linear regression analysis.

Table 7. Spring linear regression analysis.

\begin{tabular}{|l|ccc|}
\hline & AdjR2 & D-W stat & Variables \\
\hline r1t_sum & 0.39 & 2.59 & all Sum. Oscs \\
r2t_sum & 0.34 & 2.34 & all Sum. Oscs \\
r3t_sum & 0.35 & 2.34 & all Sum. Oscs \\
r4t_sum & 0.29 & 2.33 & all Sum. Oscs \\
r5t_sum & 0.32 & 1.96 & all Sum. Oscs \\
r6t_sum & 0.32 & 2.28 & all Sum. Oscs \\
\hline r1p_sum & 0.12 & 2.35 & all Sum. Oscs \\
r2p_sum & 0.09 & 2.54 & all Sum. Oscs \\
r3p_sum & 0.08 & 2.36 & all Sum. Oscs \\
r4p_sum & 0.12 & 2.43 & all Sum. Oscs \\
r5p_sum & 0.14 & 2.06 & all Sum. Oscs \\
r6p_sum & 0.17 & 1.87 & all Sum. Oscs \\
\hline
\end{tabular}

Table 8. Summer linear regression analysis.

\begin{tabular}{|l|ccc|}
\hline & AdjR2 & D-W stat & Variables \\
\hline r1t_f & 0.25 & 1.82 & all F. Oscs \\
r2t_f & 0.29 & 1.87 & all F. Oscs \\
r3t_f & 0.27 & 1.83 & all F. Oscs \\
r4t_f & 0.27 & 1.55 & all F. Oscs \\
r5t_f & 0.25 & 1.57 & all F. Oscs \\
r6t_f & 0.22 & 2.00 & all F. Oscs \\
\hline r1p_f & 0.33 & 1.86 & all F. Oscs \\
r2p_f & 0.33 & 1.75 & all F. Oscs \\
r3p_f & 0.30 & 1.74 & all F. Oscs \\
r4p_f & 0.26 & 1.75 & all F. Oscs \\
r5p_f & 0.17 & 1.92 & all F. Oscs \\
r6p_f & 0.21 & 1.82 & all F. Oscs \\
\hline
\end{tabular}

Table 9. Fall linear regression analysis. 


\begin{tabular}{|l|cccccc|}
\hline & $\begin{array}{c}\text { Orig } \\
\text { AdjR2 }\end{array}$ & Orig D-W stat & T-score & Osc(s) in reg & Adj R2 & Adj D-W stat \\
\hline R1_T & 0.46 & 1.35 & $\mathbf{- 2 . 2}$ & AMO,AO,NAO,PDO & 0.45 & 1.68 \\
R2_T & 0.43 & 1.39 & 1.93 & AMO,AO,PDO & X & X \\
R3_T & 0.44 & 1.22 & $-\mathbf{2 . 9}$ & NAO,PDO & 0.46 & 1.74 \\
R4_T & 0.46 & 1.31 & $-\mathbf{2 . 4 3}$ & NAO,PDO & 0.48 & 1.75 \\
R5_T & 0.45 & 1.28 & $\mathbf{- 2 . 5 3}$ & NAO,PDO & 0.46 & 1.75 \\
R6_T & 0.43 & 1.38 & -2 & AO,NAO,PDO & X & X \\
\hline R1_P & 0.23 & 1.93 & 0 & NAO,PNA & X & X \\
R2_P & 0.16 & 1.91 & -0.12 & PNA & X & X \\
R3_P & 0.17 & 1.96 & 0.01 & PNA & X & X \\
R4_P & 0.11 & 1.95 & -0.15 & PNA & X & X \\
R5_P & 0.07 & 2.07 & 0.27 & PNA & X & X \\
R6_P & X & 2.03 & 0.11 & PNA & X & X \\
\hline
\end{tabular}

Table 10. Winter Autoreg procedure results. Significant $T$-scores are in bold. " $X$ " = not significant, not performed.

\begin{tabular}{|l|cccccc|}
\hline & $\begin{array}{c}\text { Orig } \\
\text { AdjR2 }\end{array}$ & Orig D-W stat & T-score & Osc(s) in reg & Adj R2 & Adj D-W stat \\
\hline R1_T & 0.17 & 1.93 & -0.18 & SOI,PNA & X & X \\
R2_T & 0.22 & 2.07 & 0.46 & SOI,PNA & X & X \\
R3_T & 0.24 & 2.03 & 0.21 & SOI,PNA & X & X \\
R4_T & 0.24 & 2.06 & 0.31 & SOI,PNA & X & X \\
R5_T & 0.18 & 2.00 & 0.16 & PNA & X & X \\
R6_T & 0.14 & 2.25 & 1.03 & SOI,PNA & X & X \\
\hline R1_P & 0.08 & 1.90 & -0.28 & PNA & X & X \\
R2_P & X & X & X & X & X & X \\
R3_P & 0.06 & 1.81 & -0.62 & PNA & X & X \\
R4_P & $X$ & $X$ & $X$ & X & X & X \\
R5_P & $X$ & $X$ & $X$ & X & X & X \\
R6_P & 0.06 & 1.90 & -0.07 & PDO & X & X \\
\hline
\end{tabular}

Table 11. Spring Autoreg procedure results. " $X$ " = not significant, not performed.

\begin{tabular}{|l|cccccc|}
\hline & $\begin{array}{c}\text { Orig } \\
\text { AdjR2 }\end{array}$ & Orig D-W stat & T-score & Osc(s) in reg & Adj R2 & Adj D-W stat \\
\hline R1_T & 0.36 & 2.49 & 1.97 & AMO,AO,NAO & X & X \\
R2_T & 0.33 & 2.24 & 1.01 & AMO,AO,NAO & X & X \\
R3_T & 0.32 & 2.30 & 1.2 & AMO,AO,NAO & X & X \\
R4_T & 0.28 & 2.27 & 1.03 & AMO,AO,NAO & X & X \\
R5_T & 0.32 & 1.95 & -0.11 & AMO,AO,NAO & X & X \\
R6_T & 0.30 & 2.18 & 0.68 & AMO,AO,NAO & X & X \\
\hline R1_P & $\mathrm{X}$ & $\mathrm{X}$ & $\mathrm{X}$ & $\mathrm{X}$ & $\mathrm{X}$ & $\mathrm{X}$ \\
R2_P & $\mathrm{X}$ & $\mathrm{X}$ & $\mathrm{X}$ & $\mathrm{X}$ & $\mathrm{X}$ & $\mathrm{X}$ \\
R3_P & $\mathrm{X}$ & $\mathrm{X}$ & $\mathrm{X}$ & $\mathrm{X}$ & $\mathrm{X}$ & $\mathrm{X}$ \\
R4_P & $\mathrm{X}$ & $\mathrm{X}$ & $\mathrm{X}$ & $\mathrm{X}$ & $\mathrm{X}$ & $\mathrm{X}$ \\
R5_P & $\mathrm{X}$ & $\mathrm{X}$ & $\mathrm{X}$ & $\mathrm{X}$ & $\mathrm{X}$ & $\mathrm{X}$ \\
R6_P & 0.11 & 1.95 & -0.19 & $\mathrm{PNA}$ & $\mathrm{X}$ & $\mathrm{X}$ \\
\hline
\end{tabular}

Table 12. Summer Autoreg procedure results. " $X$ " = not significant, not performed. 


\begin{tabular}{|l|cccccc|}
\hline & $\begin{array}{c}\text { Orig } \\
\text { AdjR2 }\end{array}$ & Orig D-W stat & T-score & Osc(s) in reg & Adj R2 & Adj D-W stat \\
\hline R1_T & 0.24 & 1.85 & -0.43 & AMO,NAO,PNA & X & X \\
R2_T & 0.27 & 1.94 & -0.1 & AMO,NAO,PNA & X & X \\
R3_T & 0.26 & 1.86 & -0.34 & AMO,NAO,PNA & X & X \\
R4_T & 0.26 & 1.67 & -1.2 & NAO,TCA,PNA & X & X \\
R5_T & 0.20 & 1.58 & -1.56 & NAO,PNA & $X$ & X \\
R6_T & 0.14 & 1.95 & -0.17 & NAO,PDO & X & X \\
\hline R1_P & 0.31 & 1.75 & -0.76 & PDO,SOI,PNA & X & X \\
R2_P & 0.30 & 1.71 & -1 & PDO,SOI,PNA & X & X \\
R3_P & 0.28 & 1.69 & -0.82 & PDO,SOI,PNA & X & X \\
R4_P & 0.25 & 1.70 & -1.05 & PDO,SOI,PNA & X & X \\
R5_P & 0.07 & 1.76 & -0.84 & TCA & $X$ & $X$ \\
R6_P & 0.16 & 1.90 & -0.23 & PDO,PNA & X & X \\
\hline
\end{tabular}

Table 13. Fall Autoreg procedure results. " $X$ " = not significant, not performed.

\begin{tabular}{|lc|ccc|}
\hline & & Osc(s) & \% of Variance & Cumulative \% \\
\hline Winter & Factor 1 & (-)AO,PDO,PNA,(-)SOI & 30.766 & 30.766 \\
& Factor 2 & AO,NAO & 25.543 & 56.309 \\
& Factor 3 & AMO,TCA & 16.087 & 72.395 \\
Spring & & & \\
& Factor 1 & $(-)$ AO,PDO,PNA,(-)SOI & 32.497 & 32.497 \\
& Factor 2 & AO,NAO,(-)SOI & 22.604 & 55.102 \\
& Factor 3 & (-)AMO,TCA & 15.236 & 70.337 \\
Summer & & & & \\
& Factor 1 & (-)AO,PDO,PNA,(-)SOI & 28.541 & 28.541 \\
& Factor 2 & AMO,(-)NAO,SOI,TCA & 20.222 & 48.764 \\
& Factor 3 & AO,TCA & 16.075 & 64.839 \\
& & & & \\
Fall & Factor 1 & (-)PDO,SOI,TCA & 27.548 & 27.548 \\
& Factor 2 & AMO,(-)AO,(-)NAO & 21.649 & 49.197 \\
& Factor 3 & PNA & 20.166 & 69.362 \\
\hline
\end{tabular}

Table 14. Principle components analysis. (-) Indicates a negative relationship.

\begin{tabular}{|l|ccc|}
\hline & AdjR2 & D-W stat & Variables \\
\hline r1t_w & 0.46 & 1.47 & Wfac 1,2,3 \\
r2t_w & 0.49 & 1.58 & Wfac $1,2,3$ \\
r3t_w & 0.50 & 1.54 & Wfac $1,2,3$ \\
r4t_w & 0.52 & 1.60 & Wfac 1,2,3 \\
r5t_w & 0.52 & 1.52 & Wfac $1,2,3$ \\
r6t_w & 0.48 & 1.61 & Wfac $1,2,3$ \\
\hline r1p_w & 0.22 & 2.05 & Wfac 1,2,3 \\
r2p_w & 0.18 & 2.03 & Wfac 1,2,3 \\
r3p_w & 0.19 & 2.10 & Wfac $1,2,3$ \\
r4p_w & 0.12 & 2.10 & Wfac 1,2,3 \\
r5p_w & 0.06 & 2.13 & Wfac 1,2,3 \\
r6p_w & 0.00 & 2.06 & Wfac 1,2,3 \\
\hline
\end{tabular}

Table 15. Winter principle components analysis.

\begin{tabular}{|l|ccc|}
\hline & AdjR2 & D-W stat & Variables \\
\hline r1t_sp & 0.12 & 2.21 & Spfac $1,2,3$ \\
r2t_sp & 0.15 & 2.30 & Spfac 1,2,3 \\
r3t_sp & 0.19 & 2.27 & Spfac 1,2,3 \\
r4t_sp & 0.16 & 2.27 & Spfac 1,2,3 \\
r5t_sp & 0.16 & 2.08 & Spfac 1,2,3 \\
r6t_sp & 0.10 & 2.46 & Spfac 1,2,3 \\
\hline r1p_sp & 0.04 & 1.89 & Spfac 1,2,3 \\
r2p_sp & 0.01 & 1.79 & Spfac 1,2,3 \\
r3p_sp & 0.02 & 1.80 & Spfac 1,2,3 \\
r4p_sp & 0.02 & 1.97 & Spfac 1,2,3 \\
r5p_sp & 0 & 1.99 & Spfac 1,2,3 \\
r6p_sp & 0.05 & 1.96 & Spfac 1,2,3 \\
\hline
\end{tabular}

Table 16. Spring principle components analysis. 


\begin{tabular}{|l|ccc|}
\hline & AdjR2 & D-W stat & Variables \\
\hline r1t_sum & 0.22 & 2.40 & SUMfac $1,2,3$ \\
r2t_sum & 0.19 & 2.16 & SUMfac $1,2,3$ \\
r3t_sum & 0.20 & 2.23 & SUMfac $1,2,3$ \\
r4t_sum & 0.16 & 2.27 & SUMfac 1,2,3 \\
r5t_sum & 0.21 & 1.85 & SUMfac 1,2,3 \\
r6t_sum & 0.15 & 2.20 & SUMfac 1,2,3 \\
\hline r1p_sum & 0.02 & 2.25 & SUMfac 1,2,3 \\
r2p_sum & 0.03 & 2.48 & SUMfac 1,2,3 \\
r3p_sum & 0.02 & 2.31 & SUMfac 1,2,3 \\
r4p_sum & 0.05 & 2.39 & SUMfac $1,2,3$ \\
r5p_sum & 0.01 & 1.86 & SUMfac 1,2,3 \\
r6p_sum & 0.17 & 2.07 & SUMfac $1,2,3$ \\
\hline
\end{tabular}

\begin{tabular}{|l|ccl|}
\hline & AdjR2 & D-W stat & Variables \\
\hline r1t_f & 0.18 & 1.83 & Ffac $1,2,3$ \\
r2t_f & 0.18 & 1.85 & Ffac $1,2,3$ \\
r3t_f & 0.18 & 1.80 & Ffac $1,2,3$ \\
r4t_f & 0.21 & 1.61 & Ffac $1,2,3$ \\
r5t_f & 0.18 & 1.53 & Ffac $1,2,3$ \\
r6t_f & 0.16 & 2.07 & Ffac $1,2,3$ \\
\hline r1p_f & 0.17 & 1.52 & Ffac $1,2,3$ \\
r2p_f & 0.12 & 1.62 & Ffac $1,2,3$ \\
r3p_f & 0.16 & 1.57 & Ffac $1,2,3$ \\
r4p_f & 0.09 & 1.80 & Ffac $1,2,3$ \\
r5p_f & 0.11 & 1.78 & Ffac $1,2,3$ \\
r6p_f & 0.12 & 1.81 & Ffac $1,2,3$ \\
\hline
\end{tabular}

Table 17. Summer principle components analysis.

Table 18. Fall principle components analysis.

\begin{tabular}{|l|cccc|}
\hline Variables & $\begin{array}{c}\text { Begin } \\
\text { Year }\end{array}$ & $\begin{array}{c}\text { End } \\
\text { Year }\end{array}$ & Source & URL \\
\hline Southern Oscillation (SO) & 1948 & 2006 & CRU & http://www.cru.uea.ac.uk \\
Pacific Decadal Oscillation (PDO) & 1948 & 2006 & JISAO & http://jisao.washington.edu \\
Pacific/North American Pattern (PNA) & 1948 & 2006 & JISAO & http://jisao.washington.edu \\
Arctic Oscillation (AO) & 1948 & 2006 & CDC & http://www.cdc.noaa.gov \\
North Atlantic Oscillation (NAO) & 1948 & 2006 & CRU & http://www.cru.uea.ac.uk \\
Atlantic Multidecadal Oscillation (AMO) & 1948 & 2006 & CDC & http://www.cdc.noaa.gov \\
WV Climate Regions Precipitation & 1948 & 2006 & NCDC & http://www1.ncdc.noaa.gov/pub/data/cirs \\
WV Climate Regions Temperature & 1948 & 2006 & NCDC & http://www1.ncdc.noaa.gov/pub/data/cirs \\
WV Climate Regions PDSI & 1948 & 2006 & NCDC & http://www1.ncdc.noaa.gov/pub/data/cirs \\
WV Division of Forestry Area Burned & 1948 & 2006 & WVDF & http://www.wvforestry.com \\
WV Division of Forestry Fire Events & 1948 & 2006 & WVDF & http://www.wvforestry.com \\
\hline
\end{tabular}

Table 19. Study variables with begin year, end year, source, and site.

\begin{tabular}{|l|cccccc|}
\hline & $\boldsymbol{R 1}$ & $\boldsymbol{R 2}$ & $\boldsymbol{R 3}$ & $\boldsymbol{R 4}$ & $\boldsymbol{R} 5$ & $\boldsymbol{R}$ \\
\hline Population & 270,035 & 264,399 & 614,479 & 157,212 & 250,578 & 246,736 \\
Avg Annual Temp ( $\left.{ }^{\circ} \mathbf{C}\right)$ & 11.5 & 11.2 & 12.7 & 9.3 & 11.4 & 11.4 \\
Total Annual Precip (cm) & 105.2 & 116.8 & 110.2 & 126.2 & 102.1 & 91.9 \\
Area (ha) & $634,288.1$ & $1,022,786.3$ & $1,478,624.2$ & $1,323,742.9$ & $1,021,491.3$ & $902,092.9$ \\
Forest cover (ha) & $464,444.4$ & $671,981.3$ & $1,193,429.3$ & $950,773.3$ & $694,846.9$ & $648,118.6$ \\
Nonforest (ha) & $126,109.8$ & $282,472.2$ & $211,952.9$ & $273,494.7$ & $320,106.7$ & $218,686.9$ \\
Water bodies (ha) & $7,341.0$ & $10,967.8$ & $2,973.2$ & $15,794.9$ & 0.0 & $20,535.0$ \\
Undefined (ha) & $36,393.0$ & $57,365.0$ & $70,268.8$ & $83,680.1$ & $6,537.7$ & $14,752.4$ \\
\hline
\end{tabular}

Table 20. NCDC regional characteristics (2005-2006).

\begin{tabular}{|l|cccccc|}
\hline & R1 & R2 & R3 & R4 & R5 & R6 \\
\hline Spring Avg Area Burned & 0.06 & 0.08 & 0.54 & 0.07 & 0.24 & 0.05 \\
Fall Avg Area Burned & 0.04 & 0.05 & 1.17 & 0.16 & 0.48 & 0.04 \\
Spring Avg Number of Fires & 0.01 & 0.02 & 0.04 & 0.01 & 0.03 & 0.01 \\
Fall Avg Number of Fires & 0.01 & 0.01 & 0.02 & 0.01 & 0.02 & 0.01 \\
\hline
\end{tabular}

Table 21. Percent forested hectares area burned and number of fires by region for West Virginia from 1948-2006. 


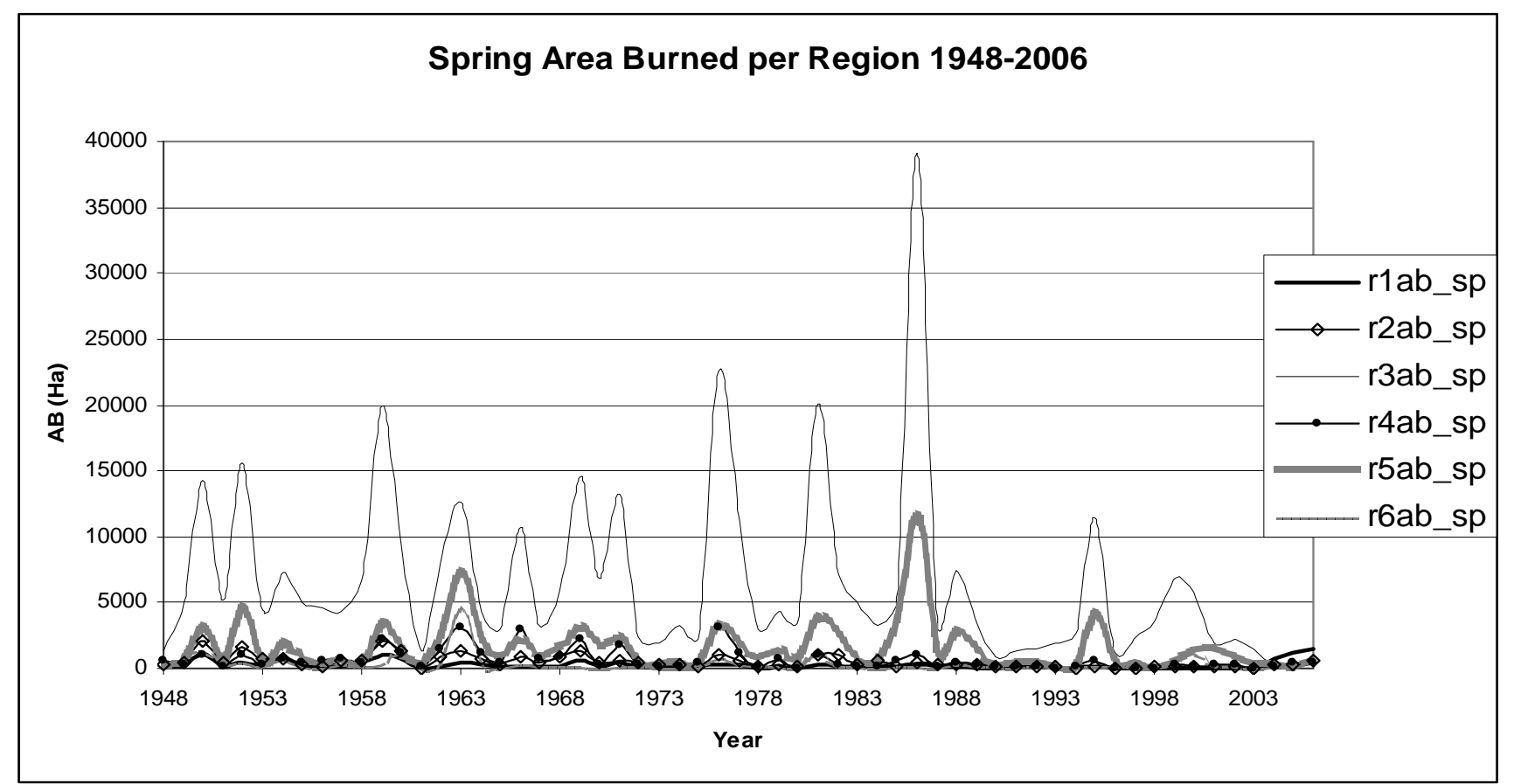

Figure 10. Spring Area Burned per Region from 1948-2006.

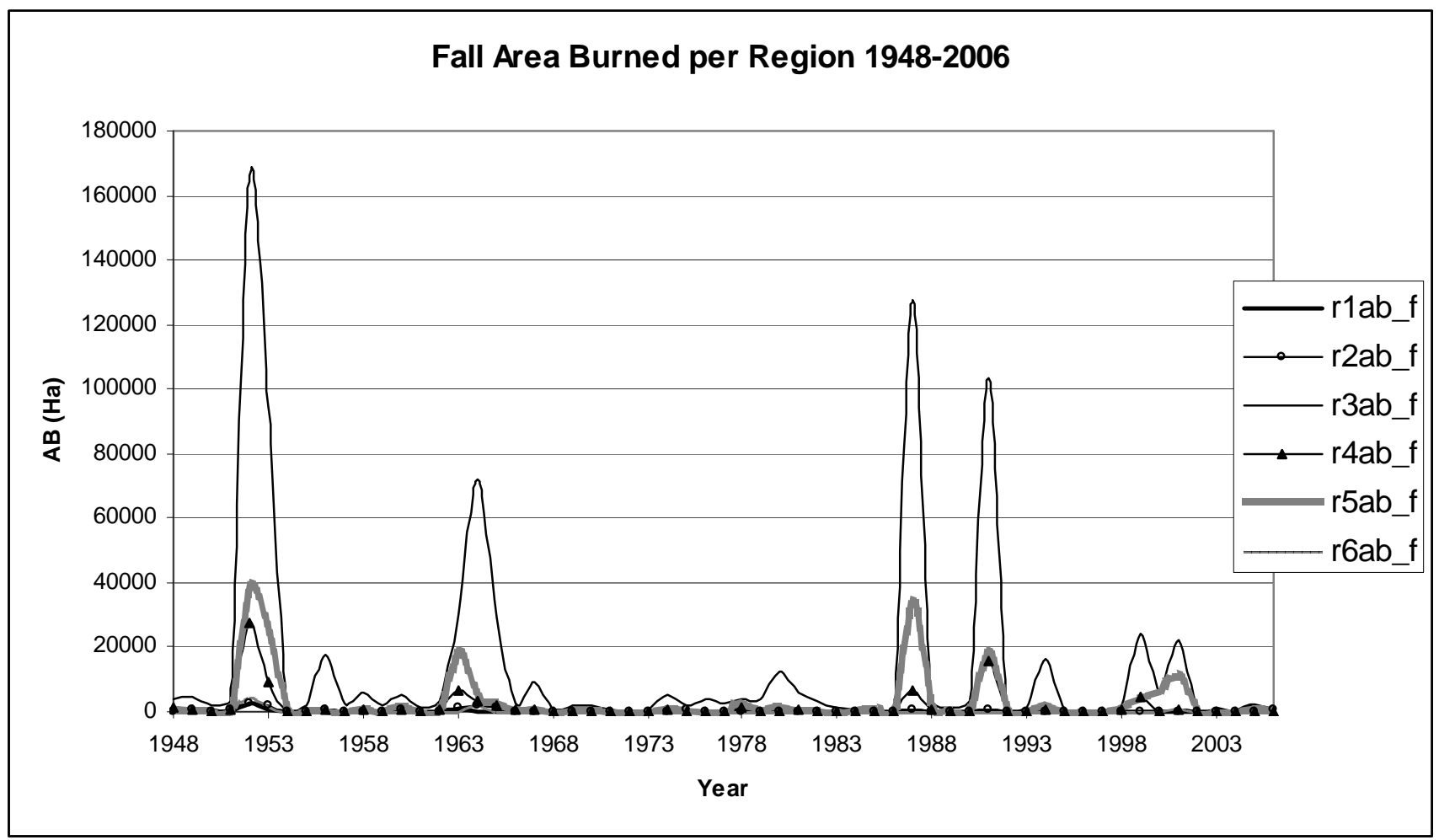

Figure 11. Fall Area Burned per Region from 1948-2006. 


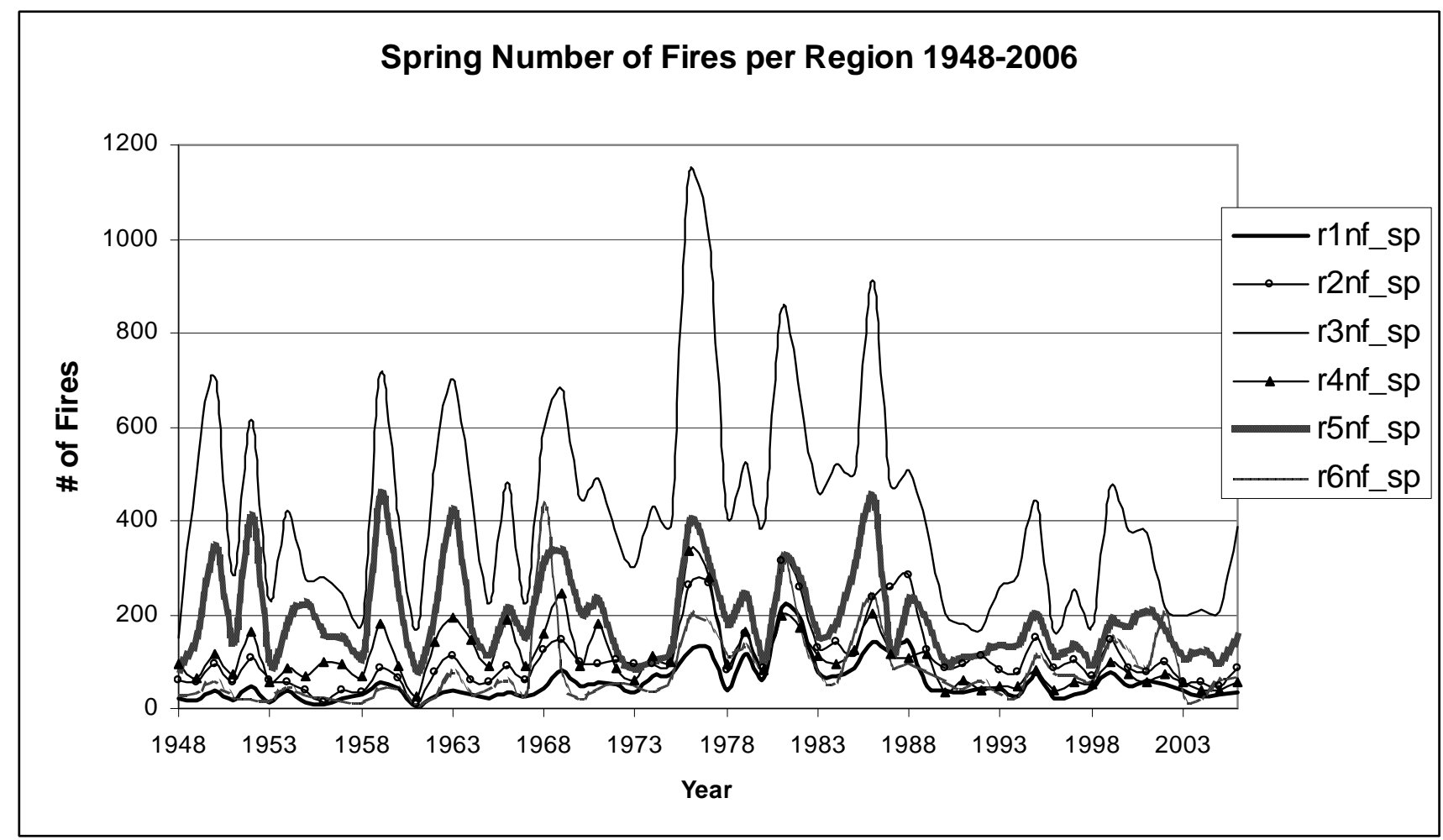

Figure 12. Number of Fires per Region from 1948-2006.

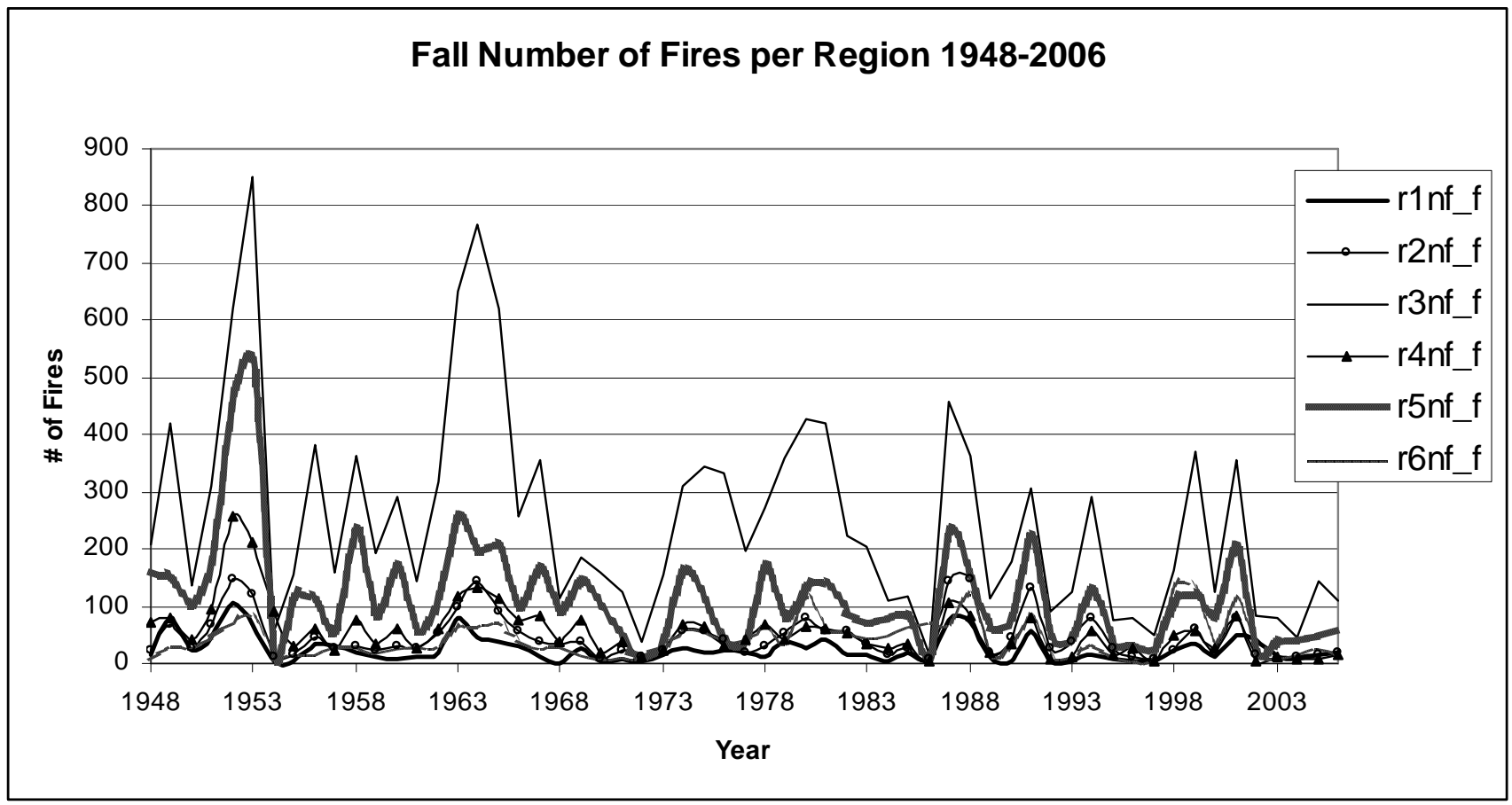

Figure 13. Fall Number of Fires per Region from 1948-2006. 


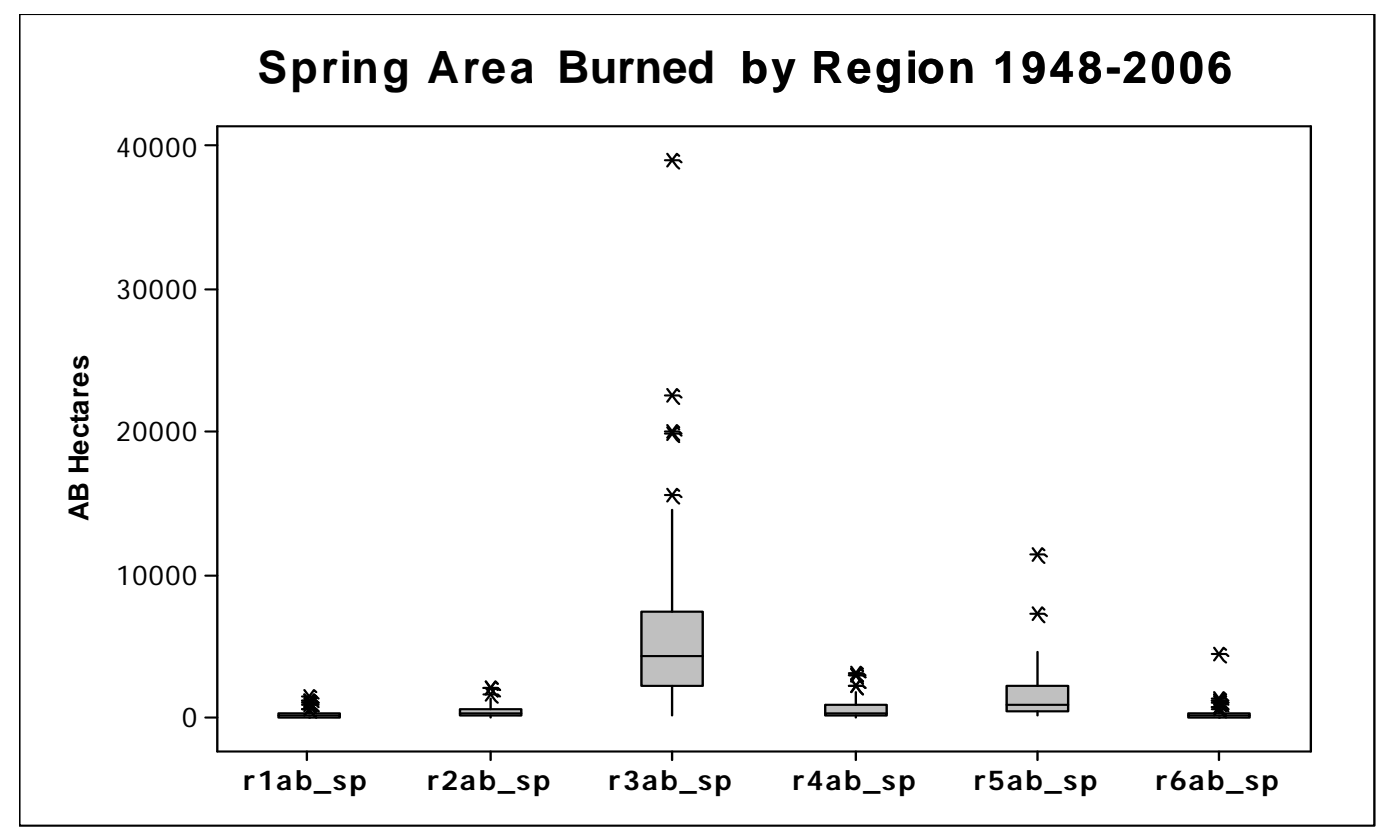

Figure 14. Spring Area Burned Box Plot.

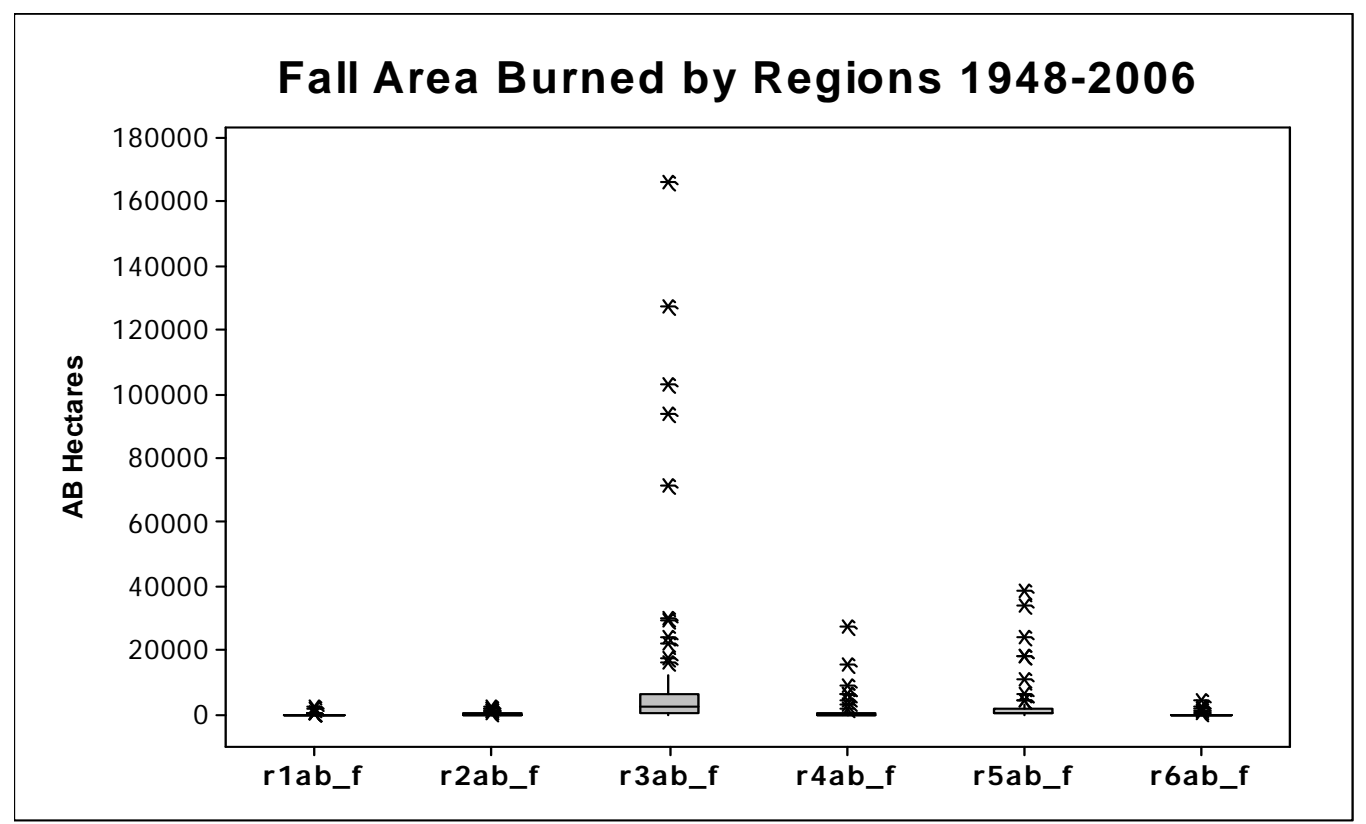

Figure 15. Fall Area Burned Box Plot. 


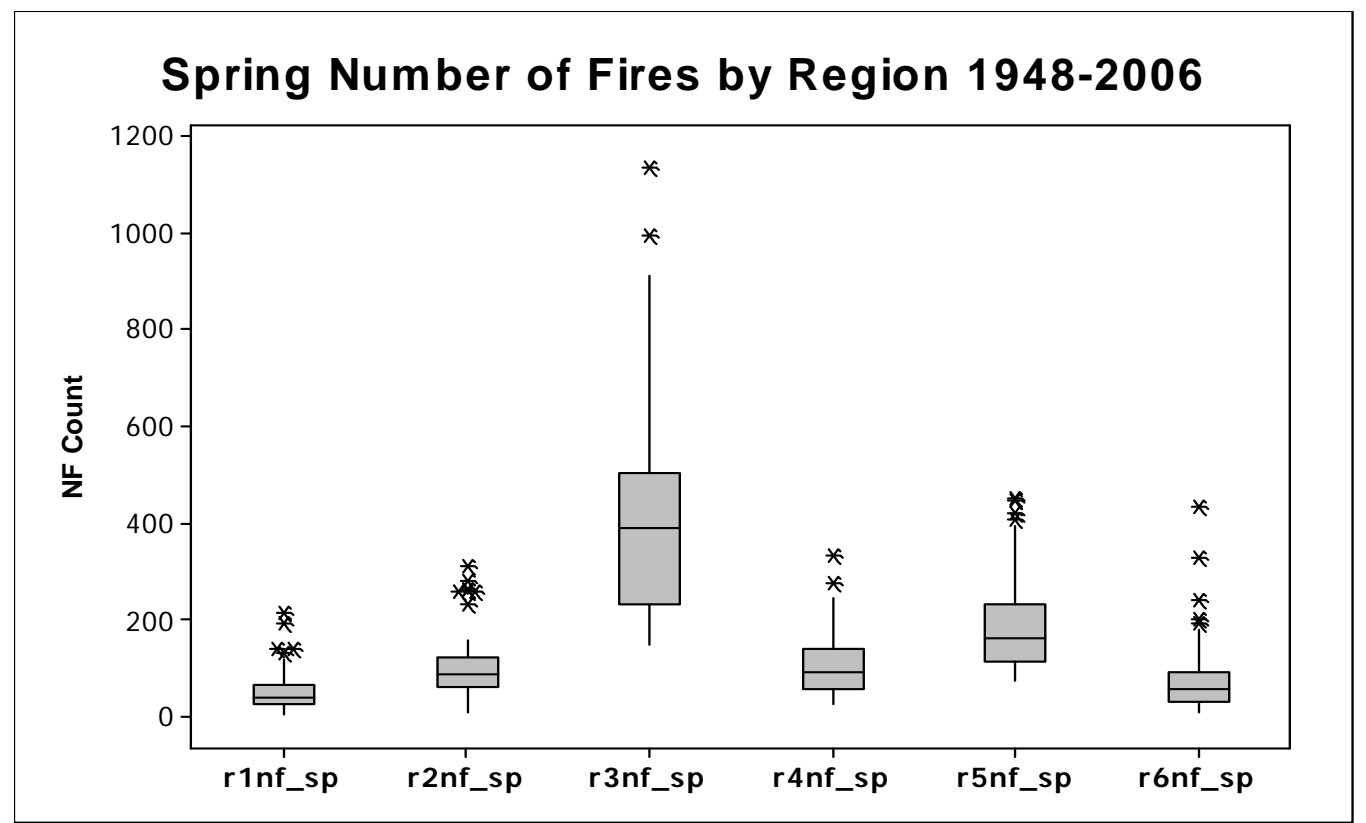

Figure 16. Spring Number of Fires Box Plot.

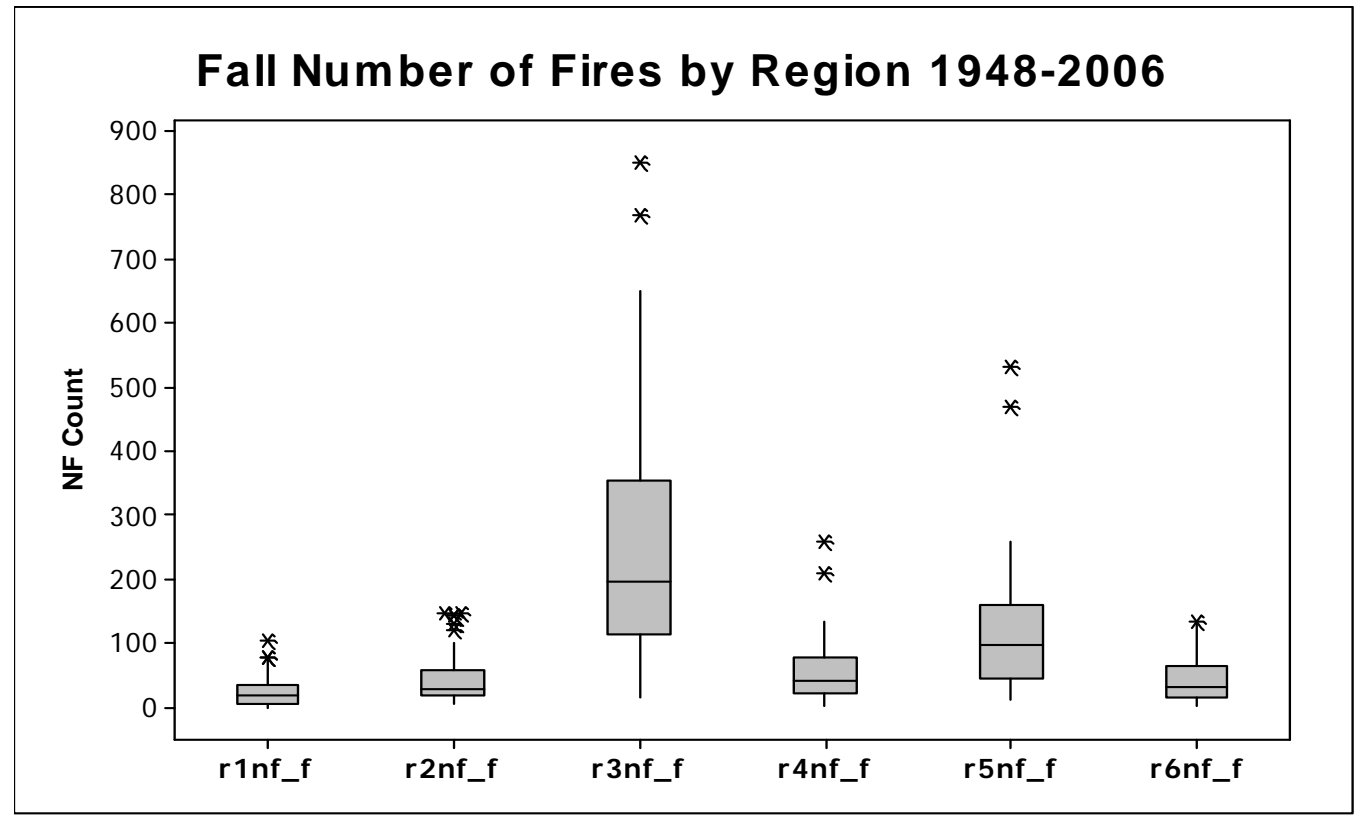

Figure 17. Fall Number of Fires Box Plots. 


\begin{tabular}{|l|ccccccccc|}
\hline & TEMP_W & PREC_W & PDSI_W & AMO_W & AO_W & NAO_W & PDO_W & PNA_W & SOI_W \\
\hline r1nf_sp & -0.08 & -0.15 & -0.02 & $\mathbf{- 0 . 4 7}$ & 0.01 & -0.07 & 0.29 & 0.18 & -0.10 \\
r2nf_sp & -0.09 & -0.16 & -0.07 & $-\mathbf{0 . 4 8}$ & 0.06 & -0.09 & 0.25 & 0.16 & -0.07 \\
r3nf_sp & -0.21 & -0.16 & -0.17 & -0.30 & -0.17 & -0.19 & -0.06 & -0.08 & 0.18 \\
r4nf_sp & -0.25 & -0.28 & $-\mathbf{0 . 3 9}$ & -0.29 & -0.28 & -0.35 & -0.16 & -0.21 & 0.18 \\
r5nf_sp & -0.23 & -0.29 & $\mathbf{- 0 . 3 6}$ & -0.07 & -0.28 & -0.32 & -0.09 & -0.15 & 0.20 \\
r6nf_sp & 0.00 & $\mathbf{- 0 . 3 5}$ & -0.21 & $\mathbf{- 0 . 4 0}$ & 0.03 & -0.14 & 0.13 & 0.10 & 0.05 \\
r1ab_sp & -0.01 & -0.01 & -0.13 & 0.25 & $-\mathbf{0 . 3 3}$ & -0.22 & -0.19 & -0.17 & 0.02 \\
r2ab_sp & -0.03 & -0.09 & -0.25 & 0.13 & -0.24 & -0.19 & -0.25 & -0.29 & 0.05 \\
r3ab_sp & -0.11 & -0.06 & $\mathbf{- 0 . 3 6}$ & -0.15 & -0.14 & -0.16 & -0.19 & -0.16 & 0.13 \\
r4ab_sp & -0.14 & -0.23 & $-\mathbf{0 . 4 2}$ & 0.01 & -0.30 & -0.23 & $-\mathbf{0 . 3 3}$ & -0.29 & 0.20 \\
r5ab_sp & -0.24 & $\mathbf{- 0 . 3 5}$ & $\mathbf{- 0 . 3 9}$ & -0.08 & -0.25 & -0.27 & -0.07 & -0.01 & 0.16 \\
r6ab_sp & 0.13 & $\mathbf{- 0 . 3 6}$ & -0.27 & 0.23 & -0.03 & -0.07 & -0.28 & -0.21 & 0.22 \\
\hline
\end{tabular}

Table 22. Bivariate correlation analysis for spring number of fires and spring area burned and winter climate variables from 1948-2006. Significant values at the 0.01level are highlighted.

\begin{tabular}{|l|ccccccccc|}
\hline & TEMP_SP & PREC_SP & PDSI_SP & AMO_SP & AO_SP & NAO_SP & PDO_SP & PNA_SP & SOI_SP \\
\hline r1nf_sp & 0.01 & $\mathbf{- 0 . 4 1}$ & -0.28 & 0.12 & -0.18 & 0.00 & -0.24 & -0.04 & 0.29 \\
r2nf_sp & 0.00 & $\mathbf{- 0 . 4 4}$ & -0.23 & -0.02 & -0.15 & 0.04 & $\mathbf{- 0 . 3 6}$ & -0.05 & 0.28 \\
r3nf_sp & -0.07 & $\mathbf{- 0 . 4 6}$ & $\mathbf{- 0 . 4 0}$ & -0.17 & -0.05 & 0.05 & -0.20 & -0.01 & 0.19 \\
r4nf_sp & 0.08 & $\mathbf{- 0 . 4 7}$ & $\mathbf{- 0 . 5 8}$ & -0.13 & 0.00 & 0.13 & $\mathbf{- 0 . 4 9}$ & -0.19 & $\mathbf{0 . 4 0}$ \\
r5nf_sp & 0.08 & $\mathbf{- 0 . 5 2}$ & $\mathbf{- 0 . 5 7}$ & -0.15 & -0.01 & 0.09 & -0.13 & -0.22 & 0.30 \\
r6nf_sp & 0.04 & -0.28 & $\mathbf{- 0 . 3 2}$ & 0.10 & -0.07 & -0.03 & -0.22 & -0.04 & $\mathbf{0 . 3 5}$ \\
\hline r1ab_sp & 0.14 & $\mathbf{- 0 . 3 9}$ & $\mathbf{- 0 . 3 7}$ & $\mathbf{- 0 . 3 6}$ & 0.03 & -0.11 & $\mathbf{0 . 3 2}$ & 0.17 & -0.01 \\
r2ab_sp & 0.05 & -0.26 & $\mathbf{- 0 . 4 2}$ & $\mathbf{- 0 . 3 6}$ & 0.09 & -0.07 & 0.30 & 0.16 & -0.07 \\
r3ab_sp & -0.03 & $\mathbf{- 0 . 5 5}$ & $\mathbf{- 0 . 4 5}$ & $\mathbf{- 0 . 3 3}$ & -0.04 & -0.04 & -0.11 & 0.02 & 0.30 \\
r4ab_sp & 0.13 & $\mathbf{- 0 . 4 9}$ & $\mathbf{- 0 . 5 9}$ & $\mathbf{- 0 . 3 6}$ & 0.01 & 0.04 & -0.26 & -0.15 & 0.28 \\
r5ab_sp & 0.03 & $\mathbf{- 0 . 4 7}$ & $\mathbf{- 0 . 5 8}$ & -0.18 & 0.00 & 0.08 & -0.17 & -0.10 & 0.31 \\
r6ab_sp & 0.12 & -0.26 & $\mathbf{- 0 . 4 4}$ & $\mathbf{- 0 . 3 3}$ & 0.19 & -0.09 & 0.22 & 0.03 & 0.05 \\
\hline
\end{tabular}

Table 23. Bivariate correlation analysis for spring number of fires and spring area burned and spring climate variables from 1948-2006. Significant values at the 0.01level are highlighted.

\begin{tabular}{|l|ccccccccc|}
\hline & TEMP_SU & PREC_SU & PDSI_SU & AMO_SU & AO_SU & NAO_SU & PDO_SU & PNA_SU & SOI_SU \\
\hline r1nf_f & 0.32 & -0.20 & -0.32 & 0.30 & -0.08 & -0.26 & -0.15 & 0.00 & -0.07 \\
r2nf_f & 0.27 & -0.29 & $-\mathbf{0 . 3 5}$ & 0.12 & -0.05 & -0.20 & -0.10 & 0.02 & -0.07 \\
r3nf_f & 0.10 & -0.30 & $-\mathbf{0 . 3 2}$ & 0.09 & -0.10 & -0.18 & -0.22 & -0.05 & 0.02 \\
r4nf_f & 0.20 & -0.21 & -0.31 & 0.20 & -0.10 & -0.20 & -0.25 & -0.03 & 0.07 \\
r5nf_f & 0.25 & -0.21 & -0.26 & 0.26 & -0.09 & -0.14 & -0.22 & -0.05 & 0.03 \\
r6nf_f & 0.20 & $-\mathbf{0 . 3 5}$ & $-\mathbf{0 . 3 5}$ & 0.19 & -0.05 & -0.20 & -0.06 & -0.01 & 0.08 \\
\hline r1ab_f & $\mathbf{0 . 3 2}$ & -0.12 & -0.15 & $\mathbf{0 . 4 1}$ & -0.05 & -0.16 & -0.13 & 0.00 & -0.03 \\
r2ab_f & 0.24 & -0.18 & -0.26 & 0.24 & -0.06 & -0.21 & -0.22 & -0.03 & -0.01 \\
r3ab_ff & $\mathbf{0 . 3 5}$ & -0.30 & -0.30 & 0.24 & -0.04 & -0.23 & -0.07 & -0.02 & -0.11 \\
r4ab_f & $\mathbf{0 . 3 3}$ & -0.27 & -0.29 & 0.24 & 0.01 & -0.17 & -0.16 & -0.04 & -0.03 \\
r5ab_f & 0.28 & -0.25 & -0.24 & 0.30 & -0.09 & -0.28 & -0.05 & -0.08 & -0.16 \\
r6ab_ff & 0.19 & -0.15 & -0.13 & 0.27 & 0.08 & -0.14 & -0.19 & -0.04 & 0.09 \\
\hline
\end{tabular}

Table 24. Bivariate correlation analysis for fall number of fires and fall area burned and summer climate variables from 1948-2006. Significant values at the 0.01level are highlighted. 


\begin{tabular}{|l|ccccccccc|}
\hline & TEMP_F & PREC_F & PDSI_F & AMO_F & AO_F & NAO_F & PDO_F & PNA_F & SOI_F \\
\hline r1nf_f & -0.17 & -0.26 & $\mathbf{- 0 . 3 9}$ & $\mathbf{0 . 3 3}$ & 0.02 & 0.09 & $\mathbf{- 0 . 3 3}$ & 0.28 & 0.05 \\
r2nf_f & -0.11 & $\mathbf{- 0 . 5 1}$ & $\mathbf{- 0 . 4 9}$ & 0.14 & -0.06 & 0.17 & -0.29 & 0.29 & -0.02 \\
r3nf_f & -0.21 & $\mathbf{- 0 . 5 8}$ & $\mathbf{- 0 . 5 0}$ & 0.02 & -0.07 & 0.13 & -0.19 & 0.23 & 0.00 \\
r4nf_f & -0.11 & $\mathbf{- 0 . 5 7}$ & $\mathbf{- 0 . 3 9}$ & 0.16 & -0.02 & 0.19 & $\mathbf{- 0 . 3 3}$ & 0.20 & 0.01 \\
r5nf_f & -0.14 & $\mathbf{- 0 . 5 7}$ & $\mathbf{- 0 . 5 2}$ & 0.18 & 0.00 & 0.14 & -0.24 & 0.15 & 0.00 \\
r6nf_f & -0.03 & $\mathbf{- 0 . 4 0}$ & $\mathbf{- 0 . 6 0}$ & 0.29 & -0.04 & 0.09 & $\mathbf{- 0 . 3 3}$ & 0.29 & 0.04 \\
\hline r1ab_ff & -0.15 & $\mathbf{- 0 . 3 6}$ & -0.24 & 0.20 & 0.05 & 0.08 & -0.14 & 0.31 & 0.00 \\
r2ab_f & -0.28 & $\mathbf{- 0 . 5 0}$ & $\mathbf{- 0 . 4 5}$ & -0.07 & -0.07 & -0.01 & -0.08 & 0.21 & -0.10 \\
r3ab_ff & -0.21 & $\mathbf{- 0 . 5 0}$ & $\mathbf{- 0 . 5 7}$ & 0.02 & -0.05 & 0.12 & -0.26 & 0.29 & 0.06 \\
r4ab_f & -0.18 & $\mathbf{- 0 . 4 7}$ & $\mathbf{- 0 . 5 2}$ & 0.02 & -0.04 & 0.23 & -0.31 & 0.22 & 0.08 \\
r5ab_f & -0.16 & $\mathbf{- 0 . 5 8}$ & $\mathbf{- 0 . 5 0}$ & 0.16 & -0.06 & 0.15 & -0.31 & 0.17 & 0.05 \\
r6ab_ff & $\mathbf{0 . 0 9}$ & $\mathbf{- 0 . 4 5}$ & $\mathbf{- 0 . 4 7}$ & -0.05 & -0.05 & 0.16 & -0.04 & 0.32 & -0.03 \\
\hline
\end{tabular}

Table 25. Bivariate correlation analysis for fall number of fires and fall area burned and fall climate variables from 1948-2006. Significant values at the 0.01level are highlighted.

\begin{tabular}{|l|ccc|}
\hline & AdjR2 & $\begin{array}{c}\text { D-W } \\
\text { stat }\end{array}$ & $\begin{array}{c}\text { Independent } \\
\text { Variables }\end{array}$ \\
\hline r1nf_sp & 0.18 & 1.74 & all W. Variables \\
r2nf_sp & 0.25 & 1.69 & all W. Variables \\
r3nf_sp & -0.01 & 1.45 & all W. Variables \\
r4nf_sp & 0.37 & 1.75 & all W. Variables \\
r5nf_sp & 0.17 & 2.13 & all W. Variables \\
r6nf_sp & 0.27 & 1.55 & all W. Variables \\
\hline r1ab_sp & 0.12 & 1.47 & all W. Variables \\
r2ab_sp & 0.14 & 1.57 & all W. Variables \\
r3ab_sp & 0.14 & 1.17 & all W. Variables \\
r4ab_sp & 0.39 & 1.95 & all W. Variables \\
r5ab_sp & 0.16 & 2.07 & all W. Variables \\
r6ab_sp & 0.13 & 2.12 & all W. Variables \\
\hline
\end{tabular}

Table 26. Linear regression analysis with spring fire and winter climate variables.

\begin{tabular}{|l|ccc|}
\hline & AdjR2 & $\begin{array}{c}\text { D-W } \\
\text { stat }\end{array}$ & $\begin{array}{c}\text { Independent } \\
\text { Variables }\end{array}$ \\
\hline r1nf_sp & 0.37 & 1.61 & all Sp. Variables \\
r2nf_sp & 0.29 & 1.6 & all Sp. Variables \\
r3nf_sp & 0.35 & 1.52 & all Sp. Variables \\
r4nf_sp & 0.40 & 1.46 & all Sp. Variables \\
r5nf_sp & 0.36 & 1.71 & all Sp. Variables \\
r6nf_sp & 0.31 & 1.87 & all Sp. Variables \\
\hline r1ab_sp & 0.24 & 1.43 & all Sp. Variables \\
r2ab_sp & 0.25 & 1.35 & all Sp. Variables \\
r3ab_sp & 0.19 & 1.04 & all Sp. Variables \\
r4ab_sp & 0.50 & 1.82 & all Sp. Variables \\
r5ab_sp & 0.45 & 1.89 & all Sp. Variables \\
r6ab_sp & 0.18 & 1.94 & all Sp. Variables \\
\hline
\end{tabular}

Table 27. Linear regression analysis with spring fire and spring climate variables.

\begin{tabular}{|l|ccc|}
\hline & AdjR2 & $\begin{array}{r}\text { D-W } \\
\text { stat }\end{array}$ & $\begin{array}{c}\text { Independent } \\
\text { Variables }\end{array}$ \\
\hline r1nf_f & 0.15 & 1.66 & all Sum. Variables \\
r2nf_f & 0.03 & 1.39 & all Sum. Variables \\
r3nf_f & 0.05 & 1.49 & all Sum. Variables \\
r4nf_f & 0.10 & 1.34 & all Sum. Variables \\
r5nf_f & 0.14 & 1.72 & all Sum. Variables \\
r6nf_f & 0.09 & 1.58 & all Sum. Variables \\
\hline r1ab_f & 0.12 & 1.81 & all Sum. Variables \\
r2ab_f & 0.06 & 1.24 & all Sum. Variables \\
r3ab_f & 0.10 & 1.93 & all Sum. Variables \\
r4ab_f & 0.10 & 1.93 & all Sum. Variables \\
r5ab_f & 0.21 & 1.90 & all Sum. Variables \\
r6ab_f & 0.04 & 1.58 & all Sum. Variables \\
\hline
\end{tabular}

Table 28. Linear regression analysis with fall fire and summer climate variables.

\begin{tabular}{|l|ccc|}
\hline & AdjR2 & $\begin{array}{c}\text { D-W } \\
\text { stat }\end{array}$ & $\begin{array}{c}\text { Independent } \\
\text { Variables }\end{array}$ \\
\hline r1nf_f & 0.18 & 1.59 & all F. Variables \\
r2nf_f & 0.28 & 1.75 & all F. Variables \\
r3nf_f & 0.32 & 1.97 & all F. Variables \\
r4nf_f & 0.29 & 2.29 & all F. Variables \\
r5nf_f & 0.35 & 1.74 & all F. Variables \\
r6nf_f & 0.29 & 1.93 & all F. Variables \\
\hline r1ab_f & 0.27 & 1.92 & all F. Variables \\
r2ab_f & 0.28 & 1.48 & all F. Variables \\
r3ab_f & 0.37 & 2.11 & all F. Variables \\
r4ab_f & 0.39 & 2.24 & all F. Variables \\
r5ab_f & 0.30 & 1.83 & all F. Variables \\
r6ab_f & 0.34 & 1.57 & all F. Variables \\
\hline
\end{tabular}

Table 29. Linear regression with fall fire and fall climate variables. 


\begin{tabular}{|c|c|c|c|c|c|}
\hline & Orig Adjr2 & $\begin{array}{l}\text { Orig D-W } \\
\text { stat }\end{array}$ & T-score & New Adjr2 & $\begin{array}{c}\text { New D-W } \\
\text { stat }\end{array}$ \\
\hline r1nf_sp & 0.38 & 1.31 & -2.62 & 0.29 & 1.75 \\
\hline r2nf_sp & 0.42 & 1.61 & -1.44 & $x$ & $x$ \\
\hline r3nf_sp & 0.44 & 1.52 & -1.67 & $x$ & $x$ \\
\hline r4nf_sp & 0.52 & 1.70 & -1.05 & $x$ & $x$ \\
\hline r5nf_sp & 0.48 & 1.94 & -0.08 & $x$ & $x$ \\
\hline r6nf_sp & 0.22 & 1.86 & -0.45 & $x$ & $x$ \\
\hline r1ab_sp & 0.44 & 1.71 & -0.81 & $x$ & $x$ \\
\hline r2ab_sp & 0.30 & 1.62 & -1.39 & $x$ & $x$ \\
\hline r3ab_sp & 0.21 & 2.03 & 0.3 & $x$ & $x$ \\
\hline r4ab_sp & 0.49 & 2.12 & 0.44 & $x$ & $x$ \\
\hline r5ab_sp & 0.28 & 1.89 & -0.35 & $x$ & $x$ \\
\hline r6ab_sp & 0.15 & 2.23 & 0.88 & $x$ & $x$ \\
\hline
\end{tabular}

Table 30. Spring Number of Fires and Area Burned Autoreg procedure results. " $X$ " $=$ not significant, not performed.

\begin{tabular}{|c|c|c|c|c|c|}
\hline & Orig adjr2 & $\begin{array}{l}\text { Orig D-W } \\
\text { stat }\end{array}$ & T-score & New Adjr2 & $\begin{array}{c}\text { New D-W } \\
\text { stat }\end{array}$ \\
\hline r1nf_f & 0.41 & 1.65 & -1.26 & $x$ & $x$ \\
\hline r2nf_f & 0.37 & 1.45 & -2.09 & 0.34 & 2.01 \\
\hline r3nf_f & 0.48 & 1.64 & -1.23 & $x$ & $x$ \\
\hline r4nf_f & 0.44 & 1.59 & -1.52 & $x$ & $x$ \\
\hline r5nf_f & 0.60 & 1.90 & -0.34 & $x$ & $x$ \\
\hline r6nf_f & 0.32 & 1.36 & -2.44 & 0.34 & 2.00 \\
\hline r1ab_f & 0.21 & 1.65 & -1.26 & $x$ & $X$ \\
\hline rab_f & 0.37 & 1.31 & -2.46 & 0.29 & 1.67 \\
\hline r3ab_f & 0.36 & 2.06 & 0.25 & $x$ & $x$ \\
\hline r4ab_f & 0.33 & 1.97 & -0.11 & $x$ & $x$ \\
\hline r5ab_f & 0.47 & 2.04 & 0.15 & $x$ & $x$ \\
\hline r6ab_f & 0.12 & 1.45 & -2.09 & 0.08 & 1.88 \\
\hline
\end{tabular}

Table 31. Fall Number of Fires and Area Burned Autoreg procedure results. " $X$ " $=$ not significant, not performed. 


\begin{tabular}{|c|c|c|c|c|}
\hline & & Variables & $\begin{array}{c}\text { Eigen Values } \\
\% \text { of } \\
\text { Variance } \\
\end{array}$ & $\begin{array}{c}\text { Eigen } \\
\text { Values } \\
\text { Cumulative } \\
\% \\
\end{array}$ \\
\hline \multirow[t]{4}{*}{ Winter } & Factor 1 & temp,AO,(-)PDO,(-)PNA & 26.16 & 26.16 \\
\hline & Factor 2 & NAO,(-)SOI & 23.86 & 50.03 \\
\hline & Factor 3 & precip,pdsi & 17.25 & 67.27 \\
\hline & Factor 4 & AMO & 12.32 & 79.59 \\
\hline \multirow[t]{4}{*}{ Spring } & Factor 1 & (-)temp(-)AO,PDO,PNA & 22.06 & 22.06 \\
\hline & Factor 2 & precip,pdsi & 20.77 & 42.83 \\
\hline & Factor 3 & NAO,(-)SOI & 20.36 & 63.19 \\
\hline & Factor 4 & $(-)$ AMO & 13.38 & 76.57 \\
\hline \multirow[t]{4}{*}{ Summer } & Factor 1 & $\begin{array}{c}\text { (-)temp,precip,pdsi,NAO, } \\
\text { (-)PNA }\end{array}$ & 21.45 & 21.45 \\
\hline & Factor 2 & (-)PDO,SOI & 17.12 & 38.57 \\
\hline & Factor 3 & AMO,TCA & 16.68 & 55.25 \\
\hline & Factor 4 & $\mathrm{AO}$ & 14.89 & 70.14 \\
\hline \multirow[t]{4}{*}{ Fall } & Factor 1 & (-)PDO,TCA & 18.84 & 18.84 \\
\hline & Factor 2 & temp,precip,(-)PNA & 17.44 & 36.28 \\
\hline & Factor 3 & (-)AMO,AO,NAO,(-)SOI & 17.34 & 53.62 \\
\hline & Factor 4 & pdsi & 16.85 & 70.47 \\
\hline
\end{tabular}

Table 32. PCA by season from 1948-2006.

\begin{tabular}{|l|cccc|}
\hline & $\begin{array}{c}\text { Spring Area } \\
\text { Burned }\end{array}$ & $\begin{array}{c}\text { Spring Number } \\
\text { of Fires }\end{array}$ & $\begin{array}{c}\text { Fall Area } \\
\text { Burned }\end{array}$ & $\begin{array}{c}\text { Fall Number of } \\
\text { Fires }\end{array}$ \\
\hline R1 & 0.3 & 0.27 & 0.12 & 0.12 \\
R2 & 0.26 & 0.21 & 0.36 & 0.32 \\
R3 & 0.22 & 0.36 & 0.34 & 0.24 \\
R4 & 0.47 & 0.48 & 0.32 & 0.28 \\
R5 & 0.39 & 0.37 & 0.26 & 0.32 \\
R6 & 0.21 & 0.17 & 0.3 & 0.34 \\
\hline
\end{tabular}

Table 33. Adjusted regression coefficients using Factors 1, 2, 3, and 4 by region and season.

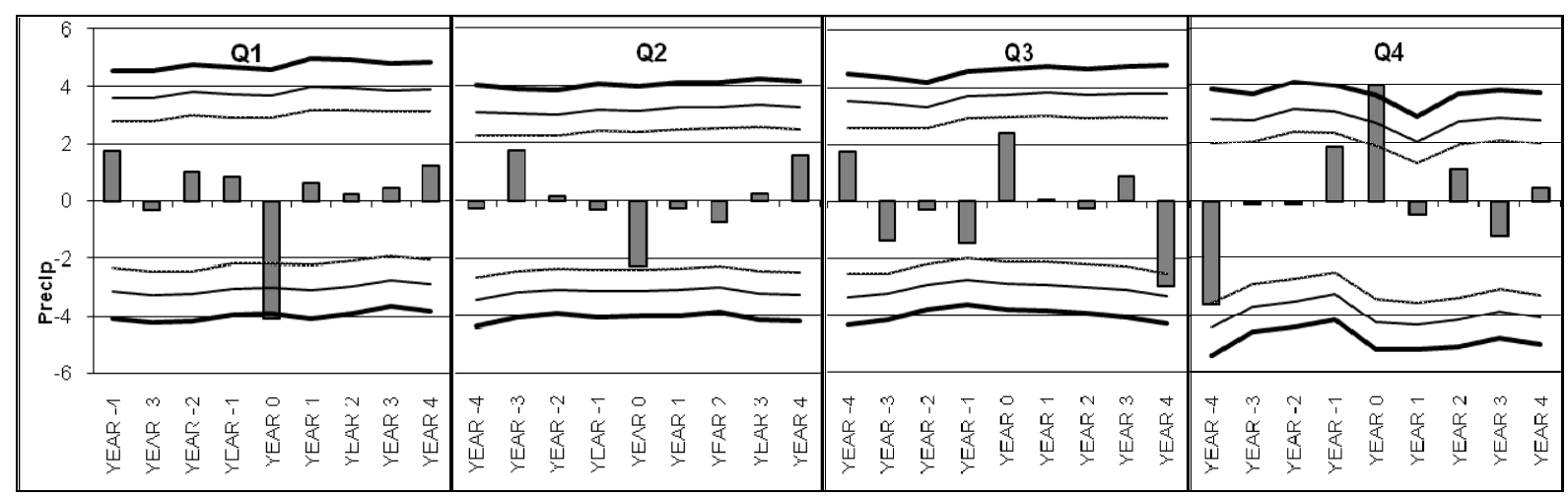

Figure 18. SEA of spring area burned and spring precipitation 1948-2006. 


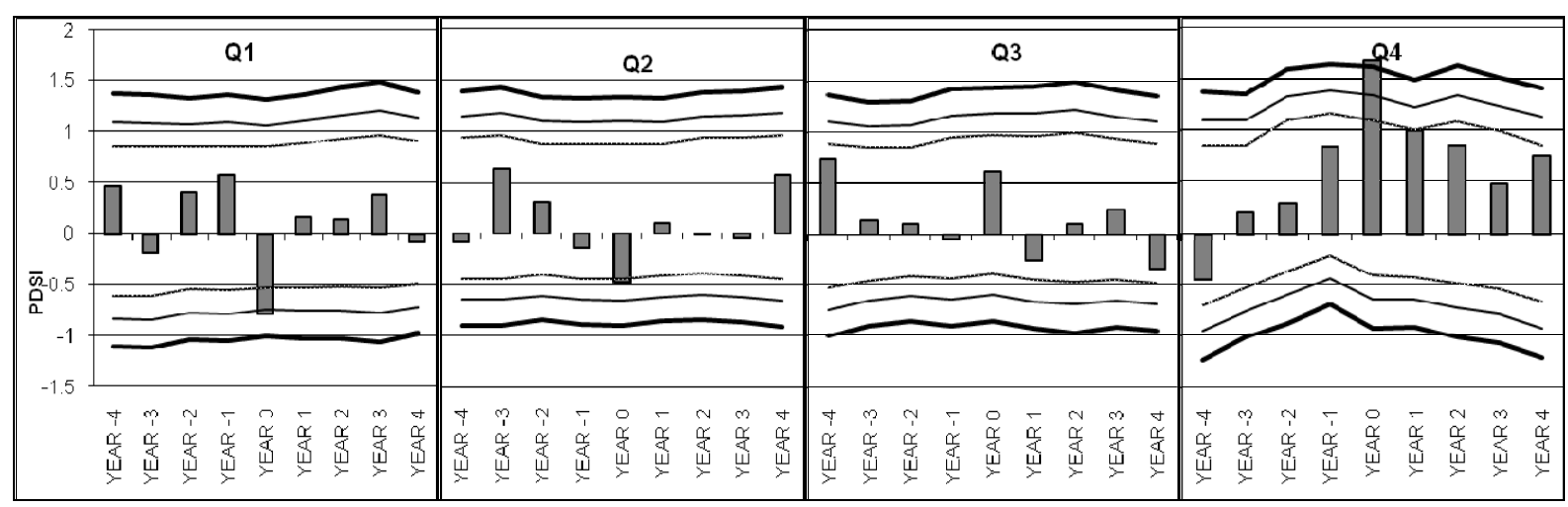

Figure 19. SEA of spring area burned and spring PDSI 1948-2006.

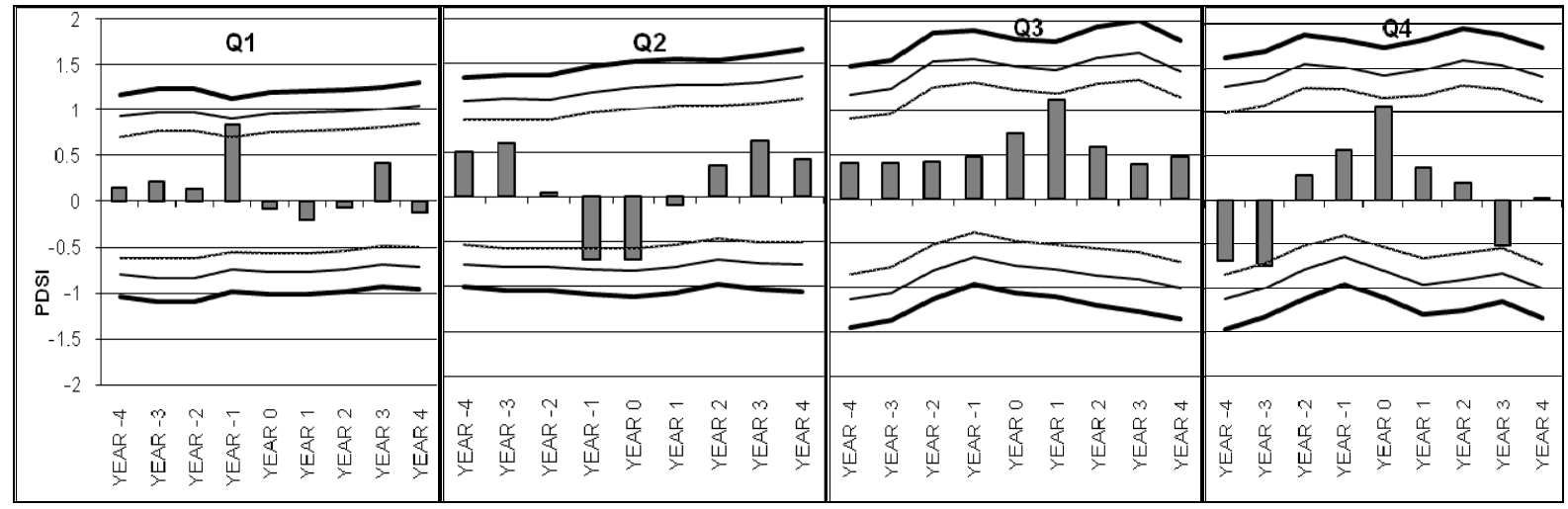

Figure 20. SEA of spring number of fires and winter PDSI 1948-2006.

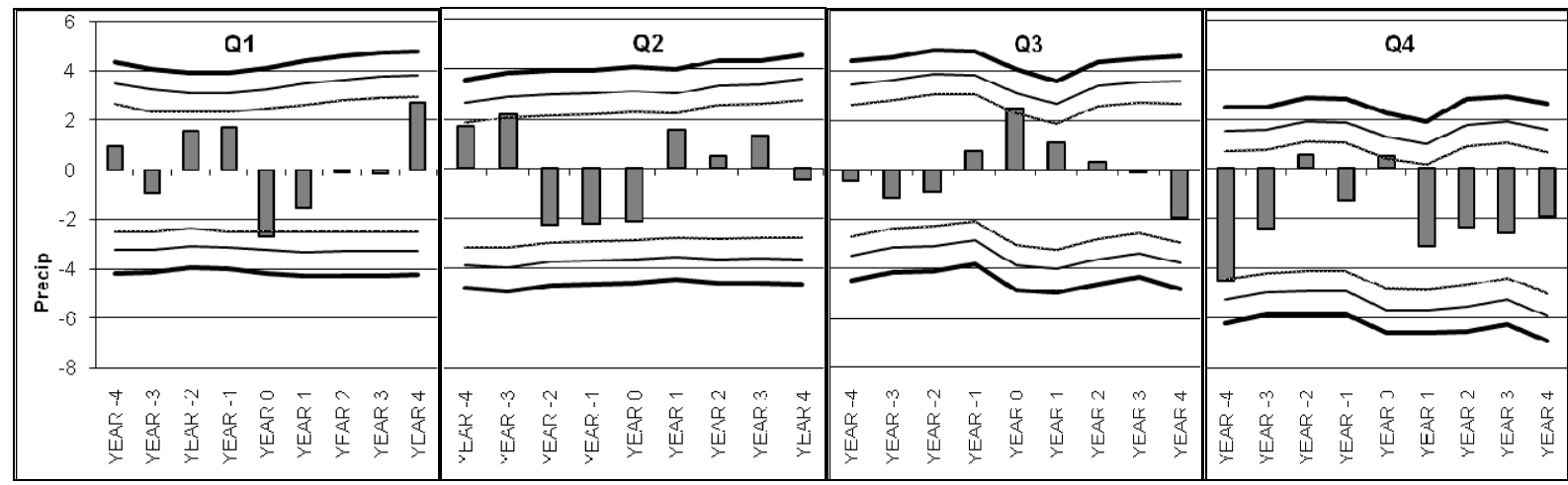

Figure 21. SEA of spring number of fires and spring precipitation 1948-2006.

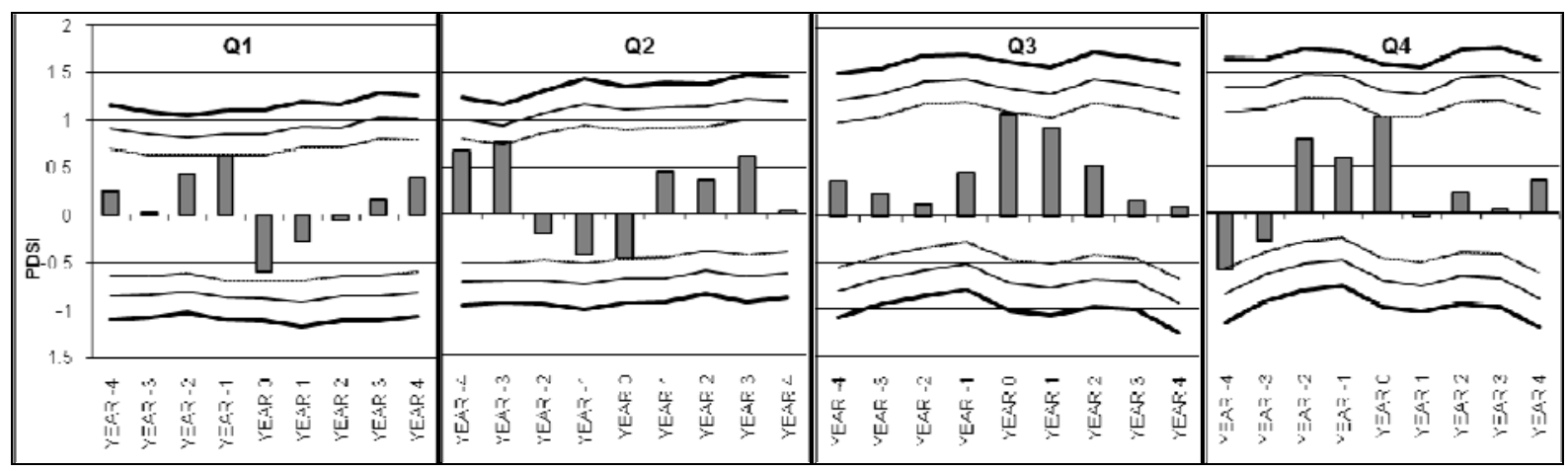

Figure 22. SEA of spring number of fires and spring PDSI. 


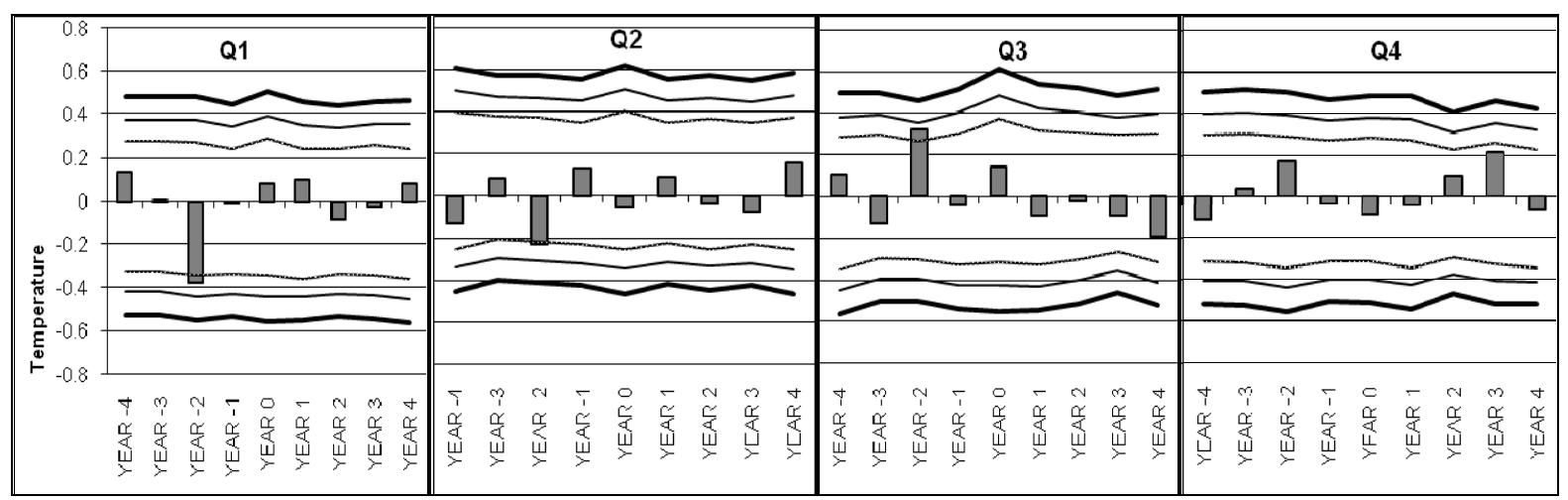

Figure 23. SEA of fall area burned and summer temperature 1948-2006.
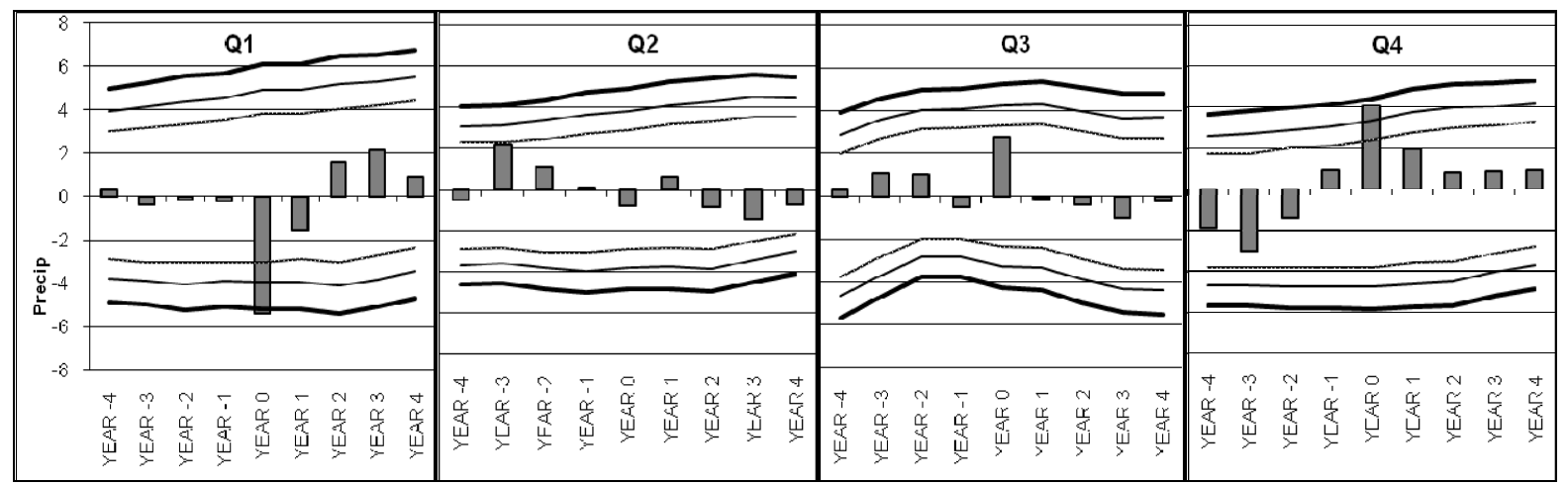

Figure 24. SEA of fall area burned and fall precipitation 1948-2006.

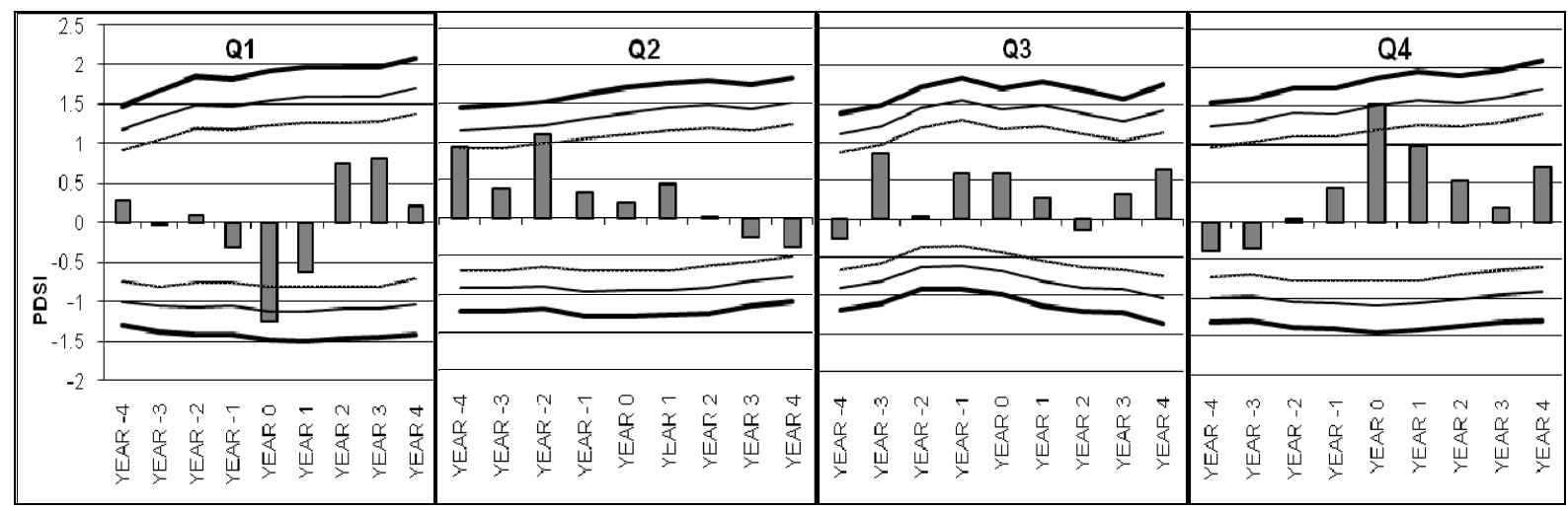

Figure 25. SEA of fall area burned and fall PDSI 1948-2006.

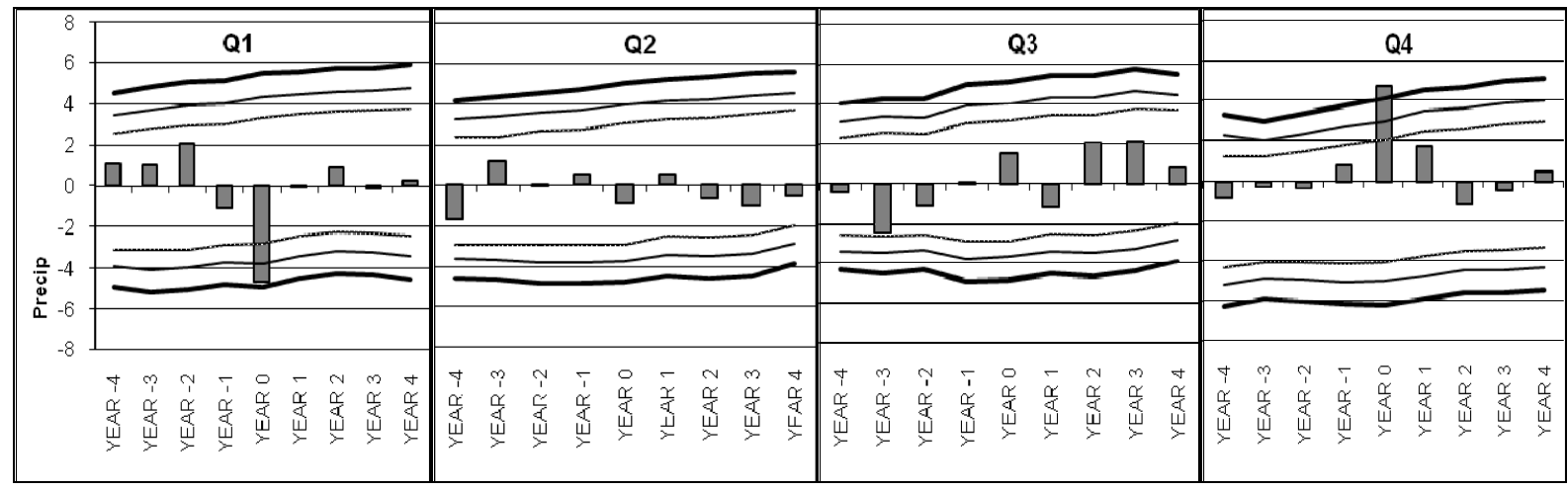

Figure 26. SEA of fall number of fires and fall precipitation 1948-2006. 


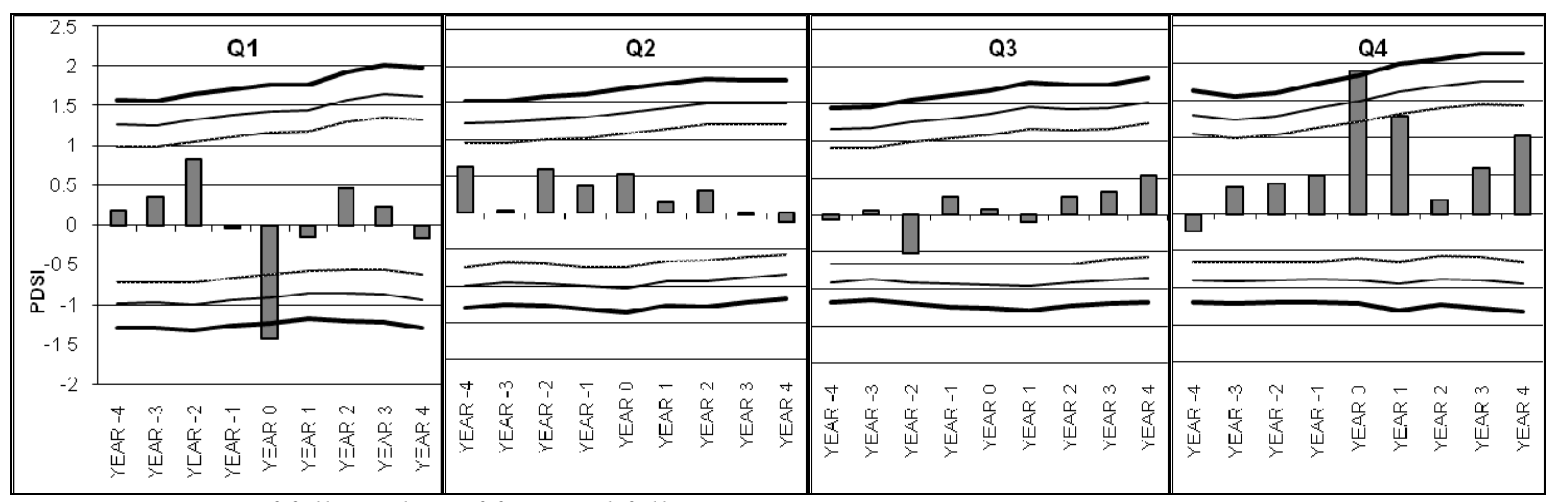

Figure 27. SEA of fall number of fires and fall PDSI 1948-2006.

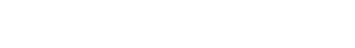

